\title{
Relation de voyage
}

\author{
Gian Batta Moccafy \\ Traducteur : Corine Maitte
}

\section{(2) OpenEdition \\ Journals}

\section{Édition électronique}

URL : http://journals.openedition.org/dht/294

DOI : $10.4000 /$ dht.294

ISSN : 1775-4194

Éditeur :

Centre d'histoire des techniques et de l'environnement du Cnam (CDHTE-Cnam), Société des élèves du CDHTE-Cnam

\section{Édition imprimée}

Date de publication : 1 décembre 2009

ISBN : 978-2-9530779-4-0

ISSN : 0417-8726

\section{Référence électronique}

Gian Batta Moccafy, "Relation de voyage », Documents pour l'histoire des techniques [En ligne], 18| $2^{\mathrm{e}}$ semestre 2009, mis en ligne le 15 septembre 2010, consulté le 14 septembre 2020. URL : http:// journals.openedition.org/dht/294

\section{(c) Tous droits réservés}




\section{Relation de voyage*}

\section{Gian Batta Moccafy}

\section{Lyon}

Le principal objet du commerce de cette ville est le change et la fabrication des étoffes de soie. Il y a les grandes et les petites fabriques : les grandes fabriques sont gérées par des entrepreneurs avec de grands fonds, et pour les petites il est permis à qui que ce soit de travailler, même en ayant un seul métier. Les marchands, tant en gros qu'au détail, vendent ce qui leur semble et leur plaît sans aucune réserve de quelque marchandise que ce soit.

Les affaires du commerce sont gouvernées par les négociants eux-mêmes avec la formation d'un conseil où siège le Prévôt des marchands avec deux maîtres et six autres négociants qui sont dans l'obligation d'être dans le conseil quatre ans chacun. Cette charge sert d'habilitation à la noblesse. Pour pouvoir aspirer à ces charges, il faut qu'ils aient été recteurs des hôpitaux et se soient employés au bénéfice du bien public. Tous les arts et tout le commerce font passer leurs représentations à ce conseil et quand il s'agit d'une affaire concernant une profession précise, les syndics de cette profession sont dans l'obligation de se réunir. De même, quand ils doivent établir un édit en faveur ou contre le commerce, ils écoutent surtout les conseillers aux affaires concernant toutes les professions afin de référer ensuite le sentiment de chacun des syndics et de prendre une décision nécessaire et fondée. Si, tous unanimes, ils rédigent l'édit, ils l'envoient pour confirmation au Grand Conseil du Roi, sinon ils l'envoient complétés par les oppositions qui ont été faites pour en entendre les déterminations suprêmes.

Tous les jours de la semaine, il y a des réunions de négociants, d'honnêtes hommes, et également de nobles, qui s'appellent académies. Dans celles-ci, chacun propose son sentiment, la preuve qui en a été faite et sa réussite. Lorsque trois ou quatre l'approuvent suite à l'expérience qui en a été faite, ils la publient. À présent, l'unique but de l'académie d'agriculture est la garance et les mûriers. Toutes les villes de commerce trouvent un grand avantage à se réunir dans un lieu public tous les jours; on en compte deux, qui s'appellent Bourse, dans cette ville, une pour l'été et une pour l'hiver. On y traite des négociations moyennes que l'on fait, et, à force de s'y rendre et d'y raisonner, les négociants se communiquent toutes les affaires, tant du pays que de l'étranger.

\section{Paris}

Son but principal est le change et la marchandise, les expéditions, la fabrication, en revanche, on y trouve peu de grandes fabriques. Parmi celles-ci, il y a la fabrique du Sieur Julienne qui fait des draps écarlates et bleus. II a une teinturerie dotée d'un privilège privatif pour teindre en écarlate ainsi qu'une manufacture de tapisserie. C'est un grand corps de maison dans lequel on exécute toutes ces opérations. II n'y a d'habitation que pour les chefs, mais les ouvriers sont cependant obligés d'habiter dans le voisinage afin de pouvoir entendre le son de la cloche et se rendre au travail. Comme grands édifices, il y a également la manufacture de porcelaines et celle de l'imprimerie des toiles qui sont à Sèvres près de Paris. Dans le reste de Paris et de ses alentours, on produit toutes sortes de marchandises, mais chaque ouvrier travaille chez lui et, une fois qu'il a fait une pièce, il la porte à un marchand expéditeur et en reçoit tout de suite plus ou moins son argent : ainsi j'ai dit tout ce que l'on peut imaginer sur toute sorte de travail. Si l'ouvrier veut faire quelque fortune, il faut qu'il s'attache à inventer tous les jours quelque chose de nouveau et une fois l'invention faite, s'il veut la publier, il va chez le gazetier et, moyennant le paiement de cina sols, il annonce son invention à toute la capitale et aux provinces.

Étant donnée la grandeur de la ville, la poste à pied, composée de cent cinquante hommes à pied, a été instituée pour la commodité de tout le Public, et principalement du commerce et des ouvriers. À chaque heure préétablie, cinquante partent du centre de Paris où se trouve la Grand Poste et ils tournent dans la ville vêtus de la livrée du Roi en claquant avec une Ténèbre qui indique que si quelqu'un veut écrire une lettre, adresser un petit paquet ou une somme d'argent, ceux-ci s'en chargent moyennant le payement de deux sous, et l'office de la poste en répond. Ce groupe fait son tour préétabli, puis se rend à l'heure déterminée pour son tour aux bureaux de

* Pour la traduction, j'ai délibérément fait le choix de privilégier le sens sur la forme. En effet, le texte italien est parfois obscur, incorrect (au sens actuel), souvent non ponctué : pour la traduction, j'ai fait le choix d'écrire dans un français actuel compréhensible, de mettre la ponctuation et parfois d'interpréter le sens. Certains mots techniques n'ont pas été traduits. 


\section{Relation de voyage}

la Poste. À la deuxième heure, cinquante autres partent; ils remettent ce qui a été reçu et reprennent ce qu'on leur remet pour le ramener au centre et ainsi de suite. II se fait à ce bureau sept levées par jour de sorte que quiconque écrit une lettre dans un angle de la ville a sa réponse au bout de trois heures. Cinquante autres sont affectés aux faubourgs et aux terres jusqu'à la première terre qui ait une poste ; pour eux, il y a une autre taxe en proportion, sans qu'ils puissent prendre un sous de plus que ce qui est taxé. Les offices, tant publics que privés, et en général tous les marchands fabricants et les ouvriers s'en servent. C'est un grand avantage spécialement pour ces derniers parce qu'ils ne sont pas détournés de leur ouvrage.

Les Académies sont immenses. II est permis à toutes sortes de personnes de faire des académies et il est permis à chaque académie de se choisir un Grand comme protecteur pour présenter leurs projets qui sont acceptés ou refusés. Mais, acceptés ou refusés par le protecteur particulier, quiconque peut faire imprimer ses projets et les donner au public pour rechercher des associés. Ceux qui sont acceptés par des protecteurs sont envoyés au Bureau du Contrôleur général pour en attendre les grâces financières du souverain.

Dans toutes les villes de France relativement importantes pour le commerce, on a établi un lieu public pour la réunion des négociants mandatés afin qu'ils traitent de leurs affaires. À Paris toutefois, il n'y avait pas de [Bourse]. Elle a été établie seulement par Louis XIV Roi de France par un édit du $247 \mathrm{bre} 1724$ [sic] car il avait reconnu l'utilité d'une telle affaire que l'on considère dans tant de pays avec une certaine indifférence. Cet édit, avec ses privilèges et ses règles, a donné un crédit et une fréquentation majeurs à toutes les autres [Bourses] du royaume.

En sortant de Paris pour prendre la route de la Normandie, la première fabrique que l'on rencontre est celle de Louviers, ville pas très grande mais peuplée. On y produit les draps les plus fins de France après ceux d'Abbeville, privilège royal concédé par le Roi au Sieur Vanrobest, fabricant originaire de Leyde où son entreprise est encore ouverte. Comme la manufacture de draps est presque partout identique, on indiquera en passant de manufacture en manufacture les petites variations qui existent, mais il est bon de commencer par une description de la manufacture des draps en général, pour en venir ensuite au particulier.

Si l'on aborde la manufacture des draps en général, il faut dire qu'avant qu'une pièce de drap ne soit conduite à sa perfection les opérations sont infinies. Nous pouvons toutefois nous en tenir aux quatre principales qui doivent obligatoirement être suivies par les autres bien que mineures, toutes par ailleurs utiles, nécessaires et indispensables, tant pour les draps fins que pour les ordinaires, et ce sont :

$1^{\circ}$ le choix de la laine, que l'on doit adapter selon sa finesse à la qualité du drap que l'on voudra faire $2^{\circ}$ différentes opérations de lavage de la laine jusqu'au tissage de l'étoffe

$3^{\circ}$ les foulons

$4^{\circ}$ la rame des draps

$5^{\circ}$ les apprêts, la presse c'est-à-dire la tonte, article infiniment nécessaire, et la presse pour lui donner le lustre.

On sait que les laines de tous les pays viennent des moutons, qui se tondent tous au printemps, et pour cela on appelle la quantité que l'on recueille d'un mouton une tonte, c'est-à-dire une toison. Elle est emballée tas par tas, c'est-à-dire tonte par tonte, et elle doit ordinairement être du poids de 2 livres à peu près lavée en balle. De chaque tonte de chaque mouton doivent sortir trois qualités de laine, c'est-à-dire 1 A très fine, fine et deuxième choix. La première est le dos, la seconde, ce sont les cuisses et la troisième le ventre et la gorge de la bête, si bien qu'en Espagne où les laines sont plus fines que dans tous les autres pays, chaque bête donne une tonte des trois qualités de laine. II y a ensuite les tontes de laines plus ordinaires qui pèsent bien plus, ce qui peut se trouver également dans les fines, mais cela vient du fait qu'elles sont plus ou moins purgées des saletés et du gras naturel de la bête.

La première opération que demande la laine est d'être lavée dans un panier immergé dans des eaux plutôt tièdes et molles que crues et gelées; des hommes doivent la fouler au pied dans l'eau elle-même, puis on doit la mettre à sécher. Si ce sont des laines fines, elles doivent être séchées à l'ombre, si elles sont ordinaires ou inférieures, peu importe qu'elles soient séchées au soleil afin que l'opération soit plus rapide. Mais qu'elles soient d'une sorte ou de l'autre, il faut les plucher dès leur premier lavage, c'est-à-dire choisir à petites poignées et leur enlever toutes les saletés sèches qui s'attachent aux poils, autrement dans le second lavage tout se blanchit et on peut plus difficilement enlever toutes ces saletés. Une fois celles-ci enlevées, on peut faire les mélanges des laines pour les draps demi-fins et ordinaires en proportion de la qualité du drap que l'on souhaite fabriquer.

$168 \diamond$ Documents pour l'histoire des techniques nº 18 - décembre 2009 
Lorsqu'on veut mettre la laine en œuvre, on doit la laver dans la fabrique pour la dégraisser totalement. Pour ce lavage, il faut un bain composé de deux tiers d'eau et un tiers d'urine : on doit le faire réchauffer de sorte que l'on puisse réussir à y tenir les mains et puis prendre un rubbo' de laine à la fois et le battre très bien dans ce bain pendant un quart d'heure ; ensuite, il faut le mettre dans un panier plutôt long pour envoyer la laine encore chaude à la rivière et la faire laver très bien jusqu'à ce que l'eau sorte limpide du panier et que la laine ne sente plus l'urine. On reconnaît que la laine est bien purgée si, en en prenant un poing dans la main et en le pressant bien afin que l'eau sorte, la laine s'élargit naturellement d'elle-même lorsque l'on ouvre la main. Si l'on veut faire le drap teint en laine, on remet tout de suite cette laine humide au teinturier pour qu'il la teigne dans la couleur choisie avant de la mettre à sécher, sinon, on la met sur les perches à sécher en blanc. On fait de même après la teinture de la laine, en faisant bien attention qu'elle ne soit pas entièrement exposée aux rigueurs du soleil qui pourraient la réchauffer un peu trop. ॥ faut maintenir pour cela des ouvriers qui la surveillent et la retournent afin qu'elle ne fermente pas et qu'elle ne perde pas son nerf et son élasticité naturelle nécessaires pour les autres opérations.

On reconnaît qu'une laine est bien dégraissée ou purifiée à sa blancheur, à sa légèreté, et si elle ne sent pas mauvais. S'il manque une de ces trois qualités, il est nécessaire de répéter l'opération, mais pas avec la même quantité d'urine que la première fois : le bain doit être plus léger sinon il peut en découler d'infinis mauvais effets dans la fabrication du drap et il peut également en sortir des défauts après la fabrication et la presse de cette même pièce.

Après que la laine a été bien dégraissée, purgée, séchée, on doit la mettre sur une table de corde et la battre sur le côté et non perpendiculairement pour lui retirer toute la poussière et la laine courte, la diviser un peu plus et la faire gonfler de manière qu'elle absorbe plus également l'huile. Beaucoup la mettent avant encore dans un burat muni d'un manche avec des dents de fer pour la fouler davantage et en détacher la poussière. Tous, une fois battue, la font choisir et bien débarrasser à la main, par des femmes, de tous les rebuts et ordures qu'elle peut contenir. Elles doivent avoir une grande attention pour éviter tous les inconvénients que pourraient causer toutes sortes d'ordures, même en faible quantité.

Une fois la laine bien nettoyée et passée entre les mains de deux femmes avisées, elle est mise dans un baril de bois où elle est arrosée avec plus ou moins d'huile d'olive selon que la laine est plus fine ou plus ordinaire. On distingue bien si cette laine est destinée à être filée fine et forte pour la chaîne ou si elle doit être filée à bras ouverts pour la trame. Pour l'arroser, il faut la retourner deux fois avant d'être prise poignée par poignée et foulée pour la remettre à la première grosse carde qui est aussi un peu mouillée d'huile. Ensuite, elle doit être passée à deux autres cardes plus fines selon le travail que l'on veut faire. A la dernière carde, le cardeur la divise en petites quantités longues d'une paume et un peu plus grosses qu'un doigt pour la donner à la filature. Ces petits écheveaux, en se filant, s'unissent les uns aux autres. II faut noter que les écheveaux destinés à la chaîne doivent être plus petits car ils doivent être d'un filé plus fin que celui de la trame. Une fois les écheveaux formés, ordinairement dans la chambre même de la filature, on les donne aux fileuses que l'on distingue partout entre celles de la chaîne et celles de la trame ; toutes sont payées également, bien que celles de la trame travaillent plus que celles de la chaîne. Les rovets sont semblables à ceux qui se trouvent ici : on verra, après cette description générale, ce qui diffère dans chaque pays. La chambre de la filature ayant rempli ses fuseaux de fil, il passe aux bavanoires pour être réduit en bobines. On commence ici à opérer une proportion qui donne la règle tant à la chaîne qu'aux petites bobines qui se font pour la navette. Une fois faites, on les met sur des vindo. On fait passer la laine filée qui est destinée à la chaîne sur de grandes bobines et la petite sur un petit instrument de canne qui doit entrer dans la navette. Tant sur ces bobines que sur la petite canne, on observe une proportion égale afin qu'en travaillant tout finisse en un point. Les petites canettes, placées dans un panier, sont portées à côté du métier afin que le tisseur puisse commodément en disposer.

On met les grandes bobines sur un petit chevalet armé de nombreuses et longues pointes de fer destinées à les recevoir et dont on prend toutes les chevilles (cavioni) que l'on attache à l'ourdissoir ; celui-ci est une bavanoire haute d'un trabut ${ }^{2}$ plantée en terre marquant les tours qu'elle doit faire pour parvenir à la mesure de la chaîne selon la longueur plus ou moins grande que le fabricant s'est proposé de donner à la pièce, selon la qualité plus ou moins fine ou ordinaire, en réglant tout cela en portées, ordinairement composées de quarante fils. Toutes ces portées sont unies ensemble quand on démonte l'ourdissoir pour composer la largeur plus ou moins grande du drap. II faut préciser que la portée de quarante [fils] est divisée en vingt de demie portée pour lui donner le croisement du haut

1 Unité de mesure de huit à neuf kilos utilisée en Italie.

2 Unité de mesure de longueur, utilisé en Italie dans la seconde moitié du XVIIII siècle. 


\section{Relation de voyage}

et du bas et pour pouvoir former la toile, afin que la chaîne puisse serrer la trame. Après que toute la chaîne est ourdie, on la démonte de l'ourdissoir en liant avec un gros fil le croisement et l'on unit les portées que l'on veut, ou bien portée par portée, et on va l'immerger dans la cuve à colle. On la sort en la pressant très bien afin que la colle puisse pénétrer tous les fils de la chaîne afin que le peigne, en frottant sur le métier, ne la fasse pas bourrer et qu'elle puisse soutenir les coups que le travailleur, c'est-à-dire le tisseur, est dans l'obligation de donner pour serrer la trame. La colle est composée d'eau et de rognures de peau bouillies ensemble le temps qu'il faut pour que les peaux fondent et incorporent l'eau. Ensuite, quand elle est bien incorporée, elle est passée afin qu'elle soit égale et sans ordure. Quand la chaîne est bien compressée, elle est doit être tordue de façon égale et être étendue en séparant chaque fil ; si certains sont rompus, ils doivent être ajustés pour pouvoir les faire passer facilement dans le peigne. Quand [la chaîne] est étendue pour sécher, elle doit être retournée deux ou trois fois afin qu'elle sèche de façon égale et que les fils ne restent pas plus collés d'un côté que de l'autre. Dès que la chaîne est sèche, elle passe dans la chambre des métiers pour être montée. Il est inutile de faire la description de l'installation de la chaîne car, tant en fil pour la toile, qu'en laine pour la toile du drap, qu'en soie pour les étoffes unies, c'est la même chose, si bien qu'on le voit tous les jours dans notre pays. S'il y a des remarques particulières, on les trouvera à leur place dans la relation. Ce qui est en général recommandé dans toutes les fabriques, c'est que le tisseur tiennent les chaînes des lisières très molles sur le métier afin qu'elles n'empêchent pas le drap de faire son opération naturelle dans le foulon. Aussi, si un drap avait les lisières très tirées ou égales au drap, serait-il mieux de les tailler afin de laisser la toile et le drap libres de se fouler. Le drap étant foulé, on recommande aussi de ne pas tirer, afin qu'il puisse donner à la carde le lainage nécessaire pour être mené à perfection. Une fois la toile faite, on doit l'enlever du métier pour la jeter sur la perche et l'examiner avec attention pour déceler les défauts à corriger avant de l'envoyer aux apprêts. Le patron de la fabrique examine la toile à la perche, puis il la donne à deux femmes qui la jettent sur une table fortement inclinée à la lumière du jour et lui enlèvent tous les groupes avec une paire de pincettes; en enlevant les groupes, elles doivent faire très attention à ne pas rompre la chaîne parce que cela est sans remède ; en revanche, s'il s'agit de la trame, on peut encore y remédier en y passant des fils. Dès qu'elle est bien pluchée et nette, la toile doit être nettoyée des groupes détachés afin que, ne restant pas sur la pièce, ils ne provoquent aucun mauvais effet dans le foulon car toute chose, même minime, peut faire des trous dans la pièce. Une fois la toile de laine dans cet état propre, on l'envoie au foulon afin de la laver et de la dégraisser pour lui enlever aussi bien l'huile dont on a enduit la laine avant de la filer que la colle appliquée dans la chaîne afin qu'elle puisse résister aux coups du peigne lors du tissage. II existe de très nombreuses manières de dégraisser les draps selon les pays, toutes différentes mais au fond très semblables. Au sein d'une même fabrique, les fabricants opèrent qui d'une façon, qui de l'autre et chacun fait selon son expérience : qui fait dégraisser son drap à force de le faire rester dans l'eau courante, en le tenant toujours ouvert et en le retournant toutes les deux heures, qui met toute sa pièce étendue dans le fleuve, qui le lave avec de la terre à force de bâtons, qui le met avec de l'urine dans les piles du foulon -beaucoup prétendent que la vieille urine est meilleure, beaucoup d'autres la veulent fraîche-, d'autres encore emploient seulement du savon ; certains veulent de l'eau écumante de savon, d'autres de la crème de savon, beaucoup, et surtout pour la draperie ordinaire, utilisent seulement de la terre car c'est la façon de dépenser moins, mais tous généralement recommandent de tout faire pour que la susdite terre soit bien pilée et dépourvue de tout grumeau, tant dans le dégraissage que dans le foulage. Les grumeaux, même en petites quantités, pourraient ruiner [le drap]. Quand un drap ou bien une toile est bien purgée, il doit être séché et remis à deux femmes avisées qui examinent avec attention s'il y a encore des groupes à enlever. Si les groupes se trouvent dans la trame, on peut les enlever à l'aide de pinces, alors que ceux de la chaîne requièrent plus de diligence car le foulon accommode plus facilement les trous de la toile qui sont dans le tissage que ceux qui sont dans l'ourdissage. Une fois débarrassée des groupes et de tous les corps étrangers qui ne soient pas de laine, la toile doit être très bien étendue et avec une petite brosse de racine forte, elle doit être nettoyée afin que les groupes de laines retirés ne restent pas sur la pièce car ils peuvent aussi déranger le fonctionnement du foulon. Dès que la pièce est bien nette, on peut écrire sur ses deux têtes ce que l'on veut, y apposer le nom du fabricant et ordinairement, dans les bonnes fabriques qui sont sûres de leurs opérations, on marque l'aunage auquel doit arriver la pièce perfectionnée. Toutefois, ceci n'est fait que par les meilleurs fabricants et pour les pièces de drap surfin uniquement, car on ne peut être certain que les opérations des autres types de marchandises puissent être justes et complètes et que la pièce ne diminue ou ne s'allonge pas. En effet, il n'est

$170 \diamond$ Documents pour l'histoire des techniques $\mathrm{n}^{\circ} 18$ - décembre 2009 
pas fréquent que l'on puisse contrôler que les ouvriers fassent chacun leur devoir sans le manquer pour arriver à ce point de perfection.

Comme il se fait trois sortes de qualités d'apprêts de draps en fonction du tissage et comme nous avons parlé en général au début, maintenant que nous en venons à l'opération du lavage, il convient de les distinguer afin de n'oublier aucune de ces opérations.

En premier lieu, on fait la toile du drap avec la laine teinte avant de la carder et de la filer : ces draps s'appellent véritablement teints en laine. Ils se produisent aujourd'hui tant en qualité ordinaire que fine, mais comme l'opération de teindre la laine avant de la filer est très coûteuse en soi-même et pour les autres opérations, surtout dans les lavages et les dégraissages qui risquent de rendre une pièce de drap défectueuse, les fabricants ont tellement augmenté les prix de cette sorte de draps afin de pouvoir se couvrir que cela était presque insupportable au public, surtout pour les draps ordinaires. Pour éviter le défaut des draps teints en pièce, lesquels à l'usage, surtout dans les couleurs fortes, blanchissent dans les coutures des habits, de sorte que les livrées des grands seigneurs restaient sales et ne faisaient pas leur effet au bout de deux mois, [les fabricants] ont adopté la solution de teindre la toile avant de l'envoyer au pilon afin que la couture ne devienne pas blanche à l'usage. Mais comme cette opération n'est pas aussi solide que la première, la couleur ne pouvant prendre aussi bien, d'autant plus que cette couleur est donnée avec les restes des autres teintures dans le but d'épargner la dépense, pour donner de la couleur à la laine, on les reteint ensuite après le foulage et après les apprêts que l'on fait à ceux qui sont en blanc pour les mettre en teinture.

On doit observer que cette toile que l'on doit teindre avant de l'envoyer au foulon doit être entièrement dégraissée de façon égale avec de la terre, afin qu'elle puisse prendre uniformément la teinture. Certains se servent d'un peu d'urine, pour faire plus vite, mais très souvent, les [draps] restent tachés si bien que dans ce cas, il est mieux de choisir l'opération plus longue mais plus sûre. Cette sorte de drap doit être absolument foulée avec de la crème de savon uniquement et en essayant de tenir le drap en lisse, c'est-à-dire en égalité de lisières, parce que la laine ayant subi cette teinture, il n'est pas aussi aisé de la faire revenir à la rame, si bien qu'un foulon expert doit sortir deux ou trois fois de la pile son drap pour le lisser avec ses mains pour que la pièce entière ait la même largeur et qu'elle ne se foule pas plus en un endroit qu'en un autre et afin qu'elle puisse avoir sur la rame toutes ses forces égales et puisse soutenir tous ensemble les apprêts nécessaires.

Dès qu'un drap est bien nettoyé et dégraissé, on le met dans la pile en le pliant en rond pour le fouler. Selon la qualité de la laine du drap, on prend plus ou moins de crème de savon et on la pèse. On prend un quart de la dose totale et on la mélange dans trois sceaux d'eau chaude : ceci s'appelle l'eau blanche. Ainsi prépare-t-on doucement le drap à être foulé de façon égale. Après un certain temps, on le sort de l'eau pour vérifier s'il n'a pas de mauvais plis qui pourraient causer un foulage inégal et entrainer le durcissement du tissu qui risquerait alors d'être trové. Une fois retiré de la pile, [le drap] doit être tiré par les lisières quand on le replie afin de le remettre de façon égale dans la pile. On commence alors à mettre la crème de savon pure, en arrosant avec de l'eau chaude : on met un tiers de la crème de savon préparée pour la pièce de drap que l'on doit fouler, en examinant si elle se foule plus en un endroit qu'en un autre, pour charger davantage de savon l'endroit non foulé. Passé un certain temps proportionné où l'on voit que la laine est prête au foulage, on retire le [drap] une troisième fois, on l'examine et on le replie en rond avec les mêmes précautions qu'avant et on le remet dans la pile avec le reste de la crème de savon. Au lieu que les marteaux au début vont doucement car la pièce de drap est faible, on les fait aller à toute force pour réchauffer la laine de sorte qu'elle puisse se fouler et se serrer au degré de perfection requis. Le foulonnier doit veiller à ce que la pièce tourne de façon égale en lui faisant passer la quantité d'eau suffisante pour la refroidir et la travailler jusqu'au degré convenable et n'y reste que le temps nécessaire afin qu'elle ne se foule pas plus que de besoin. Pour savoir si le foulage se déroule correctement, le foulonnier doit prendre un morceau de ce drap entre les dents : s'il en sort une liqueur comme de la crème, tout va bien, mais s'il en sort de l'eau simplement blanche, c'est le signe que le drap est d'une qualité de laine difficile à fouler. Dans ce cas, il doit ajouter de la crème de savon afin d'aider l'opération. Dans le cas où le drap ne veuille pas se purger avec l'eau, on y ajoute de la terre et, une fois celle-ci bien incorporée, on jette de nouveau de l'eau claire jusqu'à ce que la terre s'en soit toute allée, et que le drap reste parfaitement nettoyé $[. .$.

Comme le savon est cher, on se sert pour les draps ordinaires d'urine qui fait aussi très bien l'affaire, même pour les draps fins que l'on veut mettre en teinture bleve ou noire. Elle est introduite maintenant petit à petit. 


\section{Relation de voyage}

Quand le drap a été un certain temps dans la pile, on le lisse et on le remet en ajoutant dans la pile un seau d'urine et deux livres d'huile, qui, unis et bien battus, forment un savon encore plus fort que le savon lui-même parce qu'il agit plus rapidement. Mais ce procédé ne donne pas au drap un toucher aussi doux. Il doit être nettoyé et dégraissé avec de l'eau et de la terre dans la pile du foulon et ensuite jeté à la rivière pour finir de le laver avec des bâtons. Dans les caisses de lavage du foulon, on met les draps teints en noir ou en bleu afin de faire pénétrer davantage la couleur et afin qu'ils ne déteignent pas. Pour ce lavage, on met de la terre déjà movillée, et, si cela ne suffit pas, un ou même deux jusqu'à ce que la teinture soit tellement incorporée qu'en frottant le drap avec du tissu blanc il n'y laisse plus aucun signe de couleur.

Le fabricant doit avertir le foulonnier et se mettre d'accord avec lui sur la qualité de son drap afin que celui-ci sache comme se régler en le travaillant au foulon, procédé si substantiel pour faire un bon drap, car presque toutes les autres opérations dépendent de celle-ci. Pour cette raison, de bons foulonniers sont nécessaires pour bien conduire une fabrique et leur habileté est plus que nécessaire parce qu'un foulonnier habile sait de différentes manières si la laine est vieille ou si elle est jeune, et ainsi dans tous les autres cas il peut perfectionner les opérations précédentes lesquelles sont bien souvent corrigées par l'habileté du foulonnier.

Un drap bien foulé est comme un amas de fils de laine si étroitement mariés ensemble qu'on ne les distingue pas et, bien que de laine fine, il n'est pas doux et est un peu dur. Il a toute la substance, mais il n'a encore aucun embellissement. Il est alors mis dans les mains de ceux qui l'embellissent qui s'appellent les presseurs. Ils font les opérations de lainage, tonte et apprêt. Ces opérations bien faites couvrent et corrigent beaucoup des défauts d'un drap : mal faites, elles gâchent et détruisent un drap en le rendant hors d'usage. Ainsi un drap sorti du foulon est donné au tondeur : celui-ci l'étend sur deux perches sous lesquelles [se trouve] un récipient d'eau dans lequel il maintient plus ou moins d'eau selon le besoin, il trempe bien le drap dans l'eau et puis il fait enlever la laine du drap à l'aide de chardons et de deux bons travailleurs à bras ouverts. Les meilleurs chardons sont ceux qui ont un crochet fort et pour cela dans les pays de fabrique on en sème dans les champs les plus maigres et arides, car cette plante aime beaucoup le sec : plus ces chardons naissent au sec, meilleurs ils sont. Les chardons sont meilleurs que les cardes de fer à cause de leur élasticité naturelle, on les monte sur un bois comme dans notre pays. On utilise moins d'eau en proportion de la force du drap, de sorte qu'à la moindre faiblesse du drap, si le travailleur n'est pas attentif à le tenir bien imbibé d'eau, il risque de le gâcher. L'usage de ces chardons est d'utiliser d'abord les chardons les plus faibles avant d'en venir aux plus forts et pour cela, chaque travailleur a à côté de lui un râtelier avec sept ou huit étages, ce qui correspond au nombre de degrés dont on carde le drap. La première carde qu'il prend est la plus usagée et ensuite, un peu à la fois, par sept degrés, il va jusqu'à la nouvelle. Toutes les fois que l'on carde un drap, la première que l'on utilise est rejetée et on fait remonter les chardons neufs ; la nouvelle qui a servi six fois devient la première dont le travailleur doit se servir pour ce fait. Les deux travailleurs doivent ajuster le drap à la hauteur à laquelle leurs bras peuvent arriver afin de tirer des coups qui aillent aux genoux sans trop plier leurs corps et en tirant les coups de façon égale. Ils doivent finir le coup là où ils l'ont commencé afin que la pièce puisse être lainée de façon égale à l'avant du drap. Le travailleur doit avoir une carde dans chaque main, tant dans la droite que dans la gauche, l'une garnie de chardons et l'autre vide. Tous les deux doivent avoir la même force dans la compression des chardons pour retirer la laine afin que [le drap] soit bien lainé sur le devant. Le fabricant doit avoir à l'œil cette sorte de travailleurs afin qu'ils lainent les draps bien humides et non pas secs, car quelque fois le travailleur épargne de l'eau sur le drap pour faire plus vite et met sans remède le drap en péril. Beaucoup mettent le drap sur une seule perche avec deux croix garnies, ils le lainent des deux côtés. Le travail est fait plus rapidement mais pas avec toute l'exactitude demandée. surtout pour les draps fins. Dans ce cas, les croix ou manches de cardes doivent être garnies toutes les deux. Près des maisons des cardes, il y a deux travailleurs, l'un grand et l'autre petit : le grand monte les chardons sur les croix de chardons utilisées et l'autre nettoie les chardons de la laine qui y reste avec une espèce de peigne et les bat pour en faire sortir l'eau afin qu'ils sèchent plus rapidement et que les chardons conservent leur force pour le premier service que chacun doit faire en son temps.

Une fois le drap lainé, ils le passent à la lumière pour voir si la pièce sort son poil de façon égale, puis ils le mettent à sécher. Une fois bien sec, ils lui donnent la première tonte avec de grands ciseaux qui ne coupent pas trop. Dès qu'il a reçu cette première tonte légère, ils le renvoient au foulon pour le laver une dernière fois afin de pouvoir le dégraisser à fond et le purifier également du savon si jamais il en restait un peu. Revenu du foulon, il est mis dans l'eau et il est bien mouillé, puis on le laisse couler pour ensuite le reporter sur la perche; il est ensuite lainé avec des chardons ni usagés ni tout à faits neufs, en tenant le juste milieu. Il est très travaillé parce qu'il doit sortir le poil plutôt un peu

$172 \diamond$ Documents pour l'histoire des techniques nº 18 - décembre 2009 
long, puis il est porté au tondeur afin qu'il le tonde avec de bons ciseaux à fond deux fois. Puis on prend le drap, on unit ses lisières pour lui donner la dernière carde en se servant de chardons neufs. II faut dire que le drap doit toujours être maintenu imbibé d'eau afin qu'il puisse soutenir la force des chardons. Si le drap est teint en laine, il est plus vite regarni et tondu, mais si le drap est blanc, il faut davantage de travail, tant pour une opération que pour l'autre. Le contremaître laineur ayant contrôlé que le drap est suffisamment lainé, il l'envoie aux tondeurs et ceux-ci le tondent selon le besoin. Il y en a à qui trois tontes suffisent et d'autres qui, pour être conduits à la perfection, doivent l'être jusqu'à six fois. On donne parfois jusqu'à douze tontes aux draps qui doivent rester blancs. Ceci est l'art du tondeur qui doit reconnaître en tondant quand la tonte est parfaitement égale.

Les draps pour l'armée ne sont pas très tondus, mais dès qu'ils ont reçu la première tonte, ils sont lainés et, ainsi lainés, on doit les passer au foulon afin que le poil qui est totalement ouvert se croise bien. Cette opération fait que le drap n'est pas sensible à la pluie et de meilleur abri au soldat. Puis on lui donne une seconde tonte pour le renvoyer à la troisième qui n'est pas très vigoureuse, car il n'est pas nécessaire qu'un drap de soldat soit brillant, mais il est nécessaire qu'il soit bon et adapté aux intempéries qu'il doit souffrir.

Les ustensiles et les tables des tondeurs sont les mêmes que l'on utilise ici au Piémont, à la seule différence que le dernier ciseau qui sert une fois à tondre un drap sert pour la seconde tonte et quand il a servi pour la seconde, il sert pour la première, et pour la dernière on utilise des ciseaux frais et bien coupants. A chaque tonte, on doit étendre le drap sur une table en présence du fabricant pour examiner s'il n'a pas de défaut causé par cette opération. Ces défauts sont des choses que l'on doit marquer, car ils sont corrigibles d'une tonte à l'autre et c'est pour cette raison que, dans toutes les fabriques, les tondeurs sont dans la maison du fabricant, car on ne se fie pour cette opération d'aucun contremaître, les propriétaires voulant être eux-mêmes témoins de cette opération si essentielle.

Pour relever le poil lors de la première tonte, on se sert d'une espèce de peigne de fer, à la seconde d'une lame non coupante, à la troisième certains se servent du frottement de la main un peu humide de salive, d'autres d'une brosse de crin bien doux.

Un drap qui a reçu la troisième tonte est bien examiné sur la table par le fabricant, puis, pour le rendre parfaitement égal dans ses lisières et le faire très bien sécher, il est envoyé à la rame qui est formée à la campagne par de grands piliers plantés en terre traversés de barres de bois. À partir des trous libres des piliers, la barre supérieure se tire seulement en avant et en arrière tandis que l'inférieure, en plus de se tirer en avant et en arrière, se hausse et se baisse selon le besoin et s'arrête au terme nécessaire avec une cheville de fer. Ces barres sont garnies, à intervalle de quatre, de crochets dont la pointe regarde le ciel sur la barre supérieure et la terre sur la barre inférieure. On présente la pièce de drap à cette rame, on tire sur les deux têtes pour les rendre égales en longueur puis, à l'aide de deux cordes, on la pose sur les barres. Ensuite, pour égaliser la largeur, on l'attache à ces rames (les inspecteurs étant présents) et quand elle est attachée de tout son long, on pose la barre inférieure en ligne droite avec les chevilles et les travailleurs tirent le poil tout également avec une petite brosse. Cette opération sert aussi pour nettoyer le drap qui sèche dans cette position ; le soleil, en le réchauffant, le rétrécit de façon égale. Beaucoup de fabricants de mauvaise foi le tirent en longueur quand il est bien réchauffé. II n'y a rien qui endommage plus une pièce de drap, mais ce dommage n'apparaît pas à la vue mais à l'usage. C'est un tort fait au marchand qui l'achète pour le détailler car ce drap étiré se rétracte dans son état naturel dès qu'il y a un peu d'humidité. Dans tous les pays de fabrique bien réglés, il y a un mesureur juré pour éviter cette fraude : s'il la reconnaît, il en réfère à l'inspecteur qui doit lui mettre le plomb et par conséquent examine la mesure avec le numéro de la pièce à son état naturel. Dans les terres d'empire aux frontières de la Hollande et de Liège, où chaque fabricant est maître de faire ce qu'il veut et où il n'y a pas de règlement pour les fabriques, les fabricants eux-mêmes étant les inspecteurs, j'ai vu un drap de 100 canne en atteindre 150 de longueur : une fois perfectionné dans les apprêts, personne ne pouvait s'en apercevoir à moins de l'examiner à la grande lumière où l'on voyait les dommages subis. Une fois le drap revenu de la rame bien sec, on lui donne sa tonte de revers, si cela n'a pas encore été fait. Il faut aussi la lui donner de façon égale parce qu'à la vente le revers est une bonne recommandation pour l'endroit et il favorise beaucoup la vente d'une pièce.

Dès qu'il est tondu pour la dernière fois, le drap est de nouveau examiné, d'habitude par des femmes qui, avec leurs pinces, le nettoient des groupes et choses internes, et, avec la petite brosse, de la poussière. S'il y a quelque trou, elles le bouchent avec une aiguille et de la soie et si la corde est découverte en quelque endroit, elles la recouvrent avec un petit chardon, bref elles raccommodent au mieux qu'elles le peuvent. Mais comme dans cette visite, tout ce qui s'accommode et se raccommode est au détriment du tiers, les fabricants de bonne foi avertissent les acheteurs 


\section{Relation de voyage}

de ces défauts bien raccommodés par un fil sur la lisière afin que ce fil instruise le détaillant et le tailleur qui l'écarte de la coupe du vêtement afin qu'il ne soit pas dommageable à l'usage à celui qui l'a acheté pour s'habiller.

Une fois le drap bien examiné, le presseur l'étend sur une table inclinée à la lumière du jour, puis un ouvrier le travaille avec une planche pas très pesante mais très rêche du côté où elle doit travailler le drap car on y étend de la colle ; cette colle est bien poudrée avec de la limaille de fer également bien répartie et bien sèche. À force de repasser cette planche à deux mains comme une brosse à cheval sur le drap, le poil s'arrange tout au long de la pièce et, avec une petite brosse, on enlève la poussière du drap. Beaucoup, surtout dans les draps fins, prennent une brosse à cheval au poil fin et pas très consistante et commencent à frotter le drap pour lui enlever la poussière, puis avec cette même brosse inclinent le poil tout au long de la pièce. Certains font toute cette opération à sec, d'autres laissent aller quelques petites gouttes d'eau pure et d'autres encore mettent dans cette eau un tout petit peu de gomme. Cette opération ne sert à rien d'autre qu'à incliner le poil du drap de façon égale pour le préparer à recevoir le lustre. Ceci fait avec légèreté, on prend le drap en évitant de le frotter et on l'étend sur une longue table pour le plier, en unissant les deux lisières afin de le disposer à être mis en presse muni de ses cartons, comme nous le verrons après. De la pièce où l'on plie le drap, on le donne roulé au presseur et on le laisse ainsi roulé et préparé pour la presse jusqu'à ce qu'il faille l'expédier et alors on le met sous presse.

Les presses sont faites comme les nôtres, mais alors que les vis des nôtres sont de bois, elles sont généralement de fer ainsi que le tournevis et l'âme qui doit la régler au motif que cela presse plus fort. lls pressent à froid les draps noirs et écarlate pour ne pas leur donner autant de lustre, ce qui serait préjudiciable à leur couleur. À l'endroit du drap, ils mettent un carton très fin et bien lissé. Ces cartons sont faits de papier, c'est-à-dire une feuille coulée l'une sur l'autre comme l'on fait les cartes à jouer et lissés. De la même manière, ils mettent un carton également lissé mais plus fort et plus ordinaire à l'envers du drap. Les cartons doivent être de la largeur dont doit être la pièce une fois pliée et il ne doit pas être plus long que la largeur de la moitié du drap afin que les lisières, qui sont toujours plus fortes que le drap, restent en dehors du carré de la pièce et n'empêchent pas la compression de la machine. Une fois ajustée la pièce de drap avec ses cartons, ils la mettent sur une planche de bois dure et ils la portent sous la presse et ainsi pièce par pièce de sorte que chaque pièce est au milieu de deux planches de bois. Une fois installées les pièces qui peuvent tenir sous la presse, elle est bien serrée. Les draps restent sous cette pression deux jours : on les prend alors pour changer les cartons afin que la partie du drap qui était sur la côte du carton soit au milieu, en permettant ainsi de presser le drap de façon égale, puis on le remet sous la presse et on le laisse plus ou moins, selon la qualité du drap et des laines que l'on travaille. Ensuite, on le sort de la presse et on le remet sous une autre presse légère qui est en bois afin de les pontare. Une fois pontato, on le remet dans son sac de toile ou enveloppe de toile cousue bien étroitement afin que le drap soit bien serré ; puis on remet une pièce après l'autre sous la presse légère. Au fond de la presse, il y a une planche avec deux canaux et chaque deux ou trois pièces une autre planche mais, alors que sur la planche de dessous les canaux regardent vers le ciel, ceux de la planche de dessus sont tournés vers la terre, et puis on les comprime une nouvelle fois dans la presse. Ces canaux entaillés sur les planches servent pour passer les cordes qui doivent lier bien étroitement les draps pour la formation de la balle. Au moment de l'expédition, on les sort et on les couvre de deux toiles ordinaires en mettant de la paille entre une toile et l'autre pour les garantir contre les intempéries de la route lors du voyage.

En ce qui concerne les draps colorés, tant unis que mélangés, ils doivent être préparés à chaud, car la superficie du drap doit être satinée si bien qu'une fois les cartons placés, on met sur le fond de la presse une fonte ou des plaques de fer chaud, mais pas trop, et on répète la même opération entre chaque pièce. Certains posent la planche de bois sur la fonte, d'autres au contraire ne l'utilisent pas et mettent divers cartons usagés et, suivant la même règle que pour les draps noirs, les draps prennent un beau brillant. II faut savoir que dans les presses à chaud, le drap est laissé en presse jusqu'à ce qu'il soit bien refroidi. Dans de nombreux autres lieux, on se sert des tôles de fer fortes : on en met alors une au début, une au fond, et l'autre au milieu de la pièce d'une chaleur modérée, toujours pourtant au milieu de deux cartons. Certains pressent les draps à sec et d'autres humides; qui se sert pour les humidifier d'eau pure tandis que d'autres, qui veulent donner un fort lustre, se servent d'eau adjointe de gomme arabique -ces derniers sont ceux qui restent tâchés quand ils vont dans l'eau-. Ceux qui pressent les draps humides les laissent deux ou trois jours une fois humidifiés avant de les mettre en presse afin que l'humidité se communique à toute la pièce de drap afin qu'elle prenne son lustre de façon égale dans toutes ses parties. Une pièce de drap qui sort de la presse est presque toujours bien carrée, bien pliée, toutes les lisières en sont égales et, ce qui s'appelle en terme de fabrique, bien gaufrée. Ceci est un signe qu'elle sort des mains d'un fabricant diligent et attentif. D'ordinaire cette pièce est parfaite dans toutes

$174 \diamond$ Documents pour l'histoire des techniques nº 18 - décembre 2009 
ses parties et d'habitude elle a été soignée dans toutes les opérations, les unes comme les autres si nécessaires pour la formation d'une bonne et belle pièce de drap, mais toutes les règles générales souffrent leurs exceptions.

En ce qui concerne la main-d'œuvre, les teintures sont égales partout. Comme cet art dépend entièrement du savoir de l'habile teinturier, la vue oculaire ne sert pas et il faut un apprentissage et difficilement seuls les teinturiers nés sont habiles, c'est-à-dire ceux qui ont commencé dès leur enfance à pratiquer une telle profession. En effet, il n'existe pour cet art aucune règle fixe parce que le moindre accident fait varier la règle, la substance étant, non les drogues, mais le climat, l'air et l'eau. Tous les jours on voit une opération faire des effets différents d'un pays à l'autre. Tous les pays ne sont pas d'accord sur ce point, et chacun s'en tient aux essais réalisés et, en fonction de leur réussite, se forme un système qui sert de règle pour conduire son œuvre à sa bonne fin.

Une règle générale que les fabricants ont prétendu instaurer est que pour les draps écarlates, il faut une eau vive, molle et courante, comme celle qui se trouve naturellement à Paris à la fabrique, c'est-à-dire à la teinturerie du Sr Julienne appelée Gobelins, et pour le noir, une eau grasse et pâteuse, de sorte que dans les pays où cette eau n'est pas naturellement grasse, chaque fabrique a un récipient dans lequel on fait séjourner l'eau avant de la faire passer dans la cuve et en proportion de la qualité acquise dans cette stagnation, on augmente ou on diminue les drogues. Le Sr Julienne a le monopole exclusif de l'écarlate avec plomb d'or. II fait deux sortes de couleur écarlate. II teint d'une qualité pour tous ses clients et cette teinture prend le nom du lieu où elles sont teintes : elles s'appellent écarlate des Gobelins. II en fait ensuite une autre qualité qui est beaucoup plus belle et qui est appelée Julienne ; elles portent le nom écrit en tête de la pièce. Pour celles-là, il fait fabriquer le drap lui-même et il prétend que ces pièces sont plus belles parce que la fabrique lui est propre, mais en réalité, il y a beaucoup de draps de Sedan meilleurs que ceux du Sr Julienne, mais personne n'égale le Sr Julienne pour la couleur. La raison en est que si le Sr Julienne doit teindre trente pièces de différents particuliers, il prépare le bain et sur les trente pièces qui doivent être teintes, il en met six des siennes qui entrent toujours en premier dans les bains. II est donc naturel qu'elles prennent la fleur de la couleur et que les écarlates du Sr Julienne aient une couleur davantage de feu et par conséquent plus brillante. II faudrait aussi parler en général de la fabrication des petites étoffes, mais cela viendra ville par ville dans lesquelles elles se font et pour cela nous commencerons par passer dans la première fabrique de draps en sortant de Paris en allant en Normandie qui est Louviers.

\section{Louviers}

Louviers est une ville pas très grande dans laquelle la population est considérable et les bons particuliers sont tous fabricants. Les fabricants de quelque renom étaient au nombre de 18 avec chacun sa raison sociale, mais ils sont à présent réduits à 9 à cause d'une société qui en comprend 10. Une patente du roi concède à cette union le privilège de mettre leur raison sociale, c'est-à-dire celle de la société de Louviers, sur la tête du drap avec un plomb particulier et la lisière différente des autres particuliers de la même ville, avec privilège perpétuel en leur faveur tant que dure la société. Cependant tous les fabricants qui travaillaient les draps de basse fabrique se sont mis dans cette union. Il y a ici aussi d'autres petits particuliers qui font une pièce de drap et prennent le nom d'un autre fabricant dont ils tirent le prix de la toile, en laissant à celui dont ils ont pris le nom le soin de la faire finir. N'ayant convenu aucune soumission et comme ils travaillent sous le nom d'un autre, ils contreviennent à l'obligation de l'autorisation pour fabriquer ; cette sorte de fabricant n'a rien à faire avec l'inspecteur parce leurs métiers à tisser ne sont pas indiqués à l'inspection générale.

La ville de Louviers consiste en une grande rue avec beaucoup de rues latérales. Sur la droite de cette grande rue, il y a une rivière qui est bordée tout le long des maisons des fabricants et il est permis à chacun de faire un pont devant sa maison pour traverser de part et d'autre de la rue et de se faire des caissons ou lavoirs pour les draps à côté de sa maison. Tous doivent contribuer au nettoyage en proportion du site qu'occupe la maison ou l'édifice et tous dans le même temps, de sorte que tous les ans, ils se réunissent pour fixer et déterminer le jour du nettoyage et constituer un fonds confié à l'inspecteur qui est sur les lieux et qui est payé sur le fonds du registre des draps. Lors de cette réunion, ils fixent également le prix pour les ouvriers et surtout pour les fileuses, c'est-à-dire celles qui filent la laine pour tous les particuliers. L'intendant de la province préside ce conseil et l'inspecteur y rend compte des informations obtenues par les autres inspecteurs des autres fabriques de la même province. L'intendant a le prix courant des autres fabriques et il préside seulement pour éviter que les fabricants et l'inspecteur ne portent préjudice aux pauvres gens. Une fois cette taxe fixée, elle ne se publie pas, mais elle passe comme un accord entre les fabricants de manière que ceux qui ne veulent pas filer au prix convenu ne filent pas, mais comme ils ne peuvent vivre sans travailler, tout 


\section{Relation de voyage}

le monde travaille et ne se lamente pas du prix convenu. Les fabricants ont leur habitation sur le devant des édifices et la fabrique derrière. Ils ont une pièce près de l'eau pour l'atelier de la laine, une autre avec un tonneau pour le dégraissage de la laine. En haut de la maison, il y a les séchoirs pour les laines et comme presque toutes ces maisons ont un jardin, dans ce jardin il y a un petit pré à usage de la fabrique. Près du tonneau de la purge de la laine, il y a un autre récipient pour teindre la laine qui, une fois teinte, passe dans une autre pièce où se trouve le baril de l'huile. Dans la même pièce, il y a les cardeurs et un contremaître qui doit répondre de la laine qui y entre et la distribuer aux fileuses auxquelles on expédie un billet dont le contremaître tient un double pour le donner au patron. Celui-ci reçoit le fil de laine et le pèse afin de payer la fileuse ; à l'aide du billet reçu, il examine son compte et, au début de la semaine, quand il n'a pas reçu la laine confiée aux fileuses par le contremaître de filature, il envoie chercher le compte ; en cas de vol de la laine, l'inspecteur en décide sommairement et verbalement sans aucun coût. De l'atelier du fil, la laine passe aux ourdissoirs dont une bonne part sont dans la maison. Mais comme beaucoup de métiers sont aussi en dehors de la maison, les travailleurs propriétaires des métiers ont aussi leurs ourdissoirs et pour cela la distribution de la laine se fait au poids et une fois la toile faite, elle est restituée avec bonification de la colle employée par le travailleur pour coller la chaîne de la pièce. Lorsque la pièce est restituée en toile, le patron l'examine et la donne à la chambre du lavage afin qu'en la jetant dans la rivière, on la dégraisse pour pouvoir l'envoyer au foulon. Ici à Louviers, les fabricants s'écartent de la règle générale pour le dégraissage des pièces : ils les laissent dégraisser dans l'eau courante, puis ils les roulent et les mettent dans la pile du foulon, en laissant sortir l'eau afin que le drap se purge. lls ferment ensuite la pile et commencent l'opération du foulon avec la crème de savon comme dans la règle générale. Les foulons sont en dehors de la ville, il y en a deux publics, les autres sont particuliers aux fabricants. Exceptée l'opération de la carde qui se fait dans une pièce à côté de celle du lavage pour la commodité de l'eau, toutes les autres se font au deuxième étage de la maison. Au-dessus du deuxième étage, il y a des greniers dans lesquels logent les contremaîtres et leurs familles. Ils logent aussi quelques bons travailleurs qui attendent de devenir contremaîtres et ceux-ci mangent un peu de viande de mouton, de porc, mais la nourriture quotidienne des autres petits travailleurs et fileuses est constituée de pain, de pommes de terre et de la bière comme boisson. En ce qui concerne la filature, on travaille le plus en hiver parce qu'ils doivent travailler la campagne dans les autres saisons, bien que dans ces temps-là aussi ils travaillent. Il y a bien peu de mendiants parce qu'on les renvoie et on les envoie travailler. Ceci étant de l'intérêt de tous les particuliers est devenu pour cela général.

Presque toutes les ventes sont pour le terme de l'année comme il se pratique dans tout le royaume de France : ils donnent à chaque 20 aunes de draps une aune de bonification, un pouce en plus de l'aune officielle et aussi l'escompte de $6 \%$ à la ponctualité du payement; ils expédient aussi bien la pièce entière que des demi-pièces.

Les rovets des fileuses sont comme dans la description générale à la différence que le fuseau est soutenu par une corde de jonc et la corde de la grande rove est une grosse corde de violon et la rove a un manche qui reçoit le coup pour filer, les autres en étant dépourvu, la fileuse donnant un coup de main aux fuseaux de la rove. lls disent que les roves munies d'un manche tournent plus fermement car, recevant le coup dans le manche placé au centre de la rove, la rove tourne plus en équilibre et par conséquent le fil est plus égal et filé avec la même proportion. Les ailettes sont soutenues par deux autres petites ailettes qui soutiennent les premières afin qu'elles ne bougent pas, et cela aussi est fait pour donner plus d'égalité au fil de laine.

La façon de purger les draps dans l'eau courante fait que les draps conservent toujours un toucher doux, mais les fabricants sont soumis à beaucoup plus de risques en dégraissant dans le foulon, car si le drap pour une part flotte, comme il est teint en laine, le savon mange radicalement la couleur ou bien si, pour un temps, l'eau devient trouble, et qu'ils ne sont pas attentifs à la retirer du bain, [la pièce] se tâche.

Pour les presses, ils se servent ici de cartons très fins et ils utilisent des tôles de fer chaudes pour réchauffer la presse: ils en mettent une sur le fonds et puis une tous les cinq plis, en laissant le drap dans la première presse deux fois 24 heures et jusqu'à quatre fois 24 heures dans la seconde. Une fois la presse froide, le drap y reste encore un jour. Ici ils pressent le drap à froid sans eav et sans gomme et c'est pour cela que les draps de cette qualité conservent ce doux toucher de laine. Dans les opérations suivantes, ils suivent la règle générale de toutes les autres fabriques.

\section{Andelys}

Peu distante de Louviers se trouve la fabrique des Andelys. On y travaille les draps de la même manière, à la différence, dont ils ne savent même pas eux-mêmes à quoi elle peut tenir, que les draps double broche réussissent mieux que ceux de Louviers. L'une comme l'autre sont dans l'obligation de travailler des laines de première sorte d'Espagne,

176 Documents pour l'histoire des techniques nº 18 - décembre 2009 
en faisant la chaîne des lisières de leurs draps avec des laines du pays ; on voit cette qualité de drap sur la feuille à part au $n^{\circ}$ I sur laquelle il y a un échantillon indiqué A et l'autre B, la première est de Louviers, la seconde des Andelys.

\section{Elbeuf}

A cinq lieves de Louviers, il y a Elbeuf qui n'est pas plus long que Louviers, mais beaucoup plus grand et par conséquent il contient le double d'habitants avec beaucoup de petites maisons dispersées dans les campagnes qui, tant dans la ville qu'en dehors, sont toutes faites de bois et de boue sèche qu'ils appellent Plâtre avec bien peu de briques sur les façades et pour la formation des escaliers. La direction des fabriques est la même qu'à Louviers à la différence qu'ils travaillent ici des laines de seconde et troisième sorte et qu'ils purgent leurs draps au foulon ayant par ailleurs de l'eau qui passe à côté et dans la ville, mais elle n'est pas aussi courante que celle de Louviers. Le fleuve a un lit plus profond et pour cela l'eau est moins limpide, d'autant qu'ils la tirent en de petits étangs près de leurs maisons chacun pour l'usage de son édifice.

La distribution de chacun des édifices en particulier est la même qu'à Louviers à la différence qu'ils n'ont pas tant d'exactitude dans la fabrication, si bien qu'à force de faire de mauvais draps, la fabrique allait tous les jours en décadence. Mais à la fin du mois de septembre dernier, ceci étant venu à connaissance du Grand Conseil, les inspecteurs ont été changés de façon à leur faire suivre les ordres donnés pour la constitution de la fabrique. On a fait une nouvelle revue de tous les métiers battants et les inspecteurs ont reçu l'ordre d'essayer de mettre peu à peu en œuvre ceux qui étaient sans travail au motif qu'il n'y avait plus de vente, en obligeant les maisons les plus importantes à s'en charger afin de remettre la fabrique dans l'état initial. Les inspecteurs ont reçu l'ordre de ne plus plomber les pièces qui ne sont pas bien travaillées et, pour la bonne foi publique, de marquer lors de leur visite les défauts sur la lisière au cas où les propriétaires ne l'aient pas fait comme c'est leur devoir.

Dans ce temps, la maison du Sr Lefevre a exposé que vu le peu de vente, les métiers susdits ne pouvaient s'employer pour un tel article sans un grave dommage pour les fabricants, car la marchandise serait restée invendue. Elle promettait pour cela de s'en charger à condition qu'on lui donne le privilège, pour lui et ses successeurs, pour les articles de nouvelle invention qu'il présenterait au Conseil. Au vu de cette représentation, le Conseil a regardé les échantillons des articles de nouvelle invention fournis avec les certificats des inspecteurs et a dit qu'il ferait connaître ses intentions.

Le Sr Lefevre a d'abord présenté un échantillon de droguets de Silésie (indiqué sur le papier par la lettre A) à la mode de ceux de Reims, mais beaucoup plus forts, travaillés avec des laines d'Espagne ordinaires et rayés de deux couleurs différentes; deuxièmement d'autres échantillons de droguets ordinaires indiqués par la lettre B : ceux-ci sont travaillés à la chaîne de fioretto et tissés avec des trames de laines du pays mélangées aux restes des laines de rebut d'Espagne ordinaires ; troisièmement, deux autres échantillons de demi-draps appelés draps d'été travaillés avec une chaîne de soie et de laine surfine (la trame d'Espagne) indiqués par la lettre C. Ces trois échantillons ont été pris en considération ainsi que la demande de privilège du Sr Lefevre, mais étant donnée la maxime générale de ne plus concéder de privilège exclusif d'aucune sorte pour ne pas enlever cet avantage aux peuples, on a répondu au Sr Lefevre que le roi ne voulait absolument plus concéder de privilège exclusif, mais que pour le stimuler on lui aurait concédé 3 francs de bonification pour chaque pièce sur soie vendue à l'étranger et 1.10 franc pour tout droguet à la mode de ceux d'Angleterre qu'il aurait vendu à l'étranger, avec un plomb et une marque pour distinguer ceux qu'il ferait en tant qu'inventeur des autres, au cas où il s'en ferait ; et, pour gratification supplémentaire, on faisait de son frère un inspecteur de la manufacture de Carcassonne avec 5/M livres de salaire. Ledit Lefevre s'est mis à travailler ses pièces pour obtenir les patentes de privilège pour la bonification de sortie des états dont on attendait qu'elle soit publiée d'un jour à l'autre.

La qualité de ces draps se retrouve à la page $n^{\circ} 2$ : ils sont, comme je l'ai dit, travaillés de la même façon que ceux de Louviers, à la seule différence qu'avant de les mettre en presse ils les humidifient et ensuite ils les laissent trois jours afin que l'humidité se répande également pour ensuite les mettre en presse. Pour les humidifier, ils les allongent sur une planche et, dès qu'ils sont humides, ils les plient en deux pour ensuite les mettre en pile pour les plier avec les cartons ; ils se servent aussi de cartons fins et de tôles de fer tous les cinq plis. D'ordinaire, ils n'en pressent pas moins de six à la fois dans ces fabriques et, en cas de besoin, ils envoient chercher chez les autres fabricants de quoi remplir la presse, se restituant cette main-d'œuvre réciproquement sans pouvoir prétendre aucune rémunération. 


\section{Relation de voyage}

\section{Roven}

Il y a quatre lieux pour aller d'Elbeuf à Rouen : on y vient sur la Seine en barque en payant cinq sous par personne et cette barque part tous les jours et retourne de même tous les jours. On y va également par voie terrestre par de mauvaises routes traversant des terres médiocres. Ils se servent des plus mauvaises terres pour semer les chardons avec lesquels ils cardent ou lainent les draps. Cette semence de chardons doit être semée au printemps, elle est ensuite transplantée en automne et protégée des rigueurs de l'hiver en la couvrant de paille. Au printemps suivant, ils en prennent le fruit, en laissant quelques plantes venir à maturation complète pour pouvoir en retirer la semence. Le plus haut de ces chardons étant trop fort pour carder les draps, ils le vendent et l'expédient pour lainer les chaussettes et les autres servent pour l'usage des fabriques de draps. Dans ces terrains caillouteux (giarini), ils sèment le grain alternativement une année et l'autre non. L'année où ils sèment le grain, ils sèment en même temps un petit grain qui ne produit rien d'autre qu'une plante d'herbe dont ils se servent pour la teinture en jaune, mais comme pour que cette herbe arrive à maturité il faut deux ans, la première année ils prennent la récolte de grain et la deuxième celle de I'herbe pour faire le jaune. Une fois traversée une grande colline presque toute garnie de bois on arrive dans les faubourgs de Roven, pas très grands et presque entièrement peuplés d'ouvriers : un très grand nombre de ces habitants filent le coton et ce faubourg est fourni de tout le nécessaire sans avoir besoin de la ville. Dans ce faubourg se trouve la fabrique de velours tant uni que rayé (velours uni A). Les noirs se fabriquent comme ceux de soie, en les taillant sur le métier et ceux incanaliti [côtelés?] se taillent une fois le velours fait en faisant passer dans les incanaliture [côtes?] un petit fil de fer ayant sur le fond un petit canif (temperino) qui est très fin et qui, en rentrant, élargit comme la pointe d'un canif (temperino) avec lequel d'ordinaire on taille les plumes à écrire (velours rayé B). Le directeur de cette fabrique est le seul à Rouen, il conserve encore le privilège exclusif de travailler et a le droit de donner la permission à qui veut travailler et il la donne à condition que ceux qui travaillent prennent chez lui la matière première et mettent sa marque sur toutes les pièces fabriquées.

La chaîne de ces velours (comme à la lettre B) est de coton, c'est celle que l'on lève et où l'on croise le fil de fer. Elle est de gros coton selon la longueur dont on veut que soit formé le ras du velours, lequel, par le moyen d'un petit engin taillant qui passe sur le dernier fil de fer, donne le velours rasé, quelque p. [?] il reste côtelé (incanalito). La maison de cette fabrique n'est pas très grande et, pour former ces velours, il y a une pièce dans laquelle on choisit les fils de coton en proportion de la finesse dont on veut faire le velours. II y a un petit portique qui sert d'ourdissoir pour ourdir la chaîne avec diverses petites maisons à un seul étage où se trouvent les métiers et deux pièces pour les apprêts, lesquels consistent à tailler les velours rayés, comme à la lettre B, et une autre dans laquelle aussi bien ceux qui ont été coupés avec le canif (temperino) qu'on appelle côtelés (canaliti), que les unis, sont tondus avec une paire de ciseaux pour leur retirer les petits poils de coton que la taille a fait sortir et qui rendrait le velours inégal si on les laissait. Le coton pour les velours surfins s'utilise teint et pour les ordinaires en blanc, la pièce étant teinte une fois faite. Ils utilisent pour cette teinture un léger mordant afin que la teinture puisse tenir. La composition de ce mordant est ce qui constitue le grand secret de cet article. Dans la même fabrique et de la même façon, on fait également les peluches indiquées à la lettre $C$ : elles ont le poil de soie et la trame qui soutient le poil est de coton.

Les velours, tant unis que rayés, ont une petite demie aune de hauteur et la pièce est longue à peu près de dix-huit ou vingt aunes. Les unis sont aux prix de [?] jusqu'à 14 lires l'aune, les rayés de sept à huit lires l'aune, et les peluches à partir de sept et même plus selon qu'elles sont plus ou moins fortes en poil de soie. lls font également des molletons en coton, mais tous croisés et aucun lisse, ayant pour règle générale que tout ce qui est croisé doit être monté sur le métier avec une double chaîne.

Il y a également dans ce faubourg une fabrique de faïence ordinaire, et toutes les teintures pour les cotons et les fils de lin et de chanvre qui servent pour toutes les autres manufactures que nous allons maintenant voir.

Les maisons de ce faubourg sont toutes de bois et de plâtre avec quelques pierres pour la façade et dans les lieux où doit séjourner le feu, de sorte que pour former une maison, ils commencent par faire un squelette de travées pour ensuite le remplir de plâtre ou de pierres, selon le besoin.

De ce faubourg, on passe sur la Seine grâce à un pont bien long de barques qui est toujours flottant, surtout quand la marée monte et descend, ce qui advient deux fois toutes les vingt-quatre heures et parfois elle est si forte qu'elle inonde tant du côté de la ville que du faubourg. Ce pont s'ouvre deux fois par jour pour laisser sortir les barques [bateaux ?] qui doivent partir et celles qui doivent entrer dans le port. Au-delà du pont, il y a un grand quartier tout au long de la Seine, où se trouvent tous les vaisseaux tant ceux qui sont au chargement que ceux que l'on décharge. Les plus gros chargements sont ceux de grains et de vivres, et ces vaisseaux amènent des plombs, des laines d'Espagne et

$178 \diamond$ Documents pour l'histoire des techniques nº 18 - décembre 2009 
d'autres produits semblables. Il y a tout le long des magasins qui servent pour le déchargement et de petites maisons de bois pour les commis des fermiers généraux qui exigent les droits et les taxes que les marchandises doivent payer. À mi-hauteur de cette rue, se trouve la Bourse découverte pour l'été. Il y en a une couverte en ville pour l'hiver et les jours de mauvais temps qui est installée dans une maison construite exprès près de la route du port, et les tribunaux marchands, tant maritimes que terrestres, se trouvent également dans cette maison.

Quand quelqu'un qui n'a pas le temps de séjourner a un chargement à vendre, pour l'écouler économiquement, on en fait une vente publique annoncée par le moyen d'un billet affiché dans la Bourse. Le courtier reçoit et publie les propositions reçues tant ensemble que séparément pendant trois jours successifs et la vente reste aux derniers et meilleurs offrants tant séparément qu'ensemble sur la seule assertion du courtier.

La ville est très grande, il y a quelques maisons de briques avec quelques pierres, mais la majorité des maisons sont de bois et de plâtre. La ville est très peuplée de toutes catégories de personnes. II y a un parlement car elle est capitale de la Normandie, sa juridiction s'étendant aussi aux autres provinces voisines.

La plus grande partie du commerce de cette ville est dans les mains des commissionnaires qui achètent à toute heure pourvu qu'ils trouvent le prix bon. Il y a deux sortes de commissionnaires, ceux qui achètent en gros des chargements entiers de toutes espèces, et d'autres qui achètent de petits lots en proportion des ordres qu'ils reçoivent. Les uns et les autres font le change selon leur besoin. La fabrication de cette ville et de ses alentours consiste en articles de laine, toiles de lin et toiles de coton, et pour cela on peut dire qu'il y a des fabriques. Pour le reste, il y a des ouvriers de tous les autres genres mais de peu d'importance, ce qui ne manque cependant pas de faire un nombre de marchandises infini.

En ce qui concerne la draperie, on fait à Rouen des draps, mais bien peu à cause des autres fabriques voisines, de sorte qu'il ne se fait dans tout le territoire qu'une centaine de pièces par an. Leurs principaux articles en matière de draperie sont les ratines, les molletons ou espagnolettes et les couvertures appelées catalogne. Les ratines qui sont indiquées par la lettre D sont aussi un objet de la fabrication de Rouen bien qu'elles ne se fassent pas à Rouen, mais dans un village ayant pour nom Darnétal, distant d'une demi-lieve de la ville et où se trouve le gros de la fabrication de toute la draperie. Elle se fait avec les mêmes règles qu'au Piémont, selon les édits de Louis XIV sur lesquels ont été copiés ceux du Piémont, avec cette seule différence que les draps de Roven se fabriquent avec des laines de seconde et de troisième sorte d'Espagne et ceux du Piémont avec des laines de seconde et troisièmes sorte de Rome, selon les édits, et à présent avec des laines de toutes sortes. Les filés de ces ratines doivent être filés et foulés modérément, de sorte que plus le filé est fin plus la frise doit être belle, chaque fil, tant de la trame que de la chaîne, devant former son nœud dans la frise. II se fait des ratines ducret et Robon : les ducret sont larges 1 1/4 et les Robon deux ras, tant les couleurs fortes que les colorées. La laine des ratines doit être filée dans la même proportion que celle des draps, à cette seule différence qu'alors que la trame des draps doit être filée large, celle des ratines doit être un peu plus resserrée, n'ayant pas à être foulée autant que doit l'être un drap. En ce qui concerne la tonte, elles ne doivent pas être autant lainées et tondues : alors qu'un drap doit être tondu deux ou trois fois après le dernier lainage afin d'être bien ras, les ratines sont envoyées après la première tonte à la teinture et, après les avoir lainées encore une fois légèrement, elles doivent être envoyées bien sèches à la frise dans laquelle elles reçoivent leur dernier apprêt.

Ici les ratines sont toutes dégraissées avec de la terre dans le foulon et foulées avec de la crème de savon. S'il y a des difficultés dans le foulage, ils ajoutent de la terre mêlée à de l'eau chaude afin qu'elles se réchauffent plus vite et qu'elles puissent se fouler plus vite et avec une plus grande économie de dépense, parce qu'étant une marchandise ordinaire, elles ne peuvent soutenir de fortes dépenses.

Les ratines, tant d'une qualité que de l'autre, doivent être croisées afin qu'elles puissent soutenir davantage la fatigue, car elles doivent servir à des usages plus forts que les draps, et le fabricant doit faire en sorte qu'elles aient plus de force que de vue pour s'adapter à l'usage parce qu'elles doivent servir à des gens ordinaires qui doivent se procurer davantage l'utile que l'apparence, n'étant pas en état de renouveler leur dépense aussi fréquemment pour se vêtir.

Un autre article, et le plus important qui se fasse dans la draperie de Roven, sont les espagnolettes ou molletons portant le nom de la ville; on les retrouve sur le papier indiqués par la lettre E. II s'en fait de deux sortes, l'une croisée et l'autre lisse, c'est-à-dire en toile. Les croisées sont faites comme les ratines mais avec moins de portées, travaillées avec un fil filé très large, pas très battu sur le métier, légèrement foulé, très bien lainé mais toujours lainé dans l'eau afin qu'il se soutienne. Les lisses doivent être faites comme l'on fait la toile de la même façon que les croisées. Cet article doit être fait de laine d'Espagne fine bien choisie et bien purgée. L'essentiel est de le faire d'un fil égal afin 


\section{Relation de voyage}

qu'il puisse se lainer régulièrement. Il y a des fabricants qui leur donne une tonte et ceux-ci sont plus beaux à la vue, mais la plus grande partie n'est absolument pas tondue et ce genre de marchandise doit être dégraissé et foulé entièrement au savon parce que le plus grand usage que l'on en fait est en blanc et pour cela il faut qu'il ne perde rien de sa blancheur, autrement la vente de cet article serait très pénalisée.

On fait également des molletons de coton, ayant éprouvé que le coton se foule au foulon mais, comme on les laisse avec une chaîne forte et plutôt serrée, à l'usage, ils deviennent durs. La douceur superficielle leur est donnée grâce à la carde, à force de les regarnir en coton. Les uns comme les autres sont blanchis au soufre. Chaque fabricant a un cabinet spécial pour ce blanchissage : il a une porte seulement par laquelle ils entrent pour étendre les pièces, une fois le soufre allumé, ils ferment cette porte en obturant les fissures avec de la terre grasse, c'est-à-dire du plâtre, et ils laissent la marchandise deux fois vingt quatre heures avant de lui laisser prendre l'air.

Ils font une infinité d'autres étoffes et, comme le coton uni à la soie peut soutenir davantage que la laine, ils ont imaginé, pour multiplier l'ouvrage, de se servir de celui-ci pour lier toutes les étoffes de soie qu'ils font. C'est ainsi que les peluches pour doublure d'habits indiquées par la lettre $C$ sur le papier ont le poil de soie et sont liées de coton.

Les deux échantillons indiqués par la lettre $\mathrm{F}$ et $\mathrm{G}$ sont entièrement de coton et c'est une toile de coton dont on fait un très grand usage pour la doublure des habits de drap. Elles se font toutes comme celle indiquée par la lettre $G$ en écru. Si on les veut colorées, on les donne à la teinture et elles prennent très bien toutes les couleurs à l'exception du noir et de l'écarlate. Si on veut les blanchir, on les blanchit comme on le fait pour la toile de lin, mais le coton prend plus facilement le blanc que la toile de lin car il est déjà blanc par nature. Ils en font également de toutes blanches en soie comme celle indiquée par la lettre L, et pour faire celles-ci, ils blanchissent d'abord le coton avant de s'en servir pour tisser la chaîne de soie.

Ils font également les chamoises de soie et de coton : il y en a des rayées tant en lignes de satin qu'à lignes de fleurs de soie, d'or et d'argent. Dans celles de satin rayées, la soie est mélangée au coton par le tisseur, tant dans la trame que dans l'ourdissage. Celles rayées à fleur sont travaillées au lacet comme on fait les étoffes de soie de brocart : le lacet est situé à côté du métier de façon à ce qu'un garçon, tirant un fil à la fois, expédie au tisseur le dessin sans qu'il s'en aperçoive. Celles qui sont à bochetti avec de l'or et de l'argent sont brodées, comme on le voit mieux sur les échantillons indiqués par la lettre $\mathrm{H}$ à côté desquels on voit le prix de chaque étoffe selon que le dessin est plus ou moins riche.

Ils se servent aussi du coton pour la trame des moelles qui sont indiquées sur le papier par la lettre l, celles-ci sont de la largeur d'une demie aune, comme le sont également les grisettes de soie et de coton indiquées par la lettre M. Pour les ouvragées, ils se servent de fil pour leur donner plus de corps et afin qu'elles puissent prendre les passati avec un plus grand lustre. Toutes ces étoffes sont pressées à la calandre, laquelle est faite comme celles qui chez nous servent pour la presse des mocaliate reteintes. Ils donnent également avec celle-ci l'onde aux moelles du pays. Pour celles ornées de quelques fleurs d'or et d'argent, ils se servent du cylindre parce que la calandre n'aurait pas la force nécessaire pour comprimer la petite quantité d'or et d'argent qui compose la fleur. Les cylindres sont deux rouleaux de métal qui tournent l'un sur l'autre : en tournant l'étoffe passe entre eux et est lissée. Ces deux rouleaux prennent leur mouvement d'une grande rove qui tourne avec une force supérieure et donne un mouvement égal aux deux rouleaux composant le cylindre.

\section{Darnetal}

À Darnetal, il y a aussi une infinité de fabriques de couvertures dénommées « catalogne ". Ces couvertures sont tissées avec des fils très gros filés avec la laine aussi ouverte qu'il est possible et foulées de la même façon que les draps. On en fait de trois qualités dénommées fines, mi-fines et ordinaires. Les largeurs sont de cinq et sont marquées par des barres de couleur bleve. Chacun établit sa règle qu'il confie à l'inspecteur. Chacun a la liberté de commencer par le numéro qu'il souhaite : par exemple, celui qui veut marquer la plus petite avec le $n^{\circ} 1$ en proportion est obligé d'aller jusqu'au 5 sans pouvoir diminuer la largeur destinée de la première qualité jusqu'à la cinquième. Supposons que la couverture la plus petite soit donnée comme numéro 1, les couvertures devront être des [largeurs et longueurs] suivantes:

$180 \diamond$ Documents pour l'histoire des techniques $\mathrm{n}^{\circ} 18$ - décembre 2009 


$\begin{array}{rll}\mathbf{n}^{\circ} & \text { largeur } & \text { longueur } \\ 1 & 1 a^{3 / 4} & 1 a^{1 / 4} \\ 2 & 2 a & 1 a^{1 / 2} \\ 3 & 2 a^{1 / 4} & 1 a^{2 / 4} \\ 4 & 2 a^{1 / 2} & 2 a \\ 5 & 2 a^{3 / 4} & 2 a^{1 / 4}\end{array}$

À Darnetal, il y a aussi une importante teinturerie à la direction de laquelle se trouve un certain Lambert qui a très grande réputation dans toute la France. II a le privilège de teindre de toutes les couleurs sur l'étoffe qu'il lui plaît, et il peut également teindre en écarlate sans pourtant pouvoir apposer le plomb doré que met le Sr Julienne de Paris. ॥l a deux neveux qui font le même métier, et, interrogé par moi sur le ton de la conversation, s'il aurait envoyé travailler en dehors de l'État l'un de ses élèves, il me répondit oui, pourvu qu'il y trouve son compte. II m'a assuré qu'ils sont en état de teindre comme lui toutes sortes d'étoffes et, de fait, ce sont les neveux qui travaillent à la direction de cette teinturerie, le Sr Lambert étant un homme déjà âgé qui ne peut plus beaucoup travailler. Mais, comme au début lui seul a fait marcher cette teinturerie, il conserverait avec lui, pour promouvoir les intérêts de sa famille, le plus jeune qui, avec son assistance, serait en état de succéder à ses privilèges ; le premier, plus fort et plus vieux, il l'établirait dans un autre Éłat afin que tous deux puissent travailler plus librement.

Dans les alentours des campagnes de Roven, on fait toutes sortes de toiles tant en pur lin uni et rayé, qu'en sempiternel à fleur, à bochetti en toile unie de coton, rayé, tant en fin qu'en ordinaire, de toutes sortes qu'on sache imaginer. Comme les fabricants ne sont pas très éloignés de la ville et qu'une fois leur pièce faite, ils ont besoin de l'argent et que s'ils devaient dépendre des expéditeurs, ils ne leur donneraient pas toute la bonne justice que l'équité demande, la ville a fait construire pour cela une grande maison qui sert à de multiples usages publics. Dans cette maison, il y a une grande galerie à trois nefs, chacune large de deux trabuts à peu près et longue au moins comme notre place du château, qui s'appelle la halle ou le marché. Ce sont les inspecteurs de la ville qui ont les clefs de cette galerie et elle n'ouvre au son de cloche que le jour de marché qui est le vendredi de toutes les semaines, le matin de six heures à dix heures : qui a acheté tant mieux, sinon il faut que chacun sorte et attende le vendredi suivant pour les opérations qui restent à faire. Dans la même halle, se trouvent six taulassi de 5 aunes de long qui servent pour les mesures publiques. Ceux qui achètent la marchandise sont obligés de les faire mesurer, ils paient un liard par aune et c'est au vendeur de le payer. On ouvre cette halle seulement durant quatre heures afin que les acheteurs se dépêchent de faire leurs affaires et que les fabricants ruraux aient le temps de retourner chez eux. On commence à acheter à l'intérieur à la lumière de la chandelle parce qu'il ne fait pas encore jour. Quand je l'ai vu, il y avait dans toute dans cette halle plus de six millions de marchandises et, selon ce qu'ont dit les mesureurs, il s'est vendu ce matin-là pour un million et demi environ pendant les quatre heures qu'a duré le marché.

Une fois la marchandise mesurée, elle est envoyée au domicile des acheteurs, et le vendeur en sortant de la galerie va directement recevoir son argent avec la déduction des escomptes prévus dans les règlements publics, car il est impossible à cause du monde qui passe et repasse de faire aucun paiement (dans la halle). Ceci oblige tous les étrangers qui veulent acheter à se munir d'un expéditeur connu qui leur fournisse sa maison pour le dépôt des marchandises afin que le fabricant sache où aller prendre son argent, et pour cela ils prennent $2 \%$ de provision. Mais il est bien vrai qu'en leur payant l'emballage, ils expédient la marchandise à destination. Le jour de marché, une fois sortis de la halle, ils s'en vont tous à la Bourse où se font les assignations pour les paiements et où se donnent les commissions pour le marché suivant, chacun selon son besoin, ou, surtout, selon les commissions reçues de l'étranger. Si quelqu'un veut sortir la marchandise qui reste invendue, il faut qu'il profite des quatre heures d'ouverture de la halle, sinon il ne peut plus la prendre ni la voir jusqu'au marché suivant.

Comme le port de Roven est l'entrepôt pour toutes les marchandises des provinces de cette capitale, les marchands et les fabricants viennent à la Bourse de toutes les provinces, surtout ceux d'Elbeuf et de Louviers qui viennent régulièrement trois fois par semaine pour l'achat de leurs laines et pour négocier leurs fonds. La Bourse de Roven a comme prérogative qu'un homme ayant fait faillite ne peut plus y rentrer jusqu'à ce que toutes les dettes ne soient payées. Cette loi vaut tant pour les hommes que pour les femmes, étant permis aux uns et aux autres d'aller à la Bourse. Cette bourse jouit également de tous les autres privilèges et prérogatives dont jouissent les autres du même état selon les ordonnances du Grand Conseil. Les courtiers « placés » sont obligés de se retrouver pour rendre compte 


\section{Relation de voyage}

des commissions qu'ils ont reçues d'un jour à l'autre s'ils ne l'ont porté de bonne heure chez les négociants, afin que ceux-ci puissent savoir à la Bourse à quoi s'en tenir.

Il y a aussi une sorte de banquiers qui d'habitude ne fait pas autre chose que de recevoir les lettres de change des négociants, mais ce sont des lettres qui doivent encore courir un certain temps. Ils leur compte leur argent moyennant un demi pour cent par an, mais il faut que ces lettres soient acceptées sur les places de France. De cette façon, les fabricants dans le besoin peuvent bénéficier de leur comptant sans avoir besoin d'emprunter d'argent.

\section{Aumale}

De Rouen, je suis parti pour Amiens par une route pas très bonne et, à mi-chemin, j' ai trouvé la terre d'Aumale où, tant dans la Terre que dans ses alentours, on fait trois sortes de saies indiquées sur le papier par la lettre AA. La plus légère est appelée avec le nom du lieu et les autres " façon de Londres " et " demi Londres ». Toutes les trois sont fabriquées de la même façon avec les laines du pays, elles sont croisées, c'est-à-dire travaillées avec des chaînes à trois portées doubles, le nombre des portées dépendant des largeurs désirées. Au fur et à mesure qu'ils les veulent plus fortes, ils se servent de filés plus gros et plus larges pour la trame et ils les font rentrer au foulon. Selon qu'ils les veulent plus consistantes, ils les lainent avec la carde et leur donnent une seule tonte tant d'un côté que de l'autre. S'ils veulent les blanchir, ils les blanchissent au soufre comme on l'a déjà dit des articles de laine de Roven, et s'ils veulent les teindre, ils les teignent et ensuite les pressent comme toutes les autres saies, un peu humides au milieu de cartons chauds pour ensuite les mesurer et les plier.

\section{Amiens}

De Aumale, je suis venu à Amiens, capitale de la Picardie. Le territoire de cette province abonde de grains, elle est par conséquent très peuplée et s'active à un point qu'on ne peut exprimer. lls font ici des draps, des saies, des camelots et d'autres petites étoffes, comme on le voit sur le cahier des échantillons. La ville abonde d'eaux courantes mais, comme ces eaux ne sont pas très claires et par conséquent par très bonnes à boire, ils ont établi douze fontaines dans la ville pour la commodité publique ; c'est une equ qui passe en dehors des murailles qui leur fournit l'eau. Pour ce faire, ils ont construit une grande maison dans laquelle se trouve une pompe qui tire l'eau dans un baril à une hauteur supérieure à celle de toutes les maisons de la ville; de ce baril, elle passe dans un autre situé un pied plus bas par le moyen de douze conduits, l'eau descend de façon continue jusqu'aux fontaines qui donnent continuellement une eau très limpide, bonne et de toute perfection, de sorte que c'est la meilleure qui soit dans ce département de la France.

$\|$ y a de très belles promenades et quatre lieux publics pour le divertissement des ouvriers. Tous sont garnis de promenades d'eau tirée de la Somme qui passe près d'Amiens et comme cette eau corrodait d'un côté et de l'autre et endommageait beaucoup ici et là, ils ont choisi un circuit de dix lieves et y ont créé de petites îles entourées d'eau. Ils retirent de ces îles tous les légumes nécessaires à la ville et ses alentours. Quand l'eau n'est pas très haute, surtout en été, ils s'en servent de promenades. La ville a pour cela des barques pour le passage et d'autres pour aller charger les légumes et les transporter en ville. Cette eau traverse la ville de deux côtés, d'un côté pour arriver aux prairies, de l'autre pour les transports, tant de victuailles que de marchandises et de voyageurs pour Abbeville, y ayant pour cela une barque qui part trois fois par semaine.

Le total des maîtres fabricants est de 1500, dont 1000 sont en ville, chacun avec ses métiers battants, 200 commissionnaires qui font toutes sortes d'expéditions et 300 patrons à la campagne. Les travailleurs sont dix mille : avant de pouvoir travailler des draps comme patron, il faut posséder un fonds suffisant et avoir travaillé dix ans comme ouvrier. La fabrique est distincte en deux classes appelées de grande et de petite navette. La grande est celle qui fait les camelots fins qui doivent être larges d'un ras et un quart ; toutes les autres étoffes que l'on fait sont de petite navette et elles ont une demie aune de large, à quelques pouces près.

Pour les camelots surfins, tant de poil que de laine, il n'y a aucune filature, car ils tirent presque tous leurs fils de Hollande. La Hollande est leur intermédiaire surtout pour ceux de poil, car les poils ne peuvent sortir de Turquie s'ils ne sont pas filés.

Les camelots se font comme on fait la toile. Les balles de filés arrivent brutes dans les magasins, on les teint en pelotes, comme on le fait pour la soie qu'ils tirent teinte, lustrée et assortie en couleurs de Lyon.

Les bonnes patronnes ont leurs magasins auxquels les hommes confient les filés tant de laine que de poil en brut, et ils leur comptabilisent au poids. Elles doivent les teindre et préparer ces filés pour la fabrication des camelots, selon

$182 \diamond$ Documents pour l'histoire des techniques nº 18 - décembre 2009 
les modèles que les hommes leur donnent pour les couleurs. Les femmes font monter les chaînes pour les donner aux travailleurs et elles leur donnent les bobines de trame pour la formation de ces camelots. Les hommes ont l'inspection sur les métiers qu'ils visitent pour voir si les ouvriers travaillent selon leur devoir. Une fois la pièce faite, elle est rendue au magasin des filés, où elle est examinée par les travailleurs afin d'enlever les gros et de réparer à l'aiguille les défauts qu'ils peuvent avoir. Ensuite, elles les font ainsi passer en écru au magasin des hommes en contrepartie des filés qu'elles ont reçus, de telle sorte que le magasin des femmes ayant reçu mille lires de filé, elles doivent restituer aux hommes autant de poids de camelot ou de toute autre étoffe. La facture des camelots est payée à la mesure, c'est-à-dire autant par aune, de sorte que ce sont les femmes qui payent toute la main-d'œuvre de fabrication de la pièce, sans que les hommes ne s'en mêlent, les femmes étant toujours intéressées à la moitié des bénéfices qu'ils retirent. II reste aux hommes le soin des apprêts et de la finition de la pièce, l'écriture, la correspondance et le retrait des crédits, le soin de leurs fonds, la correspondance pour l'achat des matières premières, ainsi que le paiement des ouvriers pour les apprêts.

Les filés des camelots sont tous égaux, en proportion de la finesse qu'ils désirent, comme le filé de la toile. Le seul soin qu'ils ont est de faire servir pour la chaîne l'une des qualités les plus fines de fils, et ils se servent pour la trame de celui qui n'est pas si fin. L'opération de teinture du fil des camelots est la même que celle de la soie : d'abord purgé dans le savon, le fil est ensuite teint en bobines comme l'on fait pour la soie. Une fois le camelot donné aux hommes roulé en cru, ils mettent les pièces à part et leur donnent les apprêts au fur et à mesure qu'ils doivent les expédier.

La première opération de l'apprêt d'un camelot est de le laisser infuser dans l'eau fraîche et claire pendant trois ou quatre heures pour ensuite le faire bouillir dans la même eau pendant une demi-heure, ensuite ils le mettent bien étendu sur un rouleau pour lui faire prendre un bon pli et l'élargir sur les lisières, afin que l'une ne dépasse pas l'autre et afin qu'il soit égal tout du long, puis ils l'étendent dans un grenier que les apprêteurs ont en haut de leur maison afin qu'il puisse sécher. Ils ont pour cela des greniers avec de très larges fenêtres afin que l'air puisse y entrer et faire sécher doucement [les étoffes]. Mais il est nécessaire de fermer ces fenêtres pendant la nuit pour les défendre des éventuelles intempéries auxquelles on ne pourrait pas remédier. II y a dans ce grenier un travailleur qui ne fait pas autre chose que d'enlever les camelots des perches afin que la portion qui est sur la perche puisse sécher de la même façon que le reste qui pend, parce que si on le laissait sécher sur la perche, la portion qui y est posée pourrait prendre une couleur différente et tous les dix ras, il y aurait une barre de couleur plus foncée dans le camelot.

Quand le camelot est presque sec, ils le retirent des perches et le portent au brûloir. lls le roulent de nouveau de façon bien égale et l'étendent sur un rouleau de bois qui se trouve au fond de cette machine. Ensuite, ils prennent la tête du camelot et la passent au travers d'une échelle aux barreaux de fer bien lisses; ces barreaux de fer, au nombre de dix, sont situés l'un en haut et l'autre en bas, à l'exception des deux derniers qui sont tous les deux en haut. lls attachent [la pièce] à un autre rouleau qui est au fond de la machine, laquelle est large de huit palmes, du côté opposé au premier barreau sur lequel le camelot a été roulé ; puis ils mettent sous les deux barreaux du haut un récipient distant de deux palmes de ces barreaux supérieurs et plein de charbon allumé. Le rouleau sur lequel le camelot doit venir passe sur les deux barres supérieures sous lesquelles se trouve le récipient de feu ardent à deux manches faits a sivignoba. Deux travailleurs sont postés à ces deux manches pour faire tourner le rouleau rapidement afin qu'en passant sur le feu il ne se brûle pas, mais que seuls se brunissent les petits poils qu'un camelot peut avoir pour être bien rasé et égal. Au rouleau inférieur, sur lequel se trouve d'abord le camelot, il doit y avoir un travailleur afin que le camelot parte bien étendu et avec un mouvement égal des deux côtés. Cet apprêt, qui se fait pièce par pièce, sert, nous l'avons dit, à brûler les poils, mais aussi à réchauffer la laine afin qu'elle puisse se resserrer et donner l'égalité de corps nécessaire au camelot. Ces travailleurs doivent être trois personnes bien habiles et attentives parce que s'ils ont la moindre inattention et ne font pas l'opération avec toute la vitesse nécessaire, la pièce de camelot est immanquablement brûlée tant il faut que le feu soit ardent.

[La pièce] est passée deux fois successivement à ce brûlot afin qu'elle soit passée des deux côtés, puis on la laisse refroidir sur ce même rouleau afin qu'elle puisse prendre la consistance nécessaire. Ensuite, ils l'enlèvent du rouleau et ils la passent sous un mango qui est une machine dont nous nous servons pour imprimer l'onde. Le mango va en avant et en arrière, mais là-bas il va toujours en avant afin que l'étoffe prenne un peu de lustre sans avoir aucune onde. Pour cela, ils ont un grand rouleau de bois qui permet de reculer le mango sans qu'il comprime le camelot en venant en arrière. II y en a également qui ont un cylindre qui comprime peu, mais qui sert seulement à donner le lustre nécessaire. La dernière opération est de les plier avec des fevilles de papier un peu fort pour les mettre sous un tour de presse, pour ensuite les changer et plier la pièce pour l'expédier. Les camelots de bonne qualité sont pressés 


\section{Relation de voyage}

secs, mais les mauvais fabricants les pressent un peu humides et ils les humidifient avec de l'eau de gomme : ce sont des camelots très lustrés et durs au toucher, tout ce qu'ils ont, c'est un peu de vue, mais ils ne valent rien à l'usage.

Le travail pour les camelots est le même pour tous, mais la finesse et la bonté dépendent de la matière première et de la finesse du filé. Le camelot qui se trouve sur le cahier indiqué par la lettre A est fait dans la volonté d'imiter ceux de Turquie nommés Angora, mais comme ils ne peuvent pas avoir les poils aussi fins qu'en Turquie car l'exportation en est interdite, ils se servent de la soie pour faire la chaîne et du lin fin filé de poil (Poel) pour la trame, mais comme le Poel a une grande élasticité qui abat la soie et la force, ils sont de très peu d'usage et se coupent très facilement.

La seconde qualité de camelot à poil, indiquée par la lettre B, est nommée « façon de Hollande ». Ce sont des travaux à poils très fins, c'est-à-dire de la qualité la plus fine qu'ils puissent avoir. Mais ils n'osent pas les passer sous le mango pour leur donner lustre et douceur parce qu'ils craignent de les endommager. Pour cette raison, ils restent rêches et se coupent très facilement à l'usage.

Le travail le plus important d'Amiens est la troisième qualité de camelots à Poel, indiquée par la lettre C. Ils sont travaillés avec un poil ordinaire mais filé fin, afin qu'il puisse se soutenir. Chaque fil de poil est uni avec un fil d'organsin qu'ils prennent très fin, car plus l'organsin est fin moins il pèse, et il leur suffit qu'il abonde en longueur.

Les camelots appelés demi-soie se font également de la même façon, indiqués par la lettre D. À la différence des premiers, indiqués $C$, où il y a du poil et de la soie, ici il y a de la laine et de la soie.

Ceux qui sont indiqués par la lettre E sont tous de laine et de laine du pays qu'ils font filer dans les villages voisins. La différence est que dans les mélangés $n^{\circ} 2$ la laine de la chaîne comme celle de la trame est mélangée, tandis que dans les mélangés $n^{\circ} 1$ et 3 , ils font le mélange en mettant la chaîne d'une couleur et la trame de l'autre, comme ils le font aussi parfois dans les camelots appelés demi-soie. Dans ces mélanges, le fabricant se trompe souvent parce que très souvent il prétend faire une couleur et il en fait une autre. Pour cela, chaque patron a un petit métier sur lequel il a une chaîne formée de diverses couleurs et dans ces expérimentations, il détermine la couleur qui lui semble la plus meilleure et la plus belle.

Pour utiliser les laines qui ne sont plus bonnes à rien et qui sont les groupes retirés des camelots et les restes de toutes les mauvaises laines, ils font un drap qu'ils appellent Drap de Pieds, indiqué par la lettre F. Pour le fabriquer, ils montent une chaîne de fil très ordinaire avec un filé de laine d'une grosseur tout venant pour la trame ; ils le dégraissent et le foulent ce qu'il peut supporter de sorte qu'ils ne peuvent jamais observer une proportion déterminée et ils le laissent venir ce qu'il peut. Il y a de ces qualités de draps des pièces de long aunage, des courtes, des larges et des étroites sans la moindre proportion.

Ils font également avec les laines du pays les saies ici indiquées par la lettre G qu'ils appellent doubles croisées. La plus grande consommation de celles-ci est en noir et ils en font de différentes qualités pour consommer toutes les qualités de laine. Le travail restant le même, ils augmentent le prix en proportion de la finesse de la laine. Ils filent la laine plus forte ou plus fine selon sa qualité.

Il y a également là-bas l'article des velours de laine (panne) : ce sont les fabricants de petites navettes qui les font. Elles sont indiquées sur le cahier par la lettre $\mathrm{H}$, mais il s'en fait de très nombreuses qualités. La première qualité, indiquée $n^{\circ} 1$, est la plus fine que l'on fait. Elles sont travaillées de la même façon que ce que l'on a décrit à Rouen pour les velours de coton, comme c'est le cas de toutes les autres et également des peluches que nous verrons ciaprès. La seule différence est que la première, fine en couleur, est faite avec des laines teintes avant de faire la pièce et les autres sont toutes teintes en pièces, c'est-à-dire après avoir fait la pièce.

Les $n^{\circ} 2$ sont sislate sur le métier en faisant jouer les lacets pour le dessin comme on l'a vu et on le verra pour toutes les étoffes à fleurs et comme il se pratique ici au Piémont pour les brocarts de soie et les autres étoffes à fleurs.

Les $n^{\circ} 3$ sont imprimées : on commence à teindre toute la pièce d'une couleur claire, ou d'une couleur qui soit susceptible d'en recevoir d'autres, puis avec la planche où se trouve le dessin d'une autre couleur, on imprime avec de la colle l'autre couleur, comme on le fait également pour les flanelles sempiternes et pour toute autre saie qui ait du corps et qui puisse faire un relief une fois comprimée.

Les $n^{\circ} 4$ sont les velours de laine (panne) ordinaires qui se font en blanc ou sont teints en pièces de la couleur désirée.

Les $n^{\circ} 5$ sont teints en pièce et ensuite gaufrés au cylindre. Ce cylindre a un rouleau supérieur de métal creux sur lequel le dessin est gravé à l'extérieur. Une grosse lame de fer rouge passe dans ce creux pour maintenir la chaleur du rouleau portant le dessin. Lorsque ce cylindre tourne avec la pièce au milieu, le dessin s'imprime sur l'étoffe. Ils s'en servent également pour gaufrer les camelots et les autres étoffes de toutes sortes, à présent passées de mode

$184 \diamond$ Documents pour l'histoire des techniques nº 18 - décembre 2009 
à cause de leur faible solidité : en effet, si une étoffe fine gaufrée prend un peu d'humidité, le motif réalisé avec le gaufre s'en va et elle reste toute égale, mais d'une égalité imparfaite qui fait un très mauvais effet.

Les mêmes fabricants de panne, c'est-à-dire de velours de laine, en font aussi de poil, mais elles sont beaucoup plus chères. En plus des velours, ils font des peluches, tant de poil que de laine.

Les peluches sont indiquées par la lettre l, avec des numéros pour les différentes qualités. Celle qui est indiquée $n^{\circ} 1$ sert pour faire les habits : on en fait une grande consommation en France. Celle-ci, comme les autres, est semblable aux velours de laine (panne) en ce qui concerne l'ouvrage : elles se font également à double chaîne, une pour serrer le poil dans le tissage et une pour donner le poil à couper. Dans les velours de laine (panne), la chaîne qui donne le poil à couper doit être beaucoup plus longue que l'autre et soutenue par des contrepoids qui la laissent venir facilement avec le battement du peigne fait par le travailleur lors du tissage de la pièce ; la chaîne servant à lier le poil et la trame est de laine, tandis que la chaîne donnant le poil est de poil de chèvre. Celles indiquées $n^{\circ} 2$ sont destinées à faire des doublures d'habits, elles sont plus légères en poil afin qu'elles ne fassent pas tant de volume. Celles indiquées $n^{\circ} 3$ sont toutes en laine pour les gens ordinaires, mais les unes comme les autres sont travaillées de la même façon. Les moscate et les mélangées sont travaillées avec de la laine teinte, et les unies avec de la laine écrue, en teignant la pièce faite de la couleur que l'on veut.

Toutes les étoffes indiquées par la lettre $L$ sont les Tamines de différentes qualités comme on le voit sur le cahier. Elles sont faites avec des filés très fins de laine du pays; ils se filent à la quenouille et sont teints avant la fabrication de la pièce. Parmi les nombreuses qualités de celles-ci, il y a deux grandes sortes, comme on le voit clairement : la première est de laine et de soie et la seconde est entièrement en laine. Ces dernières, quand elles sont ordinaires, se teignent aussi en pièces une fois sorties du métier et elles sont apprêtées avec la seule presse au milieu de feuilles de papier blanc. La page sur laquelle se trouvent toutes les qualités donne leur largeur avec l'aunage, le prix, le nom particulier de chacune, selon leur finesse et qualité.

Ils font également des Tamines rayées qui sont indiquées par la lettre M. II y en a de deux qualités tant en soie qu'en laine, la soie servant à former le dessin de la ligne, tant dans celles à une ligne seule que dans celles à carreaux; dans celles-ci, on voit clairement par la variété des couleurs qu'ils teignent la laine avant la formation de la pièce.

Les commissionnaires, en plus du commerce qu'ils font des marchandises de la ville, font celui de ses environs où les fabricants qui n'ont pas de fonds ne peuvent le faire eux-mêmes. lls font également celui des terres distantes de vingt à trente lieues, comme par exemple les saies d'Aumale et Bélicour qui portent le nom du village où elles sont fabriquées et sont indiquées sur le cahier par la lettre N. Comme dans ces terres, les fabricants ne disposent pas des fonds pour se fournir de la laine, ils prennent la laine chez ces commissionnaires et ils leur paient avec la pièce, ne prenant sur celle-ci que la facture. Ils restituent la pièce brute, c'est-à-dire en toile, laissant le soin aux commissionnaires de la faire fouler, teindre et apprêter. Ces fabricants travaillent seulement sur facture, ils mettent le nom avec la marque du commissionnaire qui leur fournit la matière première nécessaire à la pièce. Ce sont des étoffes que les commissionnaires appellent de leur fabrication, comme les autres.

Les échantillons indiqués par la lettre $O$ se font en sortant d'Amiens pour aller à Abbeville. Elles sont faites à l'imitation des Anglaises et pour cela ils n'ont pas changé le nom parce ce que ce sont des étoffes très connues, l'ayant seulement embelli par le nom du dessin qu'elles portent. Ce dessin se fait au lacet comme les étoffes à fleurs. Elles sont de laines du pays filées en étaim. Les fabricants sont réglés comme ceux des saies d'Aumale dont on a parlé auparavant.

Celle indiquée par la lettre Q est une autre étoffe formée comme les diablement fort, qu'en Angleterre on appelle everlestin, et qui s'appelle Amens en anglais et turques à Amiens. Elles se font également sur la route d'Abbeville, où tous les articles à l'imitation de l'Angleterre sont déjà arrivés à la perfection. Elles sont également rendues brutes aux commissionnaires et reçoivent leurs apprêts dans la ville d'Amiens.

L'article indiqué par la lettre P est fait à l'imitation des floretes d'Angleterre : le travail réussit de la même façon, mais comme les laines de France ne sont pas aussi fines que celles d'Angleterre, elles ne prennent pas dans les apprêts le même lustre et brillant que celles d'Angleterre. Il y a sur cela des avis différents : certains prétendent que cela vient des eaux anglaises plus purgatives pour les laines, d'autres qu'il entre une certaine composition dans les cartons dont les Anglais se servent pour la presse et que c'est cela qui donne ce brillant à l'étoffe anglaise qu'elle n'acquiert pas en France. Cette qualité d'étoffe est donc aussi bonne que les Anglaises pour l'usage, mais pas aussi belle.

Les échantillons indiqués par la lettre R sont les mêmes saies d'Aumale qui, teintes, ont été indiquées par la lettre N. Pour leur donner un plus grand débit, ils les impriment de diverses couleurs. La longueur, la largeur et le prix sont 


\section{Relation de voyage}

indiqués sur le papier. À Amiens, on s'est mis à imprimer les saies afin que les imprimeries des panne ne se perdent pas, parce que les panne n'étaient plus à même de soutenir les deux imprimeries qui sont dans la ville d'Amiens.

\section{Abbeville}

J'ai poursuivi mon voyage et je me suis porté à Abbeville, dernière ville de fabrique avant de sortir de France du côté septentrional ; elle n'est pas très grande mais bien peuplée. Dans celle ville, il y a quatre sortes de fabriques : une fabrique de draps réduite à un seul fabricant avec privilège exclusif de nom et de lieu ; une fabrique d'étoffes à imitation de l'Angleterre pour la mi-saison; une fabrique de moquettes tant gaufrées que de diverses couleurs; une fabrique d'étoffes de fil et de coton, et de toiles unies de lin et de vue [?].

Malgré sa petite taille, la ville a toutes les commodités qu'ont les autres villes, elle est bien fournie de vivres. Les maisons sont de bois et de plâtre, comme toutes les autres de France. Il y a de très nombreuses petites maisons pour les ouvriers, et la seule différence est que là-bas le coût de la vie commence à augmenter. On voit des maisons bâties depuis peu avec des façades de pierres et de briques, mais ce sont des maisons de riches construites, comme je l'ai dit, depuis peu de temps. Les fabricants font presque tous leur commerce. On commence à avoir là-bas la maxime des Anglais qui est d'avoir des magasins de laines pour donner le travail aux ouvriers, ces derniers travaillant tous chacun chez eux sur facture. Il y a deux fois par semaine un marché pour ceux qui achètent la laine pour pouvoir faire une pièce avec leur propre argent et veulent vendre leur travail à qui bon leur semble. Ceux qui prennent la laine de leurs chefs doivent restituer la pièce au poids de la laine reçue en prenant seulement la facture. La majorité ont des apprêts chez eux, mais il y a deux maisons publiques pour les ouvriers qui veulent vendre sur le marché leur pièce terminée, laquelle est toujours meilleur marché, mais pas aussi parfaite. Il y a des promenades publiques très belles avec des auberges, où les ouvriers vont généralement manger tous les bénéfices de la semaine : c'est la raison pour laquelle ils seront toujours pauvres et humbles, naturellement subordonnés, à cause de leur misère, aux maisons qui ont des fonds de laine pour les faire travailler.

En ce qui concerne la fabrique de draps, c'est la plus grandiose de toutes celles que j'ai vues. Elle est située en dehors de la ville dans une grande campagne, ornée tout autour de belles allées d'arbres avec différents beaux jardins. Au centre se trouve l'habitation de la famille du Sr Vanrobest qui en est le patron : de nation hollandaise, il est natif de la ville de Leyde, où il a encore sa propre maison, sa sœur étant elle-même intéressée [à la fabrique] comme le sont tous les fils du Sr Vanrobest et deux autres neveux qui sont avec lui. A côté du jardin, il y a deux grands près dans lesquels se trouvent les rames qui forment un motif et ornent des deux côtés tant le jardin que la maison d'habitation qui est à l'étage supérieur. On se sert du rez-de-chaussée pour les magasins des draps perfectionnés et pour la caisse de tout l'argent que produit la fabrique : tout l'argent dont on a besoin y entre pour être ensuite distribué aux petites caisses que l'on verra ci-après. Cette maison communique avec quatre autres grandes maisons qui servent à la fabrique.

La première est située sur la rive de la Somme : les laines viennent par le fleuve se décharger depuis la mer, comme tous les autres produits nécessaires à la fabrication des draps. Dans la même maison, au rez-de-chaussée, il y a six grandes pièces pour les teintures avec l'habitation du teinturier et de tous ses ouvriers. Sur le devant, il y a une cour avec des terres pour les magasins du bois; du côté opposé, se trouvent les magasins des laines sales et un grande chambre où se font les choix de laines. À l'étage supérieur, il y a les cardeurs, le magasin de l'huile et un magasin où I'on conserve la laine cardée pour la distribuer aux fileuses, avec une autre pièce pour tous les filés. L'habitation pour le préposé à toutes ces opérations s'y trouve également : il a une caisse pour payer toutes ces opérations et des registres pour donner son compte à la caisse générale, dont est sorti l'argent qu'on lui a confié. À côté de celle-ci, ils en font une autre pour les fileuses, car ils veulent réunir dans le futur toute la filature qui est encore à présent dispersée en ville et dans les campagnes voisines. Deux grandes pièces en forme de galeries sont déjà faites. De l'autre côté de la maison patronale, se trouvent les métiers, les lainages pour les draps et les tondeurs, surveillés par un contremaître qui dispose d'une caisse avec un registre pour les payer. Ces deux maisons sont à côté du fleuve : par des canaux réalisés tout exprès, il alimente en eau nécessaire toutes ces opérations. Cette seconde maison est formée par des chambres très longues, les ouvriers étant tous situés en ligne des deux côtés afin que le contremaître et les patrons puissent voir en se promenant si les tisseurs, tondeurs et laineurs font leur devoir. Dans la troisième [maison], située à côté de celle-ci, se trouvent les ourdissoirs et les ouvriers qui font les navettes, avec, au premier étage, l'intermédiaire qui reçoit les draps du foulon dans une grande pièce destinée à leur visite. Dans celle-ci se trouve le commis préposé à l'inspection sur le foulon et au paiement des ouvriers susdits avec un registre de l'argent qui lui a été confié par la

186 Documents pour l'histoire des techniques nº 18 - décembre 2009 
caisse générale. À côté, se trouvent les écuries et les remises pour les voitures des patrons et les chariots à chevaux pour le service de la fabrique.

Le foulon est situé à une lieve et demie de la fabrique : il y a un contremaître, mais il dépend du troisième contremaître qui va au foulon pour payer les ouvriers et également pour voir si son subalterne fait son devoir. Dans la quatrième maison, il y a les presses avec toutes les finitions des pièces, un contremaître et sa caisse pour le paiement des ouvriers. Les draps partent emballés de cette maison pour être confiés au grand magasin d'expédition. Les draps ne peuvent être emballés si un patron ne les a d'abord examinés et n'a donné son plomb pour les faire exporter.

Toutes ces maisons sont propres : il y a deux hommes par maison pour cela, de sorte qu'on ne trouve pas de poussière, même sur les métiers. Ainsi, il n'y a pas de danger pour quiconque va visiter de se salir grâce à la grande propreté hollandaise qui règne partout.

Les patrons vont voir si les contremaîtres font leur devoir et, tous les soirs, les contremaîtres viennent rendre compte des opérations et prennent les ordres des patrons sur ce qu'il y a à faire. Quand ils doivent faire passer des ordres pour la fabrication d'une pièce de drap, ils remettent l'échantillon sur un papier à toutes les maisons avec le numéro que doit avoir la pièce sur le registre pour voir si leurs ordres ont été bien exécutés. En cas d'incident, les contremaîtres ne peuvent varier selon ce qui leur semble, mais ils doivent aller prendre les ordres et présenter la variation au patron afin qu'il puisse la noter sur le registre, de sorte que le patron, son registre à la main, sait parfaitement grâce à la date du jour où l'ordre a été donné à quel point se trouve son ordre sans avoir à se déplacer de son cabinet.

Le travail est le même que dans toutes les fabriques de draps, mais l'exactitude et l'attention, unies à la commodité de la réunion de tous les travailleurs sous les yeux des patrons, sont des choses qui conduisent à une bonne fin et à un degré supérieur cette manufacture avec très peu de fatigue des patrons. Ils se sont mis dans cette fabrique alors qu'elle avait déjà failli deux fois et sans avoir le moindre fonds. Le roi de France leur a toujours fourni les fonds à leur satisfaction sans le moindre intérêt et, bien qu'aujourd'hui ils soient à la tête d'un édifice aussi vaste et en possession d'importants capitaux et de biens fonciers dans les environs, sans compter ceux qu'ils ont acquis dans leur pays, ils sont encore débiteurs d'un demi million auprès des finances royales, sans le paiement d'aucun intérêt, ayant encore vingt-six ans pour restituer les fonds et bien qu'on sache qu'ils sont en état de restituer.

Dans cette fabrique, on ne travaille que de la laine d'Espagne très fine, qu'ils choisissent avec grand soin pour en séparer le fin du fin, employant le plus fin dans les draps double broche indiqués sur le cahier par la lettre A, fins mêlés et bleu naturels indiqués $B$, les mêmes unis indiqués $C$, les mêmes noirs et écarlate indiqués par les lettres $D$ et E, les mêmes cramoisis indiqués par la lettre G. Ils se servent également de cette qualité pour faire les draps castors indiqués par la lettre F, en la mêlant à la laine dont ils portent le nom, c'est-à-dire un tiers de laine de castor. La ratine indiquée par la lettre $\mathrm{H}$ est composée des meilleures laines de rejet et les ratines larges non frisées indiquées I et L, que dans la fabrique on appelle draps de manteau, sont formées avec le rejet des laines et avec des laines qui peuvent avoir subi quelques dommages.

La différence que j'ai pu noter est que les mélangés sont réalisés avec des paquets de laine selon le mélange que l'on veut obtenir, en en tirant une petite quantité selon le poids de chaque paquet avant de les donner au cardeur [?]. Ils foulent et dégraissent tous les draps fins au savon, ne se servant de la terre que pour les draps de manteaux et les ratines. Lors de la tonte, afin de lever le poil dans les dernières tontes, au lieu d'utiliser une lame de fer comme dans les autres fabriques de France, ou la main humide comme dans les fabriques de Hollande, ils se servent d'une brosse ou ramassetta de crin très fin et très molle dont ils se servent également pour abattre de façon égale le poil et disposer le drap à la presse, en arrosant très légèrement le drap d'eau claire. Dans les autres opérations, à part la plus grande attention, ils se règlent comme dans toutes les autres fabriques.

Les largeurs des draps, avec leurs aunages, sont indiquées sur le papier avec leurs prix courants : ils se conforment dans la vente au don d'aunage et à l'escompte selon l'usage général de France, et ils sont de même soumis à toutes les lois d'inspection qui ont été instaurées dans cet État, à la réserve du plomb qu'ils mettent eux-mêmes sans sortir leurs pièces de la fabrique. En ce qui concerne la vente, [le patron] a un usage qui ne se pratique dans aucun autre lieu : il vend vingt sous de moins chaque aune à l'étranger qui achète et fait usage de ses draps, disant que le Français est obligé, s'il veut porter des draps fins, de prendre des siens, tandis que l'étranger doit être encouragé et c'est pour ce motif qu'il a introduit cette habitude qui lui est propre.

Le second ouvrage considérable consiste en étoffes travaillées à la façon anglaise. II a commencé à cause de divers travailleurs anglais réfugiés là. Les premières étoffes réalisées sont les baracans, tant unis qu'ouvragés, tant fins que plus ordinaires. Ils ont commencé à en faire des larges, puis sont venus aux plus étroits et ouvragés, indiqués par 


\section{Relation de voyage}

la lettre A sur le papier. L'explication pour la largeur, la longueur et le prix se trouve également sur le papier. Ceux qui s'appellent 'façon d'Angleterre' sont tissés et ourdis de laine très fines du pays et d'habitude ils prennent pour le tissage la laine anglaise de contrebande. La chaîne est faite de laine filée fine; pour la trame, ils font un tort de cina ou six fils de la même laine afin de pouvoir former la canna du baracan, puis ce tort se met en croix sur le métier. On le lie de sorte que, quand on travaille, la chaîne est toujours tendue et élargie afin de pouvoir battre le peigne et resserrer fil par fil l'ourdissage de manière à pouvoir laisser l'incanalito. Pour former l'ouvrage, ils se servent du lacet, et comme il ne s'agit pas d'un dessin continu ou bien il n'y a pas de variété de couleur, les ouvriers se lèvent pour la formation de la pièce ou du dessin, les pieds touchent les pédales sous le métier lesquelles ont un fil correspondant qui, en passant dans une petite rove située au dessus du métier à la vue de l'ouvrier, règle la portion de la chaîne devant former le dessin ; en les comprimant, les pédales ou touches donnent l'effet de l'œuvre désirée. La science tient dans la situation des fils, car le travailleur mécanique ne peut être capable de réflexion, étant seulement apte à faire toutes ses opérations matériellement, comme elles lui sont enseignées. Les meilleurs travailleurs sont ceux qui sont habitués depuis longtemps et, quand il y a quelques variations, il est nécessaire que le fabricant reste longtemps à côté du métier pour leur faire prendre l'habitude de l'opération.

Les baracans qu'ils appellent « à la française » sont les premiers que les Français aient fait. Ils sont faits de la même manière, mais avec la laine de leur pays qui ne peut être filée si fine de manière à faire un fil fin composé de cina filés séparés. Ils font donc un gros étaim filé d'un seul coup qu'ils collent avant de l'employer afin qu'ils ne fassent pas ressortir de ces petits poils qui enlèveraient toute la vue de l'incanalitura. Les baracans les plus fins sont rasés et passés au feu avant de les encoller afin de brûler tous les petits poils qui pourraient faire sortir de la laine. Mais on voit, par les échantillons mêmes, que l'union torse des fils que permet la meilleure laine d'Angleterre est la meilleure façon de travailler ces ouvrages, car on distingue clairement dans les échantillons que l'étoffe qui est faite à la façon anglaise est bien plus garnie et fait un meilleur effet à l'œil, toutes les canne qui forment le baracan étant plus belles à l'œil. De même, comme plusieurs filés unis ensemble doivent nécessairement être plus forts qu'un filé unique, simplement par la raison naturelle que des forces unies valent plus qu'une seule même plus forte, pour cela les baracans à l'anglaise doivent être plus forts et d'un meilleur usage pour ceux qui les portent.

[...manuscrit coupé. Il reprend alors que Moccafy a déjà traversé la Manche et commencé à évoquer la fabrication anglaise]

[...] règle qui est d'un grand dommage à la fabrication anglaise et c'est pour cela que dans les vrais draps surfins anglais, on ne voit que des couleurs fortes et rapides sans qu'ils vevillent faire ces petites couleurs à la mode française dont la nouveauté est un stimulant à la vente ; alors qu'au contraire, si un patron français propose quelques essais à son ouvrier, celui-ci emploiera sa main-d'œuvre pour rien à cause du génie inné de la nation pour les nouveautés de tous ordres.

\section{Londres}

Pour suivre l'ordre de la fabrication locale, dans les alentours de Londres se font des draps plucheux (plucosi) pour saies qui sont indiquées sur le papier par la lettre $C$ et $D$, les draps sont travaillés en toile et les saies croisées. Cette qualité de drap est appelée en anglais Duffiel, et chez nous Quatti. Ils font six qualités de ce genre qui dépendent toutes de la plus ou moins grande quantité de poids de laine qui y entre et du filé plus ou moins fin dont ils se servent. Pour ce genre d'étoffe, ils doivent se servir de filés à grand rovet et à bras ouverts, qui doivent être bien ouverts, afin que dans le cardage ils puissent donner suffisamment de laine pour les regarnir, le regarnissage faisant la beauté de ce genre de marchandise. Les deux premières qualités sont indiquées sur le papier par la lettre $C$ : la première est mélangée ; la beauté de l'étoffe est qu'elle n'est pas composée de laines teintes, mais de laines de couleurs naturelles, c'est-à-dire blanche et noire qui, unies ensemble, forment un gris. Il y en a de plus claires et de plus obscures selon la plus ou moins grande quantité de laine blanche qu'ils y mettent. Elles sont travaillées pour la chaîne comme pour la trame en laine filée ouverte et plutôt grosse. La seconde qualité, de couleur bleue ratinée, est divisée en trois qualités, c'est-à-dire fine, moyenne et forte. Ils en font de toutes les couleurs et le prix est fixé selon la couleur et la finesse. Celles-ci sont travaillées avec un filé de chaîne un peu plus resserré que les premiers, mais la trame est de filé ouvert. Les deux autres qualités sont très fines et doivent avoir une lisère à cordon avec une chaîne forte mais plutôt serrée et une trame ouverte. Les troisièmes [?] qualités ont les lisières larges comme les draps et sont de laines ordinaires filées très gros, chaque qualité de laine pouvant y entrer. Toutes ces qualités d'étoffes sont travaillées sur le métier 
comme les draps, elles subissent les mêmes opérations que les draps au foulon, proportionnellement aux qualités que l'on veut former. Dans les apprêts, elles sont seulement lainées. Ils ne les filent pas beaucoup, mais ils les cardent fortement et, pour ce genre de poil long, ils se servent de cardes de fer à la fin du cardage. Une fois sortis du foulon, on donne à toutes ces étoffes une seule tonte pour égaliser le poil, puis on les remet aux laineurs qui les lainent jusqu'à ce qu'elles arrivent au point demandé. Les forts sont lainés et tondus en les mettant en presse, les pièces sont pliées sans carton parce qu'une grande quantité de ces articles est expédiée à apprêter, c'est-à-dire à finir de manière à ce que chaque marchand puisse lui donner la finition qu'il estime nécessaire. Cette finition peut être donnée de trois façons à poil frisé, et les surfins peuvent se perfectionner comme les draps. En Angleterre, les fabriques de papier font une forte consommation de ce genre d'étoffe pour le papier de qualité moyenne et on se sert de draps plus fins pour le papier fin. Les fins sont travaillés avec les rejets des laines fines qui ont été peignées pour être réduites en étaim et les ordinaires avec toutes sortes de laines, y ayant dans les alentours de Londres et dans la ville également une forte consommation de laines peignées et filées très finement, surtout pour la formation d'étoffes de laine et de soie comme on le verra ci-après.

La saie indiquée par la lettre C porte le nom de saie de Londres. On en fait de deux qualités subdivisées dans d'autres sous-qualités en proportion de la finesse. La distinction des deux qualités se reconnaît aux largeurs. Celle qui est appelée Londres n'est large que d'un ras et un sixième de notre largeur, et l'autre, que l'on appelle Londres impériale pour mieux la distinguer, doit être large d'un ras et un tiers abondant. L'une comme l'autre de ces saies doivent être croisées, la qualité inférieure ou supérieure de la laine est ce qui en constitue la finesse, car elles sont travaillées de la même façon sur le métier et au foulon. Elles tiennent lieu en Angleterre des molletons de France, à la différence que cet article sert à deux usages : s'ils en font tirer le poil, ils équivalent aux molletons de France ; s'ils leur font donner une tonte en les mettant en teinture et en les préparant, cela forme une étoffe qui sert pour les habits d'été des gens ordinaires et c'est ce qui, chez nous, forment les livrées d'été des Grands. On a déjà fait des droguets à l'imitation de celles-ci dans la province de Biella : il a fallu les faire plus étroits, car on a du se fournir pour cet article de laines fines de Rome qui nous coûtent plus que les laines anglaises ne coûtent dans leur pays, la différence pouvant aller au cinquième et peut-être même plus. C'est pour ce motif et pour en rendre la valeur égale qu'on les a diminués en largueur de plus d'un cinquième. Dans notre pays, les moines cisterciens en font usage pour leurs habits, les carmélitains déchaussés pour leurs chemises, et les autres pour leurs habits, sans compter la petite consommation que l'on fait de celles « à poil ॥, en remplacement des molletons. Il y a deux autres sortes d'apprêts pour celles-ci : on leur tire le poil à cru et avant cela, on les blanchit avec du soufre. Elles servent tant pressées qu'avec le poil tiré.

L'échantillon indiqué E est une ratine : elle est fabriquée comme celles de France et elle est de la même matière que celles-ci, c'est-à-dire des rejets des laines d'Espagne employées dans la fabrication des draps surfins. Les filés sont également larges, mais celles de France sont davantage foulées. Ils en font ici également de laine d'Espagne dont on fait les draps, et non de rebut, mais uniquement sur commission à cause du prix élevé qui les rend invendable. Ils font peu d'ordinaires à cause de l'article Duffiel qui en tient lieu.

L'article indiqué F est appelé Popline, la chaîne est de soie et elles sont tramées de laine teinte en fil. lls vendent beaucoup de ces étoffes en Espagne et dans les pays chauds. Le plus grand commerce s'en fait en échange des denrées qui ne se trouvent pas dans le pays. Ce qui soutient cet article et les suivantes, avec ou sans soie, est la Compagnie des Indes Orientales.

Toutes les étoffes suivantes sont faites à l'imitation des étoffes de soie. Comme la trame n'apparaît pas et que seule la chaîne doit garnir l'étoffe, la chaîne est de soie et la trame est de laine. La largeur et la longueur des pièces sont indiquées sur le papier avec le nom de chacune. Celle indiquée G est appelée Gros grain : elle est à imitation des moelles à 12 fils. La H s'appelle Codesois et imite les canele qu'on fabrique dans notre pays. Celles indiquées I s'appellent Silveretes et sont comme nos grisettes. Les L s'appelent Desdenes et ressemblent aux grisettes ouvragées. Les M sont à l'imitation des moelles ouvragées comme le sont également les satins rayés et unis indiqués N. Celles appelées gros grain et indiquées par la lettre $O$ sont à l'imitation des droguets à deux couleurs ouvragés en soie et celles indiquées P, appelées Misnats, imitent les taffetas. Celles indiquées $Q$ sont à l'imitation des damas de meubles ; elles sont entièrement en laine, comme on le verra mieux à Norwich où on en fabrique une plus grande quantité ; on parlera alors de leur apprêt et de leur manufacture ainsi que de celles du pays. Celle indiquée R est à l'imitation des moelles ondées, comme elle est effectivement appelée et elle est également, comme les suivantes, à chaîne de soie et trame de laine. Celle indiquée par la lettre $S$ est à l'imitation des taffetas valoesati, composée des matières susdites; pour la fleur, ils se servent de deux lacets appliqués au métier, comme pour les étoffes de soie. Les Corded, 


\section{Relation de voyage}

indiqués par la lettre T, ont une chaîne mi-soie, mi-laine et la trame est toute de laine, comme on le voit clairement grâce à l'échantillon lui-même. Ceux indiqués par la lettre $U$ sont des camelots de poil de chèvre : ils en font très peu, car quand on fait bouillir le poil dans l'eau, il acquiert une rudesse qu'il n'a pas en France. lls en font pourtant de deux qualités : les uns tous unis et les autres incanaliti comme les canneli de soie. Les étoffes décrites ci-dessus sont apprêtées sèches sous le mango, les unes plus, les autres moins selon le besoin plus ou moins grand qu'il y a de les rendre planes et bien égales de lisières; pour le reste, ils observent le même règlement que l'on a vu à Amiens. Les autres, indiquées par la lettre $V$, qu'ils appellent Prunelli, ont la chaîne de poil et la trame surfine de leur pays : celle-ci est spécialement choisie pour ce travail, les bergers la tondent à part, car elle est, comme ils disent, tondue au milieu des cuisses de derrière du mouton. Celles indiquées par la lettre $X$ sont de soie et de coton ; on en fait une forte consommation en Angleterre même, surtout dans les provinces du Royaume. Celles indiquées par la lettre Y s'appellent Amens : ils imitent les droguets que l'on a vu à Amiens et sont également travaillés au lacet. Ils sont travaillés avec de la laine écrue, ils sont foulés uniquement en les faisant bouillir dans l'eau et sont conservés de cette manière, prêts à être mis en teinture au fur et à mesure des demandes. Ces étoffes sont aussi travaillées avec les laines les plus fines du pays filées au rouet, comme nous l'avons observé initialement dans la distinction des filatures. Celles indiquées $Z$ et dénommées Rich Brolios sont travaillées de la même façon que les Amens, mais la chaîne est de soie et la trame teinte, toutes les deux en fil avant de les utiliser; une fois bouillis, ils les apprêtent comme les autres avec le mango. Celles indiquées AA sont des camelots entièrement en laine : ils en font de deux sortes, les uns sont de laine toute unie colorée, les autres ont la chaîne d'une couleur et la trame de l'autre, la couleur dominante étant toujours celle de la chaîne. Les apprêts sont les mêmes qu'à Amiens. La différence est que ceux-ci restent beaucoup plus rêches et secs que ceux d'Amiens, ce qui est dû aux eaux anglaises. II est vrai que les camelots anglais sont mieux garnis, car ils ont une laine meilleure et plus adaptée à ce travail que les Français, mais étant donnée la rudesse que leur apporte leur sécheresse naturelle et que leur laisse l'eau quand on la purge, ils ne sont pas d'un aussi bon usage, parce qu'ils se coupent facilement à l'usage. Ceux indiqués BB sont travaillés comme ceux indiqués AA, mais ils sont de laines plus fines et sont faits avec des filés plus égaux; pour le reste, ils sont égaux aux premiers qu'ils appellent ordinaires et ceux-ci sont appelés surfins en laine. Ceux indiqués CC sont les mêmes que les BB à la seule différence que ceux-ci sont rayés : ils imitent dans ce genre toutes sortes de rayures des étoffes de soie mais quand on désire quelque nouvelle rayure, l'ouvrier ne le fait que si on lui commande quatre pièces de chaque couleur et du même assortiment de couleur dans les rayures. Celles indiquées DD ont pour nom Durois et s'appellent marbroe chez nous. Ils en font très peu et nous en parlerons à propos de la province d'Exeter, où on en travaille une forte quantité de différentes qualités selon le prix que l'on y met. Celles indiquées HH ont pour nom saies de Nîmes : ce sont les mêmes que celles qui sont appelées saies de Rome à Abbeville. Elles sont travaillées de la même façon, à la différence que les françaises prennent le satin mieux que les anglaises, étant donnée la douceur que conserve la laine. Celles indiquées $\mathrm{H}$ s'appellent callamandre et on en verra des qualités meilleures et différentes à Norwich. La beauté de cette étoffe réside seulement dans leur apprêt dont nous parlerons en son temps. Celle indiquée LL, appelée tamine, est une saie dont la chaîne est de qualité égale à la trame, avec un lacet guidé par le pied du tisseur. Les matelots et les gens ordinaires de la campagne en font la plus forte consommation l'été. La chaîne doit être toute d'une couleur et la trame toute d'une autre, le tisseur doit faire attention à battre le peigne avec régularité afin que le croisement de deux couleurs très différentes l'une de l'autre ne laisse aucun défaut dans l'étoffe parce qu'il serait impossible de les corriger et ils ressortiraient toujours plus dans les apprêts. Celles-ci sont foulées au foulon simplement avec de la terre et ensuite purgées de celle-ci dans la rivière à force de bâtons, on les fait passer sous le mango pour ensuite les soumettre à la presse qu'ils appellent bouillante ainsi que toutes les autres petites étoffes qui se fabriquent à Norwich, comme on le verra. Celles indiquées MM s'appellent dobles etternels et everlestin, elles ont pris chez nous le nom de diablement fort et sont travaillées comme les Amens, à la différence que pour faire ces étoffes, ils se servent des rejets des filés des Amens, mais pour le reste, elles sont travaillées de la même façon.

Celles indiquées NN, ont pour nom baracane : elles ont la chaîne de laine très fine, tissée avec une trame de laine forte. D'ordinaire, elles sont teintes entièrement en laine bien que l'on en fasse en laine écrue que l'on teint ensuite en pièce. Ils en font aussi des ouvragés comme les Amens, de quelque dessin que l'on donne au fabricant, pourvu que ce dessin soit à ligne droite car s'il n'était pas [droit ?], il faudrait plus de lacets, cela provoquerait une facture plus importante et le prix serait supérieur à ce qui est habituel dans ce genre d'étoffes. Celles indiquées OO s'appellent droguets cordés et ceux-ci ont la même chaîne que les baracans, à la seule différence qu'elle est de laine plus ordinaire ; on passe un fil cordé et un autre simple pour la trame, comme pour l'ourdissage de toutes les autres étoffes.

$190 \diamond$ Documents pour l'histoire des techniques nº 18 - décembre 2009 
Celles indiquées PP ont pour nom saies drapées (pannate) : elles sont tissées de laine comme les draps en toile et ensuite perfectionnées au foulon. La laine de ces saies doit être filée au grand rovet ouvert avec la même proportion entre la chaîne et la trame que dans le tissage des draps, comme il se pratique également pour la qualité d'étoffes indiquées $Q Q$ appelés droguets et travaillés de la même façon. On utilise, tant pour les saies susdites que pour les droguets, les mêmes apprêts et la même presse que pour les draps, à la seule différence que celles-ci ne sont tondues qu'une seule fois sans leur abaisser le poil, et qu'on les laisse sous la presse dans les cartons chauds. lls en font des teints en laine, tant unis que mélangés, et des écrus de façon à pouvoir leur donner toutes sortes de couleurs comme il leur plait. Celles indiquées RR sont appelés baracans rayés : la trame comme la chaîne de ceux-ci sont mélangées, c'est-à-dire un fil d'une couleur et un autre totalement différent de façon alternée, à la différence que quand le fil d'une couleur bat au-dessus, on passe la trame de la même couleur, et ainsi alternativement l'un après l'autre, toujours de façon égale parce que si l'on passait plus une navette que l'autre, cela suffirait à faire une barre dans une pièce de ce genre de marchandise.

Celles indiquées SS, ayant pour nom allapin, ont une chaîne de soie et une trame de laine filée en deux fils tordus ensemble afin qu'ils remplissent mieux le tissu, et tant la trame que la chaîne sont teintes avant d'être mises en œuvre. Pour toutes ces étoffes, c'est-à-dire tant celles de soie et de laine que celles de soie pure, ils donnent un pouche de bonification, c'est-à-dire un à chaque verga, et ils donnent vingt et une verga pour vingt, avec un délai de six mois pour le paiement ou un escompte de $2 \frac{1}{2}$ pour cent, plus encore $2 \frac{1}{2}$ pour cent, tant pour l'argent comptant que pour le terme. Comme toutes les étoffes travaillées avec de la soie sont alourdies d'un fort droit que la soie paye en entrant dans les États d'Angleterre, quand ils expédient dans les pays étrangers ces marchandises de soie et de laine ou entièrement de soie, ils rendent à la sortie le droit que la soie a payé en entrant. Mais la réalité de l'exportation doit être prouvée et accompagnée d'attestations qu'elle est de fabrication du royaume, munie de bulletins d'expédition et du jurement de l'expéditeur. Toutes ces dépenses pour obtenir le drabech [sic] coûtent trente cinq sous sterling à peu près, et cela tant pour une pièce que pour mille ou plus, il ne convient donc pas de se charger de cette marchandise sinon en fortes quantités étant donnée la surcharge des expéditions. Ce ne sont là que des moyens de l'État anglais pour retenir l'argent de l'étranger. De même, pour les étoffes dont on peut comptabiliser combien il y entre de soie, ils rendent [la taxe] en fonction du poids de soie : pour les doubles allapin et autres semblables, ils donnent six sous sterling pour chaque pièce et les frais d'expédition sont de trente-cinq sous sterling, tant pour un petit envoi que pour un grand.

Celles indiquées T ayant pour nom allapin simple sont travaillées de la même façon que les doubles, à la seule différence que dans les allapin doubles le fil de la trame est double et tordu, tandis que dans ceux-ci le fil est simple, et c'est pour cela qu'ils prennent le nom de doubles ou de simples. Ils ont pris le nom d'Allapin du nom du poil de la bête dont on travaillait initialement la laine. Mais cela n'est pas vrai, même si à présent ils prétendent encore s'en servir, car la majorité des filés sont de laine fine du royaume.

Celles indiquées VV ont pour nom bombasine et sont travaillées de la même façon que les allapin simples qui sont en toile. Ceux-ci ont la chaîne de soie avec double croisement, pour cela l'étoffe prend ce croisement dans le tissage.

Celles indiquées $Y$, nommées sagathii larges, sont travaillées avec une chaîne de fil de laine tordue avec de la soie ; la trame est entièrement de filés de laine pure restant après le choix effectué pour les allapin et les bombasini.

Celles indiquées $Z$ sont des velours de coton travaillés de la même façon qu'à Rouen, mais ils sont beaucoup plus fins. A Roven, la plupart des cotons sont filés dans le pays, tandis que les Anglais prennent tous leurs filés de l'étranger. Ils en font de diverses qualités, comme on le voit mieux sur le papier à côté des échantillons. En ce qui concerne cet article, les Anglais réussissent mieux toutes les couleurs, à l'exception du noir qu'ils n'ont jamais pu réussir étant donné le caractère cru de leurs eaux. C'est pourquoi les noirs de Roven sont meilleurs que les Anglais, même si à la longue le noir ne peut soutenir sur le coton la vivacité qu'il conserve sur la soie et sur la laine, surtout la laine surfine d'Espagne.

\section{Leeds}

La fabrication des draps ordinaires dans le royaume d'Angleterre est restreinte à la province de Leeds, ville considérable située sur les rives de l'Are. Dans tous ses alentours, il y a une infinité de moutons qui constituent la rente de ces alentours et qui appartiennent aux travailleurs de ces terres, dont la plus grande partie est inculte et est seulement en pâturage pour [ces mêmes animaux]. Ils sont soumis à toutes les intempéries dont ils ne sont abrités que par des cabanes formées par des pieux, comme il est d'usage dans toute l'Angleterre. Ces pieux sont enfoncés par terre en un cercle de deux trabuts, toutes les pointes s'unissant au sommet pour leur donner un soutien. Au sommet, elles sont simplement liées 


\section{Relation de voyage}

et, en bas, elles sont plantées en terre d'une ou deux palmes seulement. Là-bas, chaque paysan est fabricant, il file sa laine chez lui : ceci est l'emploi des femmes et de leurs fils, le soin de la formation de la pièce étant laissé aux hommes déjà âgés. Ils filent leur laine comme elle vient, en sélectionnant simplement entre deux qualités de laine, fine et ordinaire. De ces deux choix de laine, il se fait ainsi trois qualités de draps, les plus fins sont appelés draps reffole, les seconds Bristol et les troisième du Nord. Ces dénominations leur sont données par les acheteurs dans le choix des draps eux-mêmes, selon la plus ou moins bonne qualité de laine qu'ils trouvent employée dans ceux-ci. Les fabricants, n'étant pas en état de faire ces distinctions, cèdent tous leurs draps comme draps de Leeds sans autre distinction, comme on le verra ci-dessous. Dans toutes les maisons, il se fait des draps et chaque particulier a trois ou quatre métiers, selon son fonds de laine. Une fois sa pièce de draps réalisée, il la porte aux foulons publics qui se trouvent sur le fleuve susdit. Après le foulage, ils les plient en rond et, ainsi roulés, ils vont dans la ville de Leeds les jours de marché, le mardi et le samedi, et ils y vendent leurs draps suivant les prix courants qu'établissent les acheteurs à l'ouverture du marché : une fois le prix décidé pour une pièce, il l'est pour toutes. L'acheteur examine les draps qu'il a achetés pour leur donner leurs noms, selon la qualité plus ou moins fine de la laine avec laquelle ils ont été travaillés. Un crédit est accordé à chaque particulier la première fois qu'il se rend au foulon, mais à la seconde, il faut qu'il paye la quantité qu'il a fait fouler la première fois. Ils respectent cela fidèlement, car si un homme changeait de foulon sans payer l'ouvrage de ses pièces de draps, il ne trouverait plus la facilité du crédit que lui fait l'édifice public avant qu'il ait vendu son drap au marché. Sur celui-ci, tout se vend au comptant sans le moindre délai, avec la seule règle de 2 1 $2 / 2$ pour cent d'escompte pour le paiement comptant. Pratiquement aucun de ces particuliers n'a plus de quatre ou cinq pièces à vendre. En général, en ce qui concerne les couleurs, ce sont toutes des couleurs brunes et grises. lls font d'autres couleurs déterminées sur commission des acheteurs et le prix est fixé au marché lors de la commission. Le plus souvent, ils se font donner de façon anticipée le tiers de la valeur de la pièce comme caution. C'est également ce qu'ils font pour les draps appelés du Ponent ou miffin qui prennent le nom de draps espagnols, car la consommation des draps ainsi nommés se fait entièrement en Espagne, étant travaillés très légers à la mode de ce pays, où ils servent pour les amples capes que les habitants ont l'habitude de porter dans ce pays. Ayant acheté et opéré la distinction d'appellation de qualité, on procède en ville aux apprêts plus ou moins soignés qui conviennent à chacune de ces qualités. Si un drap est de laine plus fine, il supporte d'être lainé et foulé une seconde fois et il supporte plus de tonte que n'en peut supporter un drap ordinaire. Le drap bien foulé, naturellement ils le pressent. Ceux qui sont extrêmement légers et n'ont pas été bien battus sur le métier et qui, en conséquence, ne peuvent être bien lainés, sont humidifiés dans la presse avec de l'eau de colle, surtout dans la tête de la pièce, pour leur donner un corps convenable, ce que l'on constate quotidiennement dans un pareil genre de draps. L'eau de colle qu'ils leur donnent produit deux effets : elle durcit le drap et lui donne un toucher plus fort. Ainsi, lors de la vente, le drap ordinaire présente un plus bel aspect. Le second effet est qu'elle tient le poil couché, ce qui permet au drap de prendre un lustre ou accadissaggio convenable dans la presse : cet accadissaggio n'est d'aucune substance, car ce drap, en vieillissant un peu dans les magasins, voit se rebiffer son poil et se présente à nouveau dans son état naturel. C'est la raison pour laquelle à chaque fois qu'ils doivent expédier ce genre de draps, ils les mettent sous presse pour la seconde fois et le marchand doit très souvent les y mettre une troisième fois pour pouvoir s'en défaire. Pour le reste, cela prend autant de fabriquer un drap fin qu'un drap ordinaire, à la seule différence que le drap fin est plus soigné. En ce qui concerne le drap ordinaire, il suffit qu'on lui fasse les opérations nécessaires. II est égal que ce soit avec soin ou non, même s'il est vrai qu'un drap ordinaire d'une même qualité de laine dont on a soigné la fabrication peut prendre jusqu'à un tiers de valeur en plus grâce au bon travail reçu, bien qu'il n'ait pas plus de valeur intrinsèque que l'autre drap mal travaillé qui vaut un tiers de moins.

Ceux indiqués A, appelés draps du Ponent, servent pour les Espagnols; ceux indiqués B sont tous choisis pour la dénomination Du Nord, c'est-à-dire la qualité la plus ordinaire ; ceux indiqués C représentent la qualité Bristol, soit une qualité moyenne, et ceux indiqués $D$, appelés Reffole, sont les draps de meilleure qualité qu'ils réussissent à faire dans la province de Leeds.

Quand ils ont des ordres directs, les commissionnaires du lieu les envoient de leur propre maison, sinon ils font de fortes expéditions à Londres, en écru, c'est-à-dire non encore apprêtés mais choisis dans la qualité. Ils les envoient à Londres afin qu'ils soient vendus sur le marché de la marchandise ordinaire que l'on a décrit, et qui se tient deux fois par semaine. Si ce genre de marchandise est retournée au commissionnaire, celui-ci ne peut s'en prendre au fabricant, car il ne peut plus prouver l'identité de la pièce reconnue comme défectueuse pour pouvoir dire qu'elle est d'un tel plutôt que de tel autre.

192 Documents pour l'histoire des techniques nº 18 - décembre 2009 
Les échantillons indiqués E ont pour nom scotto. Ce genre d'étoffe se fabrique dans les campagnes à mi-chemin entre Londres et Norwich. On considère ses habitants très habiles dans cet article dont il se fait une seule grande quantité. La plus forte consommation de ce genre de marchandise est en blanc écru comme l'échantillon, bien qu'il s'en vende également en blanc et en noir, le blanc naturel est capable d'ailleurs de recevoir toutes sortes de couleurs. Les qualités sont décrites ci-dessous:

Scotti de 25 yards et 22 pouces de largeur, de 30 s. jusqu'à 36 sterling la pièce

Scotti de 27 yards, 41 pouces, de 46 jusqu'à 47 la pièce

Idem, de 30 yards, 41 pouces, de 66 jusqu'à 105

idem de 42 yards, 41 pouces, de 86 jusqu'à 105

idem, ayant pour nom annascoti de 47 verghe, 41 pouces à 50 la pièce. On en fait encore de qualité supérieure jusqu'à 220 la pièce, mais comme ces qualités ne sont pas vendables de façon courante, ils ne les font pas si la qualité n'a pas d'abord été concordée et fixée sur échantillons. Cet article est fait avec les laines les plus fines de ces environs, filées à la quenouille et au rovet à pied, comme on file le lin. La laine doit être dégraissée et purgée avant de la mettre en œuvre, le tissage est le même que pour la toile, mais avec une chaîne double afin de croiser l'étoffe, comme on le voit sur le papier. La finesse de ce genre d'étoffe consiste à être plus ou moins serré sur le métier, les laines devant être toujours d'un filé très fin et la laine doit être choisie bien blanche afin que ceux que l'on vend en couleur naturelle soient du blanc naturel de la laine, ceux qui se vendent blanchis le sont au soufre. Ce genre d'étoffe se lave quand il est sale et on le lave avec du savon et de l'eau lipide. Les moines sont ceux qui font un plus grand usage de cette étoffe. lls préfèrent les blancs naturels à ceux qui sont blanchis avec le soufre car quand on lave les blancs naturels, ils restent plus blancs que ceux qui sont blanchis. Les réguliers de S. Dominique et de S. Augustin sont ceux qui font la plus forte consommation de ce genre d'étoffe qui constitue un article essentiel de la fabrication anglaise, car ce sont les laines d'Angleterre qui peuvent porter à la perfection un tel article, comme l'expérience le prouve, de nombreux pays ayant tenté d'en faire sans jamais y réussir. À Zurich, ils en font, mais cela reste un genre d'étoffe tout à fait différent, car il reste plucheux, beaucoup plus mou et de nature bien différente, qui ne peut être d'aucun usage en blanc. Les scotti d'Angleterre sont mis en vente tels qu'ils sortent du métier, certains les font simplement bouillir dans de l'eau claire pour les laver des tâches que l'ouvrier a pu faire sur le métier, puis ils les plient et mettent les pièces pliées sous presse pour qu'ils restent toujours étendus. Ensuite, quand ils les expédient, les expéditionnaires leur donnent des plis différents sous le prétexte de les contrôler pour prendre quelque commission supplémentaire. S'ils sont pliés un pli sur l'autre [?], ils sont roulés comme il est essentiel de le faire pour ceux que l'on veut mettre en teinture, cet article ne pouvant souffrir aucune presse avec cartons, car la beauté de l'étoffe est le pli ou le grain dû au croisement. L'article est d'une consommation si forte qu'à Londres, il y a des dépôts entiers de cette seule marchandise. Il y a des fabricants qui font leur commerce eux-mêmes, mais la majorité sont des agriculteurs qui, dès qu'ils ont terminé une pièce, la portent dans les dépôts communs et reçoivent quelques sommes comptant, ou bien la vendent aux commissionnaires eux-mêmes. La diminution ou l'augmentation de ce genre d'étoffe est causée par la plus ou moins grande quantité de pièces fabriquées et par la plus ou moins grande demande. D'habitude, elles sont à meilleur marché au printemps parce que les travailleurs des campagnes préfèrent le travail de leurs terres au métier et ceux qui ont quelques fonds vont vendre en cette saison le travail de tout l'hiver.

\section{Norwich}

Maintenant que nous avons vu la fabrique de scotti, et que nous sommes en chemin, nous passerons à Norwich. Très peuplée, c'est une des villes les plus belles et les plus riches d'Angleterre. II n'y a personne dans cette province qui ne fasse un commerce d'une sorte ou d'une autre. II y a en ville toutes sortes de professions et deux marchés hebdomadaires pour les vivres. Ces marchés sont proportionnellement plus abondants en comestibles que ceux de la ville de Londres, de sorte que bien des habitants de Londres font faire leurs provisions hebdomadaires sur ce marché, bien qu'il soit distant de la ville de plus de cent milles de ce pays -il faut bien trois de ces milles pour former une lieve de France-.

Cependant, le principal article du commerce de Norwich est la fabrication des camelots, callamandre et autres petites étoffes décrites sur le papier. Le règlement de la fabrication de ces genres d'étoffes est réparti entre trois mains, le fabricant ou patron, le travailleur au métier ou contremaître qui fait le négoce lui-même pour l'ouvrage du tissage de l'étoffe, et le presseur. 


\section{Relation de voyage}

Le fabricant est celui qui a la matière première. II n'a d'autre soin que celui de faire peigner et de carder sa laine. Il conserve toute la laine peignée tandis qu'il enlève la plupart de la cardée de sa fabrication et la vend dans les autres provinces. II distribue la laine peignée au poids aux fileuses éparpillées dans les campagnes de la province : cette distribution se fait les jours de marché. Les filés réduits en bobines sont teints selon le dessin et les couleurs dont doit être formée l'étoffe. L'ouvrier ou contremaître les prend et fait monter les métiers. La pièce faite, il la rend au poids et selon la mesure qui lui a été fixée par le patron. Comme nous l'avons déjà dit auparavant, toutes les étoffes ouvragées sont travaillées sur des métiers à lacets de la même façon que l'on travaille les étoffes de soie à fleurs. Dès que la pièce est fabriquée, restituée et qu'elle a reçu l'approbation du patron principal, on paye [à l'ouvrier / contremaître] la facture de celle-ci sans se mêler de savoir combien il a payé par jour son ouvrier. Il est vrai que ces travailleurs sont payés à la pièce et non à la journée. Ils sont payés à la journée seulement quand il s'agit d'un essai ou de quelque dessin nouveau et seulement pour la première pièce qu'ils font et qui entre dans le magasin du patron principal lorsqu'elle est faite à perfection selon l'échantillon donné. Quand celui-ci veut l'expédier, il la donne à l'apprêteur ou presseur. Ceux-ci font leurs apprêts et pressent de la même façon que les camelots déjà décrits à Amiens. Pour ce qui est des étoffes ouvragées qui demandent du lustre, elles sont pressées avec une presse bouillante d'abord formée du mango. C'est une grande caisse formée de planches entièrement remplies de pierres. La planche du dessous est bien lisse comme celle sur laquelle elle est posée ; une grosse corde passe en dessous et entoure la planche fixe, laquelle a en son milieu une petite rove qui tourne et qui guide avec plus de facilité la corde. En tirant cette corde d'un côté, on déplace la machine, ou cassione, d'un côté, et, en la tirant de l'autre côté, on la guide dans le sens opposé, toujours en ligne droite cependant. Pour déplacer cette machine, ils se servent d'un grand torno auquel sont attachées les deux extrémités de la corde. Le torno est attaché à un cheval qui le fait tourner. En tournant dans un sens, ce cheval tire vers lui la machine et quand elle arrive jusqu'à lui, il se retourne et va dans le sens opposé et il envoie la machine en arrière, grâce à un cri poussé par un garçon qui se munie d'un fouet pour le faire travailler. Ce même mouvement sert pour faire tourner une autre rove au milieu de laquelle se trouvent les rouleaux de bois sur lesquels roulent les pièces d'étoffe pour les passer sous le mango ou cassione. Ce travail comprime la laine et oblige les fils à s'adapter l'un à l'autre. Quand les fils sont bien écrasés, ils enlèvent la pièce et ils la plient en mettant au milieu de chaque pli un carton très fin dont un échantillon se trouve sur le papier indiqué par la lettre [?]. À peine les pièces sont-elles ainsi pliées qu'ils les mettent sous le torchio qui s'appelle la presse. Entre une pièce et l'autre, ils mettent une planche de bois sur laquelle ils mettent une autre planche de fonte bien chaude en la couvrant d'une autre planche de bois, afin de pouvoir mettre une pièce sur l'autre. lls font chauffer ces planches de fonte dans un four qui est fabriqué à côté des tours, ou presses. Les tours sont situés en ligne droite les uns après les autres dans une grande pièce située au rez-de-chaussée et sur le devant de laquelle se trouve, à la distance d'un trabut de notre mesure, une grande table longue sur laquelle ils plient la pièce afin de la mettre sous ce même tour. Celui-ci a les côtés très résistants faits de bois doublé de lames de fer de l'épaisseur de deux onces avec incanalitura pour tenir l'axe qui comprime. Celui-ci est cerclé de fer, avec deux manches également de fer qui rentrent dans l'incanalitura dans laquelle se trouvent les manches de fer susdits qui sont attachés à cette même planche qui comprime, étant comprimée d'abord naturellement par une grande masse de plomb située sur le fond d'une vis de fer qui tourne dans un trou de métal appelé la vis mère. Ils règlent cette vis qui forme le tour en la faisant tourner à l'aide de quatre barres de fer actionnées chacune par quatre hommes et qui passent dans la lanterne également de métal. Le tour est posé sur trois grandes pierres qui forment un four ouvert sur le devant. lls y mettent le feu qui réchauffe avec une telle force la presse et les étoffes qui sont en-dessous que, lorsqu'on les enlève, elles sont bouillantes, et il semble que les étoffes aient été en fusion dans l'huile. Quand elles sont chaudes, elles sont si flexibles qu'en les pressant, les cartons comme l'étoffe se plient en leur milieu. Ils jettent les pièces une par une sur la table qui se trouve devant le tour et, en l'espace d'un quart d'heure, l'étoffe comme les cartons sont extrêmement durs et les étoffes sont luisantes comme des miroirs. Quand ils les mettent [sous la presse], ils les mettent sèches, les cartons sont secs, les laines sont purgées car elles sont teintes. On prétend que le huileux est ce qui leur donne ce grand lustre, mais je ne sais d'où il provient. Les marchands de ce genre d'étoffes sont tous d'accord pour dire qu'il peut venir d'une certaine composition dont ils supposent qu'on se sert dans la fabrication des cartons. La matière essentielle de cette composition, d'après ce que j'ai pu savoir après des conjectures longuement obtenues, serait le blanc d'œuf. Le Sr Musso, piémontais, en fait faire l'expérience aux batteurs de bainette appartenant au Sr marquis d'Ormea. La réussite de cette expérimentation assurerait à ces cartons une forte vente, tant pour le pays que pour la fabrique de Lille en Flandres où ils travaillent également ce genre d'étoffes lustrées, mais pas à la perfection des Anglais. En enlevant les cartons, ils plient les

194 Documents pour l'histoire des techniques nº 18 - décembre 2009 
étoffes sur les planches pour ensuite les consigner au patron principal et pour en faire l'expédition. Elles sont toutes envoyées à Londres, emballées selon les ordres reçus, tant pour l'étranger que pour le pays lui-même, à l'exception des provinces qui se trouvent de l'autre côté pour lesquelles chaque particulier profite des voitures qu'il estime les plus avantageuses à son intérêt. S'il s'agit de petits paquets, les expéditions vers Londres sont faites par la voiture publique qui va et vient trois fois par semaine l'été et conduit les étrangers en un jour seulement, en deux jours l'hiver, saison où le voyage n'a lieu que deux fois par semaine. Pour les gros poids, il y a deux chariots tirés par six chevaux attachés l'un derrière l'autre qui vont et viennent deux fois par semaine. Tant les chariots que la voiture publique partent à jour et à heure fixe, qu'ils aient ou non leur chargement, comme les voitures de France, car c'est la règle dans les établissements publics. Toutes les étoffes de cette fabrique sont pliées sur de très fines planches de bois et encartées de fin papier blanc enveloppé à son tour de papier ordinaire, qui est un papier formé avec les cordages usagés qui servent pour la navigation, ou de papier formé de chiffons de toile et d'étoffes de laine.

Pour le règlement des prix des voitures susdites, quatre réunions se tiennent par an auxquelles président les principaux fabricants, le maire et les membres du conseil de la ville. Ils décident d'une taxe qui sert seulement pendant trois mois à la fin desquels elle est confirmée ou modifiée, à la hausse ou à la baisse selon la variation des temps. Tout le public est obligé de suivre le même prix qui ne peut être modifié. En cas de contravention, les peines tant pécuniaires que corporelles sont très fortes. En cas de controverse entre les fabricants, le maire de la ville, qui est un négociant, juge le tout sommairement sans aucun appel, sauf pour les fortes sommes, mais d'habitude, ils acquiescent. Le maire est élu par tout le peuple une fois par an et, pour cette élection, le Parlement est obligé d'envoyer des troupes pour contenir le peuple afin qu'à cette occasion les factions n'en viennent pas aux mains.

Ayant décrit en général la fabrication, j'ai maintenant l'honneur de montrer la qualité des étoffes qui se fabriquent dans cette province. Celles indiquées par les lettres A et B, indiquées avec leur vrai nom en anglais sur le papier, sont des callamandres de diverses couleurs, travaillées comme les damas de soie avec un métier à lacet. La différence est que les étoffes de soie restent égales sur le métier, tandis que celles-ci ont un dessin très relevé qui est égalisé par la calandre et lissé avec un si beau lustre par la presse chaude, comme nous l'avons vu. Échantillons indiqués par les lettres C et D : le premier, indiqué C, est à l'imitation des damas de soie et le second, D, est à l'imitation des satins de deux couleurs. Ces étoffes sont ouvragées comme toutes celles qui suivent. Elles servent toutes pour les tapisseries et les meubles de maisons, c'est-à-dire les lits, les chaises, et autres choses semblables. Les prix sont indiqués sur le papier en monnaie anglaise avec leurs largeurs et longueurs respectives. Celles indiquées par la lettre E sont des camelots rayés nuancés. Ils sont passés sous le mango et pressés, non pas avec des cartons, mais au milieu de papier fin et réchauffés seulement avec les planches de fonte intercalées entre des cartons durs alors que les draps sont mis au milieu de planches de bois.

Celles indiquées $\mathrm{F}, \mathrm{G}, \mathrm{H}$, l, ont toutes un nom différent en anglais, mais sont généralement appelées chez nous mezza florete. Elles sont également travaillées au lacet, mais celui-ci est réglé par des pédales situées en-dessous des pieds du tisseur. Elles sont pressées avec une presse chaude comme le sont les callamandres, mais elles sont de laines moins fines que celles-ci.

Celles indiquées $L$ jusqu'à la lettre $S$, ont chacune un nom différent en anglais, mais elles s'appellent chez nous florete et taboretti. Elles sont travaillées avec un métier à lacets et pressées avec la presse bouillante comme toutes les étoffes lustrées satinées.

Celles indiquées $T$ et $X$ sont des camelots rayés pressés comme ceux indiqués par la lettre $\mathrm{E}$, à la seule différence qu'ils sont filés de laines plus ordinaires.

Ceux indiqués par la lettre $\vee$ sont appelé chez nous callamandres. Celles-ci sont travaillées avec les rejets des filés de toutes les autres étoffes de pareil genre et nature c'est-à-dire de toutes les étoffes qui se travaillent là-bas.

Celles indiquées par la lettre $X$ sont appelées chez nous camelots rayés en longueur et en largeur, comme sur le papier. Ils sont également constitués par les rejets des filés qui ont été choisis pour les camelots plus fins, comme le sont également les arlichine indiqués Y. Ceux indiqués K sont des camelots surfins travaillés en pure laine ; ils sont travaillés avec les mêmes apprêts que ceux qui ont été décrits à Amiens, mais comme la laine reste plus rude tant à cause de sa nature même qu'à cause des eaux après la purge, ils sont en apparence très beaux mais de mauvaise qualité à l'usage. C'est le sort que subissent tous les camelots de ce pays qui sont travaillés en fin de matières ordinaires mais rudes, la matière fine ne pouvant être mise en œuvre dans ce genre d'étoffes, comme, par exemple, ne peuvent servir à ces étoffes les laines d'Espagne car elles sont trop courtes. Celles indiquées Z sont encore des camelots, comme 


\section{Relation de voyage}

ceux indiqués $\mathrm{E}$, à la différence que ceux-ci sont travaillés à double chaîne et à lacet pour le ramage des fleurs et passés à la calandre pour être ensuite pressés à la presse chaude.

L'échantillon indiqué AA est un camelot qui est travaillé avec la chaîne d'un fil de laine tort et d'un fil de soie, la trame étant entièrement de laine. Pour faire cette qualité de camelots, ils se servent du filé le plus fin qu'ils peuvent avoir ; le moyen sert à faire la qualité indiquée BB et l'ordinaire, la qualité indiquée CC. Ils en expédient de cette qualité des unis et des à ondes. La plus grande vente de ces qualités de camelots est en Espagne.

Les échantillons indiqués DD sont de même des camelots rayés auxquels on brode la fleur avec l'aiguille, celles-ci étant ensuite aplaties avec le mango et la presse chaude.

\section{Exon}

Pratiquement du côté opposé de Norwich se trouve la province d'Exon. La fabrication est étendue à d'autres produits et on y travaille des draps comme nous l'avons vu dans la description des fabriques de Londres et de ses alentours.

À Exer ou Exon, on travaille également en grande quantité des draps miffin, doubles broches, ordinaires. Les fabriques travaillent en fonction des ordres qu'ils reçoivent, tant de Londres que des commissionnaires de l'étranger.

La fabrication des genres suivants est réglée là-bas de deux façons. La première est celle des fabriques qui travaillent chacune son article : qui fabrique des draps ne fabrique pas de droguets, qui fabrique des droguets ne fabrique pas de saies, et ainsi de suite. La plupart de ces fabriques travaillent chacune pour leur compte et elles donnent les apprêts nécessaires dans leur maison même. Il y ensuite une seconde sorte de fabriques : ce sont les commissionnaires qui ont des magasins de laine et des ouvriers à façon dans la campagne qui travaillent les pièces en écru avec leurs métiers. Ils reçoivent la laine du commissionnaire et lui rendent la pièce en écru, ne se mêlant ni de teinture, ni de foulon, ni d'aucun autre apprêt qui puisse être nécessaire pour rendre la pièce parfaite. Le soin de toutes ces opérations est laissé au commissionnaire, ou magasinier de la laine lui-même. La première sorte de fabrique a comme avantage que la marchandise est suivie pas à pas car elle est travaillée entièrement dans un même site. Dans la seconde méthode, on trouve d'ordinaire de meilleures qualités de laine, car [les commissionnaires] peuvent faire de meilleurs choix grâce aux quantités de laine qu'ils ont dans leurs magasins. Dans cette province, il se fabrique plus de laine cardée et filée large comme celle que l'on file pour les draps, bien que pour les lagatis et Duransi et salia sottile, ils se servent également des étaims peignés et filés à la quenouille, comme on pourra plus facilement le voir dans la description des étoffes qualité par qualité.

L'échantillon de draps indiqué par la lettre A est celui qui est appelé miffin. Ils en font de toutes les qualités en proportion du prix et de la qualité qu'on leur demande. Ils sont mélangés de laines d'Espagne ordinaires et des laines courtes du pays car, de fait, dans cette province, les moutons ne donnent pas une laine aussi longue qu'à Canterbury et dans d'autres régions semblables. Les laines sont mélangées grasses comme elles sortent de la tonte et, ainsi mêlées, ils leur font toutes les autres opérations que l'on a présentées dans la description générale du début, et ceci jusqu'à la finition de la pièce. Ils font également dans cette province des draps surfins, mais ils ne sont pas aussi parfaits que ceux qui sont fabriqués dans les alentours de Londres.

La seconde qualité de draps spécifiques à cette province sont les doubles broches ordinaires indiquées par les lettres AA. Ils sont travaillés de la même façon que ceux des Andelys. La plus ou moins grande finesse de cette qualité de draps dérive de la plus ou moins grande quantité de laine d'Espagne que l'on mélange aux laines du pays. Ils fabriquent tant d'une qualité que de l'autre selon le prix qu'on leur demande, la matière première plus ou moins fine étant ce qui décide de l'article.

Celles indiquées B sont des droguets qui sont travaillés en toile comme les draps, mais ils ne leur couchent pas le poil et ils sont pressés dès qu'ils ont reçu une seule tonte. Une fois conduits à perfection, ils sont larges d'un ras, et pour cela ils les fabriquent en général d'un ras et un tiers et les foulent jusqu'à ce que le tiers de plus qu'ils ont en toile soit rentré dans l'étoffe. La purge de la laine est la même que pour les draps et il n'y a pas d'autres observations à faire que la plus ou moins grande finesse de ceux-ci, selon la plus ou moins grande finesse de la laine et du filé qui est toujours plus fin si la laine est plus fine et de meilleure qualité. Ils sont obligés de marquer à la tête de chaque pièce s'ils sont des plus fins, des moyens ou des ordinaires, mais cette marque sert uniquement pour les acheteurs anglais parce que, quand ils expédient à l'étranger, il est permis à chacun d'enlever les marques et de leur mettre celles qu'ils jugent le plus opportun pour l'étranger. Ils font de tels articles en écru, qui sont susceptibles de recevoir toutes les couleurs, et ils en font également des teints en laine, surtout dans les mélangés qui ne peuvent se faire que teints

196 Documents pour l'histoire des techniques nº 18 - décembre 2009 
en laine à cause du mélange. Par conséquent, ceux-ci sont plus chers, car pour mélanger la laine des droguets, ils se servent de paquets, comme nous l'avons vu pour les draps.

La presse est la même que celle des draps. Elle est faite avec les cartons chauds et avec des planches de fonte au milieu, mais il est défendu de les humidifier avec aucune sorte de gomme ou de colle qui pourrait trahir la bonne foi publique et donner à un droguet une apparence meilleure que celui qu'il a en substance.

Les échantillons indiqués par la lettre C ont pour nom droguets cordés. Ils sont fait comme les baracans, à la différence cependant que les baracans sont entièrement tissés de gros étaims pour que l'incanalitura soit égale, tandis que les droguets cordés sont tissés avec un fil de gros étaim et trois fils de laine fine. De même, les baracans ne supportent aucun foulon tandis que les droguets cordés sont passés légèrement au foulon et ils les mettent en presse comme tous les autres droguets tandis que les baracans se roulent simplement et se dégraissent au foulon.

Ceux indiqués $D$ sont de laine plus ordinaire que ceux indiqués $B$; ceux indiqués $E$ sont ceux qui sont travaillés en fin, écrus, et teintés en pièces ; ceux indiqués $F$ sont plus ordinaires et teints tout en laine ; ceux indiqués $G$ sont de la même qualité mais teints en pièces comme on peut facilement le voir par les prix qui sont annotés sur le papier avec leur largeur, longueur, comme pour tous les autres articles.

Les échantillons indiqués $\mathrm{H}$, nommés sagatis, s'appellent communément chez nous crosie. Ce sont des saies croisées comme on l'a déjà vu dans les fabriques des alentours de Londres mais on les répète ici car elles sont de qualité plus fine, car ils se servent des étaims ou des filés de laine fins qui restent après la fabrication des Durois ou Duranze fins. Ceux qui sont unis, ils les font en écrus et ceux qui sont mélangés, ils les travaillent avec des laines teintées en fil en mettant la chaîne d'une couleur et en se servant pour la trame d'une autre couleur. Ces saies croisées sont pressées à la presse bouillante avec des cartons fins et ils ne prennent pas autant de lustre que les autres articles car ils sont de matière inférieure.

Celles indiquées par la lettre I sont appelées saies de Londres comme celles que nous avons vues fabriquer à Londres et dont l'échantillon en blanc est indiqué par la lettre D. On a ici remis les échantillons, car c'est la province où se travaille la plus grande quantité de cet article et à la plus grande perfection. Ils en font d'autant de qualités qu'on le voit indiqué sur le papier et, bien que sur le papier ils soient tous de couleur écarlate, ils en font cependant de toutes les couleurs. Cet article se fait entièrement en écru et on les teint de la couleur que l'on juge le plus à propos. Ils les teignent en fonction des qualités et des couleurs qui leur sont demandées. Cette saie a deux usages: le principal est de faire des habits et l'autre est de faire l'usage de molletons de France, après qu'on lui ait tiré le poil avec la carde. Elles sont à double chaîne croisée sur le métier dans la fabrication de la toile, puis passées au foulon pour les dégraisser et les rendre plus fortes et compactes.

Celles indiquées $L$ s'appellent Durois et chez nous Marbrochi. Ils en font de différents prix selon que l'on en demande des plus fins ou des plus ordinaires. Ils en font des unis et des mélangés teints en laine et des ordinaires en écru qu'ils teignent en pièce. Ceux-ci, comme les ouvragés et rayés qui suivent, sont tous pressés avec la presse bouillante pour donner le lustre qui fait le brillant de l'étoffe.

Celles indiquées M sont aussi des Durois mais elles sont rayées. Pour composer la rayure, ils mettent les différentes couleurs dans la chaîne, la trame devant être de couleur plus dominante, comme on le voit clairement par l'échantillon lui-même.

Celles indiquées $\mathrm{N}$ ont le même nom et il s'agit de la même qualité d'étoffe. Dans cet article, on fait tous les dessins et les ouvrages qu'on leur demande pourvu qu'ils soient de deux couleurs. Les apprêts et la finition de ces étoffes sont les mêmes que pour les unis et les rayés à la seule différence que le dessin est travaillé au lacet comme toutes les autres étoffes à fleur.

Celle indiquée O s'appelle Duranza. Elle est faite comme la toile, à la seule différence qu'elle est croisée et pressée à la presse bouillante, elle est travaillée avec de la laine purgée et blanchie au soufre avant de la mettre en presse. Cet article doit être mis sous presse plié en deux et, avant de le mettre en presse, il est passé en double à la calandre de façon qu'il soit luisant d'un côté et ondé de l'autre. Afin que cet article ne perde pas de son lustre dans les expéditions du fait de l'emballage, ils le plient à force de tour sur une planche de bois.

Celle indiquée P est la même qualité d'étoffe, à la seule différence qu'elle est en toile sans être croisée et par conséquent beaucoup plus légère.

Celle indiquée $Q$, appelée saie simple est travaillée de la même façon que celle indiquée $O$, à la différence qu'elle est travaillée avec les restes des étoffes $O$ et $P$. Les apprêts et les presses sont égaux pour les trois et, bien que sur le papier ils figurent seulement en blanc et en noir, ils en font de toutes les couleurs imaginables. Ces trois étoffes sont travaillées uniquement avec les laines du pays. 


\section{Relation de voyage}

Celle indiquée $R$, ayant pour nom Bava ou flanellone, est une étoffe dont ont fait une infinité de qualités selon les prix que l'on veut y mettre. Elle est faite avec une chaîne de fil filé de façon assez resserrée et la trame doit être de fil beaucoup plus ouvert. Comme elle reste naturellement comme elle a été tissée, on peut se rendre compte à l'oeil de la différence qui existe entre le filé serré et celui ouvert. Une fois la toile faite, on la blanchit et on la carde immédiatement une seule fois parce qu'elle ne pourrait supporter plus à cause de sa légèreté. La plus ou moins grande finesse de cette marchandise provient de ce qu'elle est plus ou moins battue sur le métier (plus les cartons de Norwich?).

Celle indiquée S a pour nom flanetta. Cet échantillon est croisé, mais il existe aussi la lisse ou en toile qui est indiquée par la lettre T. Elles sont travaillées avec des laines fines mélangées avec un tiers de laines du pays. Elles sont travaillées comme les saies de Londres indiquées par la lettre l, à la seule différence que les laines sont plus fines et les filés également plus fins, mais elles sont passées de la même façon au foulon et cardées en cas de besoin. On vend également une forte quantité de cet article uniquement pressé comme les droguets, mais sous presse pas trop chaude. Celles-ci se vendent comme les droguets roulées en large et seulement pontato (appuyé avec force) sur les lisières.

Celle indiquée V a pour nom Dufiels et chez nous Quatti. II s'en fait des qualités très diverses selon les prix demandés. La plus grande quantité de cet article se vend en blanc écru seulement tondu et prêt pour la teinture, car chaque marchand ou acheteur en gros se le fait apprêter comme il lui est plus avantageux. On se sert de celles-ci, tant en poil que frisées, dans toutes sortes de couleurs et on donne quelque fois aux plus fins un apprêt et une finition identiques à ceux d'un drap. On les vend comme draps aux réguliers vêtus de blanc afin qu'ils s'en fassent des manteaux pour se protéger du froid. Bien que forte, cette étoffe est plus légère qu'un drap fin et, à cause de sa douceur, elle tient plus chaud que le drap lui-même. Une telle étoffe est travaillée avec les filés comme le sont les draps, c'est-à-dire filés ouverts et on leur donne les mêmes apprêts que l'on doit donner à un drap du Nord ou Bristol.

L'échantillon indiqué $X$ est celui des cartons dont on a parlé dans les apprêts bouillants. Seule l'industrie anglaise a le monopole de cette perfection, ce qui rend la fabrique tant de Norwich que d'Exeter aussi florissantes et qui occupe et fait travailler une population immense. Bien que le coût de la vie soit aussi cher, la main-d'œuvre est à meilleur marché que dans tous les autres pays que j'ai vus.

\section{Lille}

De Londres, en repassant par Calais, je suis venu dans un caraballa ou voiture publique à Dunkerque où j'ai dû séjourner pour attendre la diligence qui part pour Lille. A Dunkerque, un bon tiers des habitants sont anglais et, bien qu'ils aient la commodité du bois pour faire du feu, ils font venir leur charbon de pierre pour s'en servir et suivre leur coutume. Le commerce de cette ville est un commerce d'expéditions, tant par mer que par terre, mais il diminue car le port se remplit de bancs de sable sans que les Français puissent y remédier, car l'Angleterre a un régent qui veille à l'observation du traité signé sur cet article durant la dernière guerre. La plus grande partie des expéditions sont de victuailles, mais toute la marchandise que l'on exporte des Flandres vers l'étranger part également d'ici. Après m'être arrêté un jour en raison de l'absence de la voiture publique qui part seulement trois fois par semaine, je suis allé à Lille. C'est une ville très peuplée étant donné le grand commerce que l'on y fait dans la fabrication qui est réglée de la même façon que dans toutes les autres places françaises. Les articles qu'on fabrique sont presque tous d'étaim ; on y fait aussi des draps, mais en très faible quantité. Ils font deux sortes de draps : la première est un drap plus ordinaire que celui d'Elbeuf et [la seconde] une qualité de drap de pied qu'ils appellent Viciora et dont ils se servent comme habit au cœur de l'hiver en tentant d'utiliser ceux qui, par hasard, sont plus mous. Dans cette sorte de drap, ils se servent de toutes les laines les plus ordinaires, y mélangeant également du poil de vache dont ils prennent le plus fin pour ce travail, le reste va en Hollande et à Sedan pour les lisières des draps. Il y a une Bourse et ils soutiennent plus que dans toute autre partie le commerce d'expéditions parce que ce sont les expéditionnaires qui donnent la règle aux fabricants. Ces derniers sont dispersés dans la ville et les campagnes voisines et, en vertu du règlement, aucun fabricant ne peut détenir et faire battre plus de six métiers sur lesquels chacun travaille ce qu'il veut. Toutes les étoffes qu'ils font ici sont à imitation de l'étranger. Une fois les pièces faites en écru, ils les vendent aux commissionnaires dénommés marchands, en leur laissant le soin de la finition. Les presses sont toutes à l'imitation des anglaises, mais elles ne sont pas de la même perfection, car ils n'ont pas les cartons des Anglais. De fait, en France et en Hollande, ils ne sont pas encore parvenus à la perfection des Anglais dans la fabrication de ces cartons. Les teintures sont les mêmes que partout ailleurs, mais toutes les couleurs qu'ils entreprennent sont d'une perfection médiocre. Le pays abonde de vivres, les campagnes étant bien cultivées. C'est pour soutenir à la fois la culture des terres et la manufacture des

$198 \diamond$ Documents pour l'histoire des techniques nº 18 - décembre 2009 
étoffes qu'ils ne veulent pas qu'un particulier ait plus de six métiers, ayant comme principe que là où se trouvent de grandes fabriques, elles provoquent l'inculture des terres, à cause de l'emploi [qu'elles procurent aux] travailleurs. Grâce à cette maxime, ils prétendent soutenir à la fois la fabrication et la culture des terres.

L'état général des étoffes que l'on fabrique à Lille est sur le papier. Les genres propres à ce pays sont les calmandes (callamandre) larges et les camelots de laine, tant étroits que larges, teints en pièce, même s'ils en teignent également en laine, comme on le verra ci-après.

Les échantillons indiqués par la lettre A sont des calmandes dont la largeur et la longueur sont notées sur le papier. C'est l'article par lequel a commencé la manufacture de Lille. Comme toutes les autres étoffes du même genre, celles-ci sont passées à la calandre et ensuite pressées sous une presse aussi chaude qu'ils le peuvent.

Celles indiquées B sont des calmandes également, à la différence que celles-ci sont rayées et mélangées. On ne les fabrique que depuis deux ou trois ans, de même que celles indiquées $C$ qui sont rayées de deux couleurs sur le métier. Toutes ces étoffes sont travaillées avec une chaîne très fine, installée en double sur le métier à l'imitation des satins. Celles indiquées D sont à imitation des calmandes ou damas de laine qui se fabriquent à Norwich, de même que les E qui sont rayées. Elles sont travaillées de la même façon qu'en Angleterre, mais elles ne sont pas de la même perfection, d'abord en raison de l'inexpérience dans la presse due à l'absence de cartons, deuxièmement à cause de la qualité des laines des alentours qui ne sont pas aussi longues que celles d'Angleterre et ne peuvent donner des filés de la même finesse et de la même égalité que les filés anglais.

Les F ont pour nom couti surfins. Ils sont fabriqués de fil et, pour l'ouvrage, du dessin et de la couleur demandés. Elles sont pressées avec la calandre comme le sont également les $G$ qui sont de la même qualité, mais plus ordinaires, étant donnée la qualité plus forte et ordinaire de la matière première employée. Les H sont encore le même genre de marchandise à la seule différence que ceux-ci sont travaillés de fil et de coton au lacet, les lacets étant réglés par les touches ou pédales que le tisseur a sous les pieds.

Les I ont pour nom griselle et sont à l'imitation des étoffes de Norwich, mais ils n'ont jamais pu les porter au même degré de finesse que les Anglais et non plus les orner du lustre brillant qu'ont les étoffes de Norwich. Les Français prétendent que cela ne provient pas d'autre chose que des cartons. Je ne doute pas que les cartons puissent jouer un rôle, mais la qualité de la laine doit être ce qui compte le plus. D'ailleurs, à Lille, ils ont fait l'expérience de faire de semblables étoffes avec de la laine tirée en contrebande d'Angleterre et pressées avec les mêmes cartons, il est vrai qu'elles sont restées bien meilleures, mais ils n'ont pu arriver au niveau de perfection totale.

Les L ont pour nom sampareilles (samparelie), ce sont des camelots ordinaires. La manufacture de ceux-ci, comme celle des plus fins, est la même qu'à Amiens.

Les M sont d'une qualité plus fine et sont ondés à la calandre. lls servent pour les meubles de maison ou d'église, de même que les $\mathrm{N}$, gaufrés au cylindre.

Les $O$ sont de la qualité la plus fine que l'on fasse. Les plus grandes ventes sont en bleu et écarlate et ils sont pour l'essentiel destinés aux uniformes des officiers français. Ils se font en écru, c'est-à-dire avec la laine blanche naturelle et ils teignent la pièce une fois faite, comme ils le font aussi pour l'échantillon indiqué par le n² qui est ici mis pour montrer qu'ils en font également en petit teint. Le n 3 montre qu'ils en font également des mélangés, en mettant la chaîne d'une couleur et en se servant d'une autre pour la trame, n'ayant pas l'habitude de mélanger le fil lui-même comme à Amiens.

L'échantillon P est aussi un camelot de la même qualité que les surfins. Il a été mis pour faire comprendre qu'ils teignent également en laine, comme on le voit clairement par la lisière de l'échantillon.

Les $Q$ sont des camelots étroits beaucoup plus fins et plus légers. Ils en font de quatre qualités qu'ils notent de 4 numéros successifs pour les distinguer. Par exemple, la fabrique ou le commissionnaire qui commence au numéro 1 va jusqu'au 4, chacun étant libre de commencer par le numéro qui lui plait le plus. Ils observent pour ceux-ci la même règle que pour les larges.

Ceux indiqués K sont des camelots rayés comme ceux d'Angleterre et ils se servent pour ceux-ci des filés qui restent des choix qu'ils ont faits pour les camelots fins.

L'échantillon S, appelé saie de Rome, est à l'imitation des saies de Nîmes faites à Londres, indiquées par les lettres HH. La facture de celles-ci est la même que celles d'Angleterre; elles ne sont pas aussi bien rasées, mais le noir de celles-ci est meilleur et est presque égal à celui que l'on fait à Berlin, les Prussiens ayant été les inventeurs d'un tel genre d'étoffe. 


\section{Relation de voyage}

L'échantillon T est une toile teinte à l'imitation des toiles appelées de la vallée (della valle), mais elles n'ont pas encore atteint le degré de perfection pour la bonté et le prix des toiles rayées indiquées par la lettre $V$.

L'échantillon indiqué par la lettre $U$ est à la façon des velours appelés d'Utrecht bien qu'ils n'en fassent pas là-bas. Pour la chaîne, le poil de ceux-ci provient de poil de chèvre, tandis que la trame est de fil comme l'est également la moquette (Mochetta) indiquée par la lettre X, à la seule différence que la première, appelée velours, est composée de poil de chèvre et de fil, tandis que celle-ci est composée de laine et de fil. Toutes deux sont imprimées au cylindre pour les rendre, comme on le dit, gaufrées.

L'échantillon indiqué par la lettre $Y$, nommé drap de pieds ou Viciora, est composé de la matière première précisée au début dans les généralités sur les articles qui se fabriquent à Lille, d'où j'ai poursuivi mon voyage et je suis allé avec la voiture publique à Courtrai.

\section{Courtrai}

Ville très grande ; leur commerce principal est en toiles fines et mantilaria fine et principalement en mantileria damasquée (de fil). Ils font aussi (avec le fil ?) des damas en couleur et en deux couleurs pour meubles. Les teintures tiennent très bien, ils les font superbement de sorte qu'au premier coup d'œil, grâce à son beau lustre, ils semblent être de vrais damas de soie. II se fait ici deux marchés par semaine : tous les particuliers des campagnes viennent y vendre leurs toiles en cru. En ce qui concerne la mantileria et le damas en fil, les fabricants sont dans la ville, chaque ouvrier travaille chez lui, presque toujours sur commission des marchands eux-mêmes. Beaucoup de ces toiles passent en Hollande pour être blanchies avec les laits hollandais, bien meilleurs que ceux de Courtrai, et aussi parce qu'ils n'en ont pas autant qu'en Hollande. Ils exécutent à Courtrai tous les dessins de damas et ils sont capables de faire sur une serviette de table les armes de tous les Grands aussi compliquées qu'elles puissent être.

De Courtrai, je suis venu à Gand, ville qui fait également une grande quantité de toiles ordinaires extra larges, de sorte qu'ils font même d'une seule pièce des draps de lit de quelque largeur que ce soit.

\section{Bruxelles}

De Gand, je me suis rendu à Bruxelles cité très vaste, située à moitié sur une colline et l'autre moitié dans la plaine. Elle est considérée comme la capitale du Brabant, où réside le gouverneur général des Pays-Bas, auquel on fait les mêmes honneurs qu'à un souverain. Toutes les magistratures qui se trouvent dans la ville où réside le souverain existent ici. On peut aller de cette ville jusque dans les États de Hollande par eau : il y a en été une barque qui part deux fois par semaine pour le transport fluvial des marchandises et des voyageurs; en hiver, elle ne part que tous les quinze jours. Autrefois, le commerce principal de cette ville était les dentelles (pisetti), tapisseries et camelots.

En ce qui concerne les Pisselli, il y a dans chaque angle de la ville des fabricants de ce genre de tapisserie. À Ponti, il y a deux fabriques et dix ou douze fabriques de camelots, pour la plupart tous travaillés en poil, bien que l'on en fasse aussi quelques uns de laine, comme on le voit facilement d'après les échantillons.

De ceux indiqués $A$ jusque ceux indiqués $D$ se trouvent quatre qualités de camelots travaillés avec du poil de chèvre fin. Ceux indiqués E, F, G sont de poil plus ordinaire, mais, aussi bien dans le fin que dans l'ordinaire, on voit la dégradation proportionnelle aux prix qui sont indiqués sur la carte. Les camelołs de cette qualité tant renommée sont aujourd'hui fabriqués de façon supérieure en Hollande et, effectivement, la fabrique de Bruxelles est en décadence pour cet article.

Les opérations de fabrique sont les mêmes que dans tous les autres pays à une seule différence : à peine sortis du métier, ils passent avant toute chose les camelots sous le mango pour les froisser et en même temps adapter le tissage de façon égale tout du long, puis ils les font bouillir et ils leur font tous les apprêts que l'on a déjà observés en Angleterre et à Amiens. Cette opération, qui ne se fait aux camelots en cru que dans cette fabrique, [est faite?] pour leur donner l'onde qui se perd quand on les fait bouillir dans l'eau pure, opération que l'on a observée dans tous les apprêts de cet article.

De Bruxelles, je suis passé à Malines, petite ville où l'on fabrique aussi une grande quantité de pissetti portant le nom de la ville même. Les fabricants travaillent presque tous avec des fonds dépendants de la ville d'Anvers où ils portent leurs travaux à vendre. 
La ville d'Anvers, qui est la dernière des Pays-Bas avant les États de Hollande, est une grande ville, bien tenue et illuminée de nuit, avec de beaux édifices et des rues bien alignées. Elle a un canal d'eau qui communique même avec les États de Hollande et avec toutes les autres parties des Flandres. Toutes les terres voisines travaillent également les pissetti et ils viennent les vendre à Anvers les jours de marché où ils trouvent toujours des acquéreurs aux prix courants. Les fabricants laissent leur marchandise à $10 \%$ de moins à l'acheteur habituel par rapport à l'étranger.

De là, je suis parti sur une voiture de poste à la hollandaise et je suis allé jusqu'aux plages du Mordic que j'ai traversé facilement. Avec une autre voiture prise au-delà du Mordic, je suis allé jusqu'à Rotterdam, première place de la Hollande presque aussi considérable pour le commerce qu'Amsterdam. Le motif pour lequel le commerce de Rotterdam est si florissant est la facilité de la navigation dans les canaux en raison de leur grandeur. Dans toute la ville, les vaisseaux sont chargés pour la Meuse, ils entrent dans les canaux et vont décharger la marchandise à la porte des négociants. L'abondance des vaisseaux qui vient dans cette ville est telle que l'on trouve plus facilement à s'embarquer à Rotterdam qu'à Amsterdam même. Pour parcourir la ville, il y a de petites barques qui portent les citadins d'une partie à l'autre du canal de sorte qu'il est très facile de faire ses affaires parce qu'il n'est pas besoin de faire des détours dans la ville du moment qu'il y a toujours des canaux remplaçant en droite ligne la route, ou par terre ou en traversant d'un canal à l'autre.

Les alentours de la ville sont très beaux : ils sont tous garnis d'arbres, ainsi que les bords des canaux de la ville. Tout autour de la ville, il y a de très belles maisons de campagne. Depuis cette ville, on peut parcourir toute la Hollande, en allant jusqu'à Amsterdam à très peu de frais, parce qu'à toutes les heures du jour il y a une barque qui part d'un lieu à l'autre. Cette barque est divisée entre les sièges destinés aux gens honorables et ceux réservés à la populace qui forment un grande pièce occupant les deux tiers de l'espace tandis que l'autre tiers forme une pièce assez propre qui s'appelle le Rouf. Chacun paye à part tout ce qui est demandé. Une fois sonnée l'heure, une cloche sonne depuis la petite chambre située près du canal où se trouvent les directeurs : à peine a-t-elle fini de sonner que la barque part sans plus attendre personne. Je me suis embarqué sur cette barque et je me suis rendu à La Haye, ville de cour pas très grande et peu peuplée, bien ornée de rues et de places, surtout la place [située] devant le palais du Stadhouder. Dans cette ville, il y a toutes sortes de professions nécessaires à la vie civile. La plus grande partie des habitants est noble ou militaire.

\section{Leyde}

De là, il y a une autre barque qui part toutes les heures pour Leyde et je l'ai prise.

La ville de Leyde est grande et bien peuplée. Tous les principaux fabricants y sont, mais il y a bien peu de métiers parce que les draps sont tissés à vingt ou trente milles de la ville et viennent [ensuite] recevoir leur finition des mains des patrons. Ceux-ci vont faire le tour de leurs fabriques une fois ou deux par semaine pour voir si toutes les autres fabrications qui précédent la formation de la toile se font correctement et conformément à ce que nous avons vu dans la description générale de la fabrication des draps.

Dans la filature des laines, ils observent la méthode d'Elbeuf, à la seule différence que les Hollandais filent la laine plus ouverte que dans tous les autres pays que j' ai vus. C'est pour cela que les draps hollandais sont forts avec un fil plus gros et que, usés pour faire sortir le poil, ils ne sont pas aussi fins que les autres [?], mais ils font plus d'usage car ils sont plus forts.

La grande plaine dans laquelle est située la ville et les grands canaux d'eau font qu'ils ne peuvent établir de moulins à eau par manque de pente. Ils sont pour cela tous à vent et, par conséquent, les foulons et les édifices à papier eux-mêmes prennent tous leur mouvement du vent et non de l'eau. Les foulons exécutent la même opération que ceux à eau, mais les marteaux de ceux-ci sont faits comme autant de tuyaux d'orgue et ils battent perpendiculairement au lieu que dans les foulons à eau, ils ont leur mouvement naturel. De ceci provient le fait que les foulons à eau battent et ceux-ci frappent dans une caisse où est posée la pièce de drap. Sur le devant de cette caisse, il y a un petit canal d'eau qui en verse sur la pièce en proportion de ce que le maître juge à propos. II faut peu de place pour faire un de ces foulons parce qu'avec une petite terre pas très élevée il y a autant de place qu'il en faut. Mais ils confessent eux-mêmes que les foulons à eau sont bien meilleurs. La raison en est claire : c'est que dans les foulons à eau, les marteaux frappent toujours de façon régulière et selon le désir du maître foulonnier, tandis que dans ceux à vent, comme le foulonnier ne peut régler le vent comme il régule l'eau, les marteaux prennent un mouvement irrégulier et les draps ne peuvent jamais être foulés de façon égale, ils ne peuvent jamais être réduits comme le sont ceux qui sont foulés dans les moulins à eau. 


\section{Relation de voyage}

L'autre incongruité qui naît des foulons à vent est que parfois, quand ils ont le plus besoin de se servir de leurs moulins, il n'y a pas de vent et, par conséquent, ils ne peuvent pas travailler.

L'autre différence qu'il y a entre la fabrication hollandaise et les autres, réside dans les dernières tontes des draps: qui se sert de petites brosses (spasetto) pour relever le poil, qui se sert d'un fer ; les Hollandais le relèvent avec la main mouillée de leur propre salive afin qu'il tombe sous le coup de la force : comme le mouvement de la main ne peut jamais être toujours égal, le drap ne peut jamais être tondu de façon égale. De même, la main en passant provoque deux effets, l'un, causé par son humidité, relève le poil ; l'autre, au contraire, comprime le poil, car pour le niveler avec la main, il faut comprimer le drap ; pour cette raison, le poil ne peut se relever de façon égale et, par conséquent, il ne peut tomber tout également sous le coup de la force. C'est pour cette raison que les draps hollandais n'ont pas l'air aussi fins : ils ne peuvent être tondus à fond.

J'ai demandé à un patron fabricant pourquoi, connaissant une meilleure méthode, il ne la faisait pas mettre en pratique, il m'a clairement répondu que les travailleurs quitteraient sa fabrique plutôł que de varier leurs habitudes et que c'était pour ce motif qu'il les laissait faire comme ils en avaient l'habitude.

II n'est pas surprenant que la teinture en noir des draps de Hollande soit meilleure que dans tous les autres pays en raison des bons règlements qui sont instaurés : il n'est permis à aucun teinturier de teindre un drap en noir si il n'est pas d'abord teint en bon bleu Roi et, pour la sûreté de cette opération si nécessaire, aucun teinturier ne peut teindre un drap fin si la pièce destinée à une telle couleur n'a pas d'abord été présentée teinte en bleu à l'inspecteur, lequel y appose son plomb une fois qu'il l'a examinée, permettant ainsi au teinturier de passer au noir. Cette pratique existe aussi à Sedan, mais elle est voulue par le fabricant, qui a la liberté de faire comme il le veut. En ce qui concerne les autres opérations, ils font la même chose que dans les autres pays, à l'exception des frises pour lesquelles le mouvement de vibration égale, sans lequel la pièce ne pourrait jamais être frisée de façon égale tout du long, est très nécessaire. Mais il ne peuvent pas avoir de frises à eau pour les motifs rappelés plus haut, à vent le mouvement ne serait jamais égal ; ils se servent donc d'un moulin à quatre roues, l'une donnant le mouvement à l'autre, la première prend son mouvement du manège d'un cheval qui le communique à la première rove, laquelle le communique aux autres, de telle façon qu'au point fixe de la barre qui est destinée pour la frise, le mouvement est parfaitement égal comme peut l'être celui de l'eau, mais il est plus lent, de sorte que pour friser une pièce de drap ou ratine, il faut une moitié de temps en plus qu'avec l'eau.

Maintenant que nous avons observé la diversité des finitions, nous montrerons les différentes qualités d'étoffes de laine qui se fabriquent sous la dénomination générale d'Hollande, car il n'y a pas de lieu fixe où une pièce soit commencée et finie, comme nous l'avons montré précédemment.

Les échantillons indiqués A sont tous des draps de laine d'Espagne ouvragés. Leur diversité est due à la diversité des couleurs, la plus ou moins grande largeur selon les plus ou moins grandes portées de fils fixées par les établissements, la plus ou moins grande finesse de la laine elle-même, bien qu'ils soient tous de la meilleure qualité de laine d'Espagne dont la tonte est divisée en trois qualités, comme nous l'avons vu au départ.

Les deux échantillons couleur rouge indiqués B, que nous avons appelés dans les autres fabriques par le nom de double broche, s'appellent ici écarlate ou drap de manteau. Ils sont foulés autant qu'ils le peuvent alors que dans les autres fabriques, ils tentent d'observer une proportion déterminée. Ceux de Hollande sont plus forts, mais ils ont l'inconvénient qu'ils sont d'un port beaucoup plus lourd. Leur défaut substantiel est qu'ils sont tellement serrés que la teinture ne peut les pénétrer, de sorte qu'à l'usage toutes les coutures deviennent blanches en très peu de temps, ce qui fait un très mauvais effet, surtout dans les habits.

Ceux indiqués par la lettre $C$ sont tous des draps fins et légers qui s'expédient au Levant. Chaque qualité a sa largeur avec un prix différent d'une qualité à l'autre. Sous la même lettre, il y en a un avec le signe // et ceci est un drap castor travaillé avec deux tiers de laine de castor et un tiers de laine d'Espagne. Comme la laine de castor ne se resserre pas autant que la laine de mouton, quand la pièce est en toile, la laine de castor n'apparaît pas tellement, mais c'est le foulon qui la fait ressortir parce qu'en se resserrant, la laine de mouton fait glisser au dehors la laine de castor. Le mélange de la laine se fait lors du cardage avant de la filer pour la disposer à la filature. On ne donne à cette sorte de drap que deux tontes légères parce que si on les tondait à fond, on risquerait d'enlever le poil de castor qui est ce qui fait la richesse du drap. Avant de les presser, on ne couche pas le poil, mais on les presse comme les droguets ordinaires.

Ceux indiqués par la lettre D sont des demi-draps, tant unis que rayés et à fleur. Les unis sont travaillés comme le sont d'ordinaire les draps ; les rayés le sont grâce à la diversité des couleurs que l'on met dans la chaîne ; pour ceux 
à fleur ou ouvragés, l'ouvrage est réglé par le lacet placé dans la pédale qui se trouve sous les pieds du tisseur : il est ainsi réglé par celui-ci en même temps qu'il tisse. Sous la même lettre il y a également un échantillon indiqué $S$ qui est composé de laine de castor travaillée comme le drap et il a pour nom demi-drap droguet de castor ; tous les autres sont travaillés avec des laines d'Espagne très fines, comme le sont également les ratines indiquées par la lettre E et $F$, les premières hautes et les secondes étroites comme c'est indiqué sur les échantillons à côté de leurs prix respectifs.

Les échantillons indiqués par la lettre G sont des felpe imprimées au cylindre que nous appelons velours d'Utrecht. La chaîne est en fil de laine de chèvre et la trame est en fil de lin plus fin ou plus ordinaire en proportion de la plus ou moins grande finesse du fil de chèvre, bien que pour la trame ils se servent parfois de fil de poil de laine de chèvre comme de fil de laine de mouton.

Ceux indiqués $\mathrm{H}$, appelés Peluches (Peluzzi), sont travaillés, tant en chaîne qu'en trame, avec un fil filé gros et très ouvert de laine du pays et cardé autant qu'il peut l'être, c'est-à-dire autant que peut en donner l'intérieur des fils avec le poil comprimé droit sans être couché, comme l'on fait pour toutes les autres étoffes de ce genre.

Ceux indiqués par la lettre I sont tous des camelots de poil de chèvre travaillés teints en fil. Selon leur plus ou moins grande finesse, ils ont un prix plus élevé et ceux-ci ne sont pas calandrés comme le sont ceux de Bruxelles, mais seulement bouillis comme ceux d'Amiens. Ils sont cependant tous travaillés avec des fils de poil très fins et pressés comme on l'a vu dans la fabrication d'Amiens, mais ils sont beaucoup plus doux. On juge que ceci est une propriété des eaux hollandaises qui sont presque stagnantes et non limpides comme les eaux coursives, dont on prétend qu'elles sont trop crues et rudes en raison de leur mouvement. On dit que cette rudesse se communique à l'étoffe. II semble clair qu'une eau douce doit communiquer sa douceur à la laine elle-même, comme de fait on le voit : toutes les étoffes de laine travaillées en Hollande sont par nature plus douces que dans tout autre pays en proportion de la laine que l'on emploie.

Ceux indiqués par la lettre I sont fabriqués de laine du pays à la façon des saies d'ammunda dont la hauteur et le prix sont indiqués sur le papier.

Ceux indiqués M sont à la mode des flanelles rayées, à la différence que les rayures en couleur de celles-ci sont de laine du pays et les rayures qui restent blanches sont en coton, si bien que la chaîne, qui est celle qui doit former la diversité des rayures, est de laine et de coton tandis que la trame est entièrement de fil blanchi. Toutes sont de plus ou moins grande finesse comme on le voit en fonction des prix notés à côté de chacune d'elles.

\section{Utrecht}

De Leyde, je suis passé à Utrecht, où je n'ai trouvé qu'une seule fabrique de draps, dont les échantillons sont indiqués par la lettre N. On voit qu'il n'y a aucune différence avec les autres, bien qu'en ce qui concerne les couleurs, elle passe pour être celle qui travaille de façon superlative, bien qu'on ne puisse discerner aucune différence en les comparant avec les autres pièces. Dans cette fabrique, ils m'ont montré le magasin de leurs draps, dans lequel il y en avait en bien faible quantité, mais, malgré mes instances, le patron de cette fabrique n'a voulu me laisser voir ni les métiers, ni ses teintures, ni ses apprêts. Quand aux métiers, ils disent ne pas les avoir à Utrecht mais à Telborg. Cette maison a un petit nombre de métiers qui est parfois insuffisant pour réaliser la quantité de draps qui leur est demandée, elle achète alors les draps en blanc aux autres et les fait finir dans sa maison.

\section{Amsterdam}

De Utrecht, par une route très spacieuse, et un gros canal orné d'un côté comme de l'autre de maisons de campagnes surprenantes par la magnificence, tant au dehors qu'au dedans (j'en ai vu deux, elles sont richement édifiées et meublées). Par cette route donc je me suis porté à Amsterdam, capitale des États de Hollande, ville très riche dont la richesse est formée par le seul commerce parce que l'air est malsain à cause de la puanteur des canaux : il n'y a rien d'agréable à l'intérieur de la ville pour inviter les habitants à s'y maintenir, et les [maisons] de campagne, au lieu d'être utiles aux habitants, leur sont d'une si forte dépense que sans les grands bénéfices que leur amène le trafic du commerce, tous les négociants se trouveraient mal. Ce grand commerce est apporté par la mer et par la grande quantité de vaisseaux qu'ils ont à leur compte qui circulent et sont toujours en route. La ville est presque moitié plus petite que celle de Londres et très peuplée. La bourse est de la même grandeur que celle de Londres mais beaucoup plus fréquentée, de sorte que tous les jours, on ne peut plus y entrer deux heures avant qu'elle ne ferme à cause du monde. 


\section{Relation de voyage}

Les courtiers sont pour la plupart juifs. Ils sont en si grand nombre qu'ils composent et habitent presque un quart de la ville. Ils se rendent presque nécessaires à la ville d'Amsterdam par la grande attention qu'ils donnent au commerce de toutes sortes de biens et par leur grande activité. Le commerce compte très peu de catholiques, mais ils sont nombreux parmi les gens de la campagne et ils sont très riches par l'activité qu'ils prêtent à la culture des terres. Les édifices remarquables d'Amsterdam sont l'amirauté, où plus de 2000 personnes sont payées par le public pour la fabrication des navires de guerre. II y a également des magasins pour toutes les provisions qui peuvent être nécessaires aux navires de guerre, et chaque navire construit a son magasin d'ustensiles prêts pour les réparations et sa restauration en cas de besoin. La compagnie des Indes a un autre site, pas très grand mais avec les mêmes provisions, ses propres navires où l'on travaille toujours. Le commerce a un autre édifice où se construisent seulement les navires marchands. Les fonds employés dans ces ateliers [de construction] de navires, tant de guerre que de commerce, sont presque insondable ; les fonds qui sont emmagasinés ici pour la construction de ces navires sont immenses; les gens qui sont rassemblés pour une telle affaire constituent un peuple entier.

Les maisons dans leur perspective sont très belles mais mal construites à l'intérieur et de peu de solidité.

Le palais de la ville est très vaste et entièrement formé de pierres de taille. Le port est magnifique et très sûr, car il est entièrement protégé par des digues qui s'étendent à perte de vue. Le nombre de vaisseaux qu'il y a est presque infini : tous les jours, ils partent en grand nombre et arrivent en nombre non inférieur.

Les négociants de la ville d'Amsterdam se consacrent tous aux commissions et l'échange des marchandises d'une partie à l'autre du monde. Tout ce qui arrive trouve acheteur. La plupart du temps, ils donnent en payement d'autres marchandises, tant du pays que venues d'ailleurs. Tous les plus grands négociants n'ont aucun genre de marchandise fixe, mais ils règlent leurs investissements d'argent en proportion des biens que les spéculations leur indiquent comme les plus avantageux. Le gros de leur spéculation de draps est le Levant, presque toutes les maisons d'Amsterdam y sont intéressées. Tous les fabricants viennent ici faire leurs achats de laines : ils font ainsi retomber presque tous les fonds retirés de la fabrication des draps dans les mains des banquiers de cette ville, en se prévalant sur ceux-ci d'argent en fonction de leurs besoins, en leur payant un quart pour cent de provision tant à l'entrée qu'à la sortie de l'argent, de sorte que tous les états travaillent et Amsterdam, c'est-à-dire ses habitants, profite du travail de tous les états.

Les voitures, objet essentiel pour le commerce, sont toutes taxées par le public. Elles sont toutes dans les mains des matelots, tant d'eau que de terre, et à cette fin il y a à Amsterdam une salle dans laquelle les principaux convoyeurs, ou matelots, se rassemblent : quand il y a une voiture à prendre, ils la jouent aux dés et celui qui gagne part, car le sort en a ainsi décidé et c'est la loi en la matière.

Les négociants en gros sont plutôt rudes et ils ont très peu de manière pour vendre leur marchandise. Presque tous les contrats se font par l'intermédiaire des courtiers qui ont également le droit de négocier sur la place pour leur propre compte. II y en a de très riches et, en bien des circonstances, ils sont mieux informés que les autres de la solidité des maisons. Ils en ont tenu sur pied qui, sans leur aide, auraient failli et se sont au contraire remises. Ceci fait que cette profession est estimée en Hollande et ces personnes sont reçues partout. Les gros magasins sont à l'intérieur des maisons et il y a très peu de négociants qui ne tiennent qu'un seul article, étant permis à quiconque pourvu qu'il soit citadin, de s'appliquer à la marchandise et au négoce qui lui plait et lui convient le mieux. Comme les biens qui arrivent chaque jour sur cette place sont infinis, et afin que les négociants puissent être commodément informés de tout ce qui se trouve sur la place, trois gazettes paraissent chaque jour qui parlent indistinctement de tout, tant des nouveautés du port que de la ville ou de l'État hollandais comme également de toutes les provinces des États dépendants. Ces gazettes sont imprimées à Rotterdam et à Leyde comme dans toutes les villes principales des États. Toutes les maisons les prennent et chacun, en combinant les informations particulières les unes avec les autres, se détermine depuis son cabinet.

Seule la religion catholique paye un droit pour la liberté de religion et elle est dans l'obligation de maintenir ses pauvres parce que, si ceux-ci veulent changer de religion, ils sont tout de suite pris en charge par les religieux hollandais, des fonds très importants étant destinés à cette fin.

Dans les souterrains du palais de la ville, il y a deux sortes de prisons, l'une destinée aux voleurs, mal vivants et assassins, l'autre pour les faillis ou banqueroutiers et les dépensiers (spensirati) : ils les obligent à travailler jusqu'à ce qu'ils aient payé leurs dettes grâce à leur travail. Beaucoup sont donc enfermés pour le restant de leur vie. Les malfaiteurs doivent être condamnés et justiciés dans le terme de deux ans au plus. Ils sont condamnés par un conseil composé d'un grand officier, deux bourgmestres, quatre syndics et soixante conseillers. II n'est pas permis à la religion 
catholique de faire assister ses condamnés à mort par des ministres catholiques, mais ils doivent être assistés par des ministres protestants.

A Amsterdam, les fabricants de draps portent à vendre tout en blanc, il y a très peu de draps en laine teints de ce genre, et il y a de très forts magasins. Ils les mettent en teinture et ils les font terminer au fur et à mesure qu'ils doivent les expédier.

Les droits des marchandises, les gabelles sont payés sur la valeur, et sont reçus selon la déclaration qui en est faite par les négociants. Ils ne sont pas très fidèles dans ces déclarations, car, s'ils le peuvent, ils font de la contrebande. Afin que les déclarations soient faites fidèlement, l'officier du fisc peut visiter toutes les marchandises après qu'elles aient été déclarées et si l'une d'elles est effectivement de contrebande, elle est perdue, mais si la marchandise n'est pas de contrebande et si le négociant prouve que cet arrêt lui a été dommageable et préjudiciable, le fisc est obligé de payer la marchandise au prix indiqué, en accordant au négociant une bonification pour tous les dommages qu'il peut avoir souffert à cause d'une telle arrestation, et cela sur l'attestation de deux personnes de probité reconnue.

La marchandise ne tombe jamais en contravention à moins qu'elle ne soit déclarée de moins de deux tiers de sa valeur intrinsèque, en payant chaque marchandise selon sa valeur. Mais il est toujours possible au propriétaire de déclarer davantage s'il le veut. Cela a deux buts : le premier tient à la variété des prix qu'une marchandise peut prendre d'un jour à l'autre ; l'autre est que, comme il est certain que les négociants ne veulent pas payer un droit plus élevé que celui auquel la loi les oblige, cela sert de précaution à l'officier du fisc qui parfois reste surpris [?] par la plus grande valeur qu'un négociant a déclaré parce que sans formalité, ou la marchandise est de contrebande et elle est perdue, ou elle n'est pas de contrebande et le fisc est obligé de la payer ainsi au négociant sans formalité. Ceci fait que le fisc prend ses justes mesures avant de confisquer une marchandise et n'inquiète pas le cours naturel des affaires s'il n'est pas absolument sûr de lui, tous les bénéfices des contraventions lui étant dévolu. Ce qui est pire et qui limite grandement le fisc est que quand il veut vendre ces marchandises, il ne trouve pas acheteur, à part les juifs qui d'ordinaire ne les achètent qu'à un tiers de leur valeur.

Il est permis à quiconque d'acheter des biens immobiliers et il n'y a pas de religion qui en soit exclue. Ils les payent à des prix exorbitants et tous les négociants sont avides d'en avoir à cause du grand crédit qu'ils établissent sur la place à ses possesseurs. Les biens immobiliers de la campagne, surtout dans les alentours d'Amsterdam, sont ordinairement la ruine y compris des bonnes maisons, parce que la grande affaire dans ce pays est d'avoir toutes sortes de fruits en toutes saisons. Là-bas, la nature produit peu, mais tout est le fruit de l'art, c'est-à-dire à force d'engrais et de feu en enfermant les plantes dans des cabinets vitrés : ils font ainsi pour les vignes et pour toutes sortes d'arbres fruitiers et autres choses semblables, comme les fleurs et les légumes. Ils en ont de toutes sortes en toutes saisons. Ce sont des dépenses immenses qui d'ordinaire précipitent toutes les maisons d'Amsterdam. Ce qui vaut plus que toute autre chose à leurs tables est ce qui dure peu et qu'ils veulent avoir à n'importe quel prix, et par lequel ils font briller leur luxe.

Les maisons se lovent meublées et tous les meubles appartiennent au patron propriétaire de la maison, à l'exception cependant de ceux qui sont quotidiennement mobiles à l'usage des locataires. Les meubles fixes sont par exemple les tapisseries, les cadres, les miroirs et autres choses semblables; les meubles à l'usage des locataires sont les lits, les chaises, les tables et autres. On voit la richesse des habitants dans les maisons à la quantité des couverts d'argent et aux tapis étendus par terre dont presque toutes les chambres sont garnies.

L'usage de la place pour les lettres de change du pays dépend de l'expression des lettres elles-mêmes, mais il y a toujours de 20 à 30 jours de grâce s'il n'y a rien d'expressément contraire sur la lettre elle-même. L'escompte est à raison de $5 \%$ à l'année et l'intérêt était dans ce temps de $4 \%$, l'agio de la valeur est plus ou moins variable et il est allé jusqu'à $6 \%$.

Les ventes publiques sont taxées, c'est-à-dire que la marchandise n'est pas exposée en vente sans être estimée, comme en Angleterre, mais elle est appréciée et il est également permis au propriétaire d'attribuer à sa propre marchandise (sa valeur ?) et si (la vente) aboutit, il n'a rien d'autre à payer que le tant de pour cent convenu avec le courtier qui fait la vente sans que le public sache de qui elle est et à qui elle appartient. Au-dehors, les maisons sont presque toutes uniformes, mais au-dedans, elles sont presque toutes mal construites, à part celles qui sont construites depuis dix ans. Il faut descendre deux ou trois marches pour entrer dans la plupart, rares étant celles où l'on monte des marches et où l'entrée est au niveau de la rue. Ils sont la plupart obligés de laver en hiver comme en été, dedans comme dehors, et plus dehors que dedans étant donné la saleté que l'air afflige aux murs à cause des canaux peu profonds et stagnants qui se trouvent partout et qui puent à l'excès. La ville de Rotterdam est beaucoup plus saine 


\section{Relation de voyage}

et commode étant donnée la profondeur des canaux qui amènent les navires de commerce devant la maison des négociants, de sorte que le patron voit charger et décharger sa marchandise. Dans les chambres où ils dorment, ils sont obligés de tenir les lits défaits et de laisser toutes les fenêtres ouvertes du matin jusqu'à la moitié de l'après-midi afin que l'humidité ne pourrisse pas les meubles.

La nourriture est chère, l'eau est très mauvaise à boire, beaucoup ont de l'eau de citerne, mais l'une comme l'autre doivent être dépurées et bouillies avant de s'en servir. Cependant, dans leur cherté, l'alimentation, c'est-à-dire les viandes, le pain, les hortages et le beurre et autres choses semblables sont de toute perfection et bonté. Le pays abonde de poisson qui est meilleur que dans tous les autres pays maritimes que j' ai vus.

\section{Bois-le-Duc}

De Amsterdam, je suis repassé par Leyde, et je suis allé à Bois-le-Duc. C'est une ville encore assez grande où il y a une forte garnison, car c'est une ville de frontière ; son commandant dépend entièrement du grand conseil des États. Il y a un petit port dans lequel les barques chargées de poissons arrivent par le moyen d'un grand canal; deux fois par semaine, ils en font de grandes expéditions en Brabant, Pays de Liège et Maastricht et dans tous les environs : ils expédient aussi bien des poissons frais que salés. L'autre activité principale de la ville est la fabrication de verres ordinaires. Le bois commence ici à être abondant. Dans tout le reste de la Hollande, ils brûlent une terre sèche mêlée avec des racines réduite en briques appellée « Tourble » et dont ils font une grande quantité. Les cheminées sont faites à l'anglaise avec des grilles servant à brûler le charbon de pierre. En Hollande, la " tourble » ne pue pas, mais elle envoie une forte poussière sur tous les meubles, tandis qu'en Angleterre, le charbon de pierre pue le soufre et celui qui n'y est pas habitué peut à peine y résister. Comme je l'ai dit, étant donnée l'abondance du bois, ils brûlent à Bois-le-Duc plus de bois que de « tourble ».

De Bois le Duc, je suis venu à Telbourg, où les Hollandais ont la plupart de leurs fabriques, toutes les terres voisines étant dédiées à cette fabrication de drap pour la seule formation de la toile de laine, puis les pièces sont envoyées pour la finition à Leyde et à Amsterdam.

A Verviers, ils réussissent très bien les draps teints en laine et les mélangés, chose qu'ils ne peuvent faire ni à Montsovene [ ? ?] ni à Maastricht.

\section{Najvenis, Audimont, Aix-la-Chapelle, Borcette}

Dans toutes ces fabriques, ils font des draps de toutes sortes et avec les marques de tous les pays munis des plombs étrangers. Ce qui est pire est que chaque fabricant est maître de faire ce qu'il veut, de façon que chacun donne l'organisation qu'il veut à sa fabrique. Avec ce système et avec l'imitation des draps des autres pays, afin de se procurer du travail, ils le font de qualité inférieure, tant pour le lainage que par l'économie des matières et des opérations. Mais ce qui est pire, c'est que presque tous leurs draps sont forcés sur la rame, de sorte que j'ai vu un drap de 110 aunes de Hollande qui est arrivé à 150 aunes à force d'être énervé sur la rame. La rame est faite pour égaliser les lisières et donner une certaine longueur proportionnée à toute la pièce de drap. Dans toutes les fabriques, ce qu'un fabricant peut honorablement prétendre est que la pièce rende deux ou trois pour cent, mais un tel excès comme dans ces contrées est une trahison de la foi publique parce que si un acheteur attentionné examine très bien son drap, il s'aperçoit qu'il est mal travaillé. Les acheteurs au détail payent dix ce qui pourrait valoir cinq, étant donnée la mauvaise qualité de la marchandise. Maintenant que l'on a parlé en général de cette fabrication, on montrera la nature des articles.

La première fabrique que j'ai vue dans ces environs est Maastricht, ville pas très grande qui appartient pour moitié aux États de Hollande et dont l'autre moitié est sous la domination du prince de Liège. Les habitants sont pour moitié protestants et l'autre catholiques, sans payement de droit d'aucune sorte pour la liberté de leur religion. Elle est gouvernée par un conte, deux bourgmestres et quarante conseillers, tantôt d'une religion, tantôt de l'autre. Ils se rassemblent dans le palais de la ville qui est un bel édifice orné d'une belle bibliothèque. Il y a des pièces unies et distinctes pour les deux religions, qui sont destinées aux réunions et aux audiences ; une pièce distincte est destinée aux princes, c'est-à-dire au stathouder et à l'évêque, les députés s'y assoient également quand ils forment le conseil. La ville est gardée par une forteresse située sur un mont appelée la montagne de Saint Pierre, qui est presque entièrement creuse et constituée d'une pierre molle qu'ils extraient tous les jours pour s'en servir dans les fondations des 
maisons. Ce vide est fait comme un labyrinthe soutenu par de grands piliers ; il est déjà large de quatre milles et long de huit, de sorte que si un homme entre sans marquer par où il passe, il ne sort plus sans l'aide de ceux qui connaissent et y passent tous les jours. On y entre avec des torches ou des lumières car il n'y a aucun soupirail de lumière à l'exception de l'entrée et des anti-chambres. On allait de Maastricht à Liège entièrement sous terre, mais, bien qu'il existe encore à présent, ce passage est interdit par le prince de Liège, si bien que l'on voit ce souterrain moitié d'un côté et moitié de l'autre. Au-dessus de la montagne, il y a la forteresse, un couvent de réguliers, il y a des bois et des terres cultivées et tout ce qu'il y a au-dessus est indiqué en dessous. Dans un angle de ce souterrain du côté de Maastricht, il y a une fontaine qui, par-dessus [?], donne continuellement une goutte d'eau filtrée par une pierre dure et pas très large, bien qu'au-dessus l'eau ne soit pas visible. Jusqu'à présent, ils n'ont pas encore pu comprendre d'où cette eau peut venir. Quand ils creusent ces pierres molles, ils trouvent des coquillages de mer et des pierres ayant la forme de poissons, mais elles se défont quand on les prend en main et se réduisent en poussière. Ici comme à Aix-la-Chapelle, bien qu'ils aient certaine quantité de bois, ils brûlent une certaine pierre comme en Angleterre et ils l'appellent olie. Il y en a de deux sortes, de la maigre et de la grasse : s'ils veulent un feu ardent, ils prennent de la grasse et pour un feu doux de la maigre.

Dans cette ville, les draps sont travaillés à la Hollandaise ; ils se servent, les uns comme les autres, des mêmes travailleurs tisseurs et ont la même règle pour les apprêts. En ce qui concerne les teintures, et surtout pour le noir, ils font un drap égal à celui des Hollandais quand ils veulent travailler selon le devoir. Ils font venir la plupart des teinturiers de Saxe, et si jamais on voulait en avoir, on pourrait en avoir un des meilleurs moyennant 40 lires par mois et le manger. Celui qui a fait cette proposition est Mr Elia Hanssen de Maastricht auquel il faut s'adresser en cas de besoin. Les échantillons des fabrications de cette ville sont indiqués sur le papier avec les explications nécessaires par la lettre A, feuillet 34.

Sur le même papier, feuillet 35, il y a également les qualités de draps qui se font à Aix-la-Chapelle, indiquées avec leur largeur et leurs prix respectifs par la lettre B. Sur la même feuille, ceux indiqués $C$ sont de Borcette. Ces deux lieux travaillent sur le même pied. Dans la ville d'Aix-la-Chapelle comme dans la terre de Borcette, le commerce principal réside dans les manufactures de draps, d'aiguilles à coudre, et de dés à coudre ; bien qu'ils semblent peu importants, ces deux articles donnent du pain à une infinité de gens et amènent des profits considérables à cette population.

La ville d'Aix-la-Chapelle n'est pas très grande, mais elle est très bien peuplée. Elle tire des bénéfices considérables des bains chauds que la nature lui fournit. II y a neuf grandes maisons, chaque maison a six ou sept bains d'eau si bouillante que l'on ne peut résister à y tenir la main, de sorte qu'il est nécessaire de remplir le bain 24 heures avant d'entrer dans les bains. Dans ces maisons, ils fournissent tout le nécessaire selon la pension convenue, même le médecin qui donne la règle pour les bains. La pension dépend du grade et de la condition des personnes. II y en a également qui boivent ces eaux : il y a pour cela, en face de ces maisons, un jardin de promenade et une fontaine dont on se sert comme on le désire.

Le premier bain qui a été fondé, et dont tous les autres dérivent, est celui qui est communément appelé le bain de l'empereur. Il fournit de l'eau de chaleur égale à tous les autres. Le palais de la ville est un bel édifice et dans une grande galerie se trouvent tous les portraits des ministres étrangers qui sont venus ici à l'occasion d'un traité de paix : parmi les autres il y a celui de notre cavalier d'Osorio. À un quart d'heure d'Aix-la-Chapelle, se trouve la terre de Borcette. Pour y aller, il y a une très belle route le long de laquelle coule d'un côté de l'eau bouillante et de l'autre de l'eau fraîche. Dans le lieu de Borcette, il n'y a rien de remarquable que le puits d'eau bouillante que la populace appelle le puits du diable, mais il n'est pas probable que ce puits soit celui qui fournisse l'eau aux bains, car il est en contrebas. Autour de ce puits, il y a d'autres maisons de bains destinées aux gens ordinaires.

De Aix-la-Chapelle, en repassant par Maastricht, pour poursuivre mon voyage, je me suis rendu à Liège, ville de résidence du prince ecclésiastique décoré du grade épiscopal. Le principal commerce de cette ville est le fer et le cuivre d'Allemagne, car elle leur sert de dépôt. De Liège en passant par Fuo [?] petit village dépourvu de tout, j'ai traversé les Ardennes en passant par Rosfort, terre elle-même dépourvue, et je suis arrivé à Bouillon, terre pourvue de vivres mais mal située, car elle est entre la profondeur de deux montagnes de sorte qu'il y a une descente très rapide pour y arriver et une très forte montée pour en sortir. La traversée des Ardennes est très mauvaise car c'est un pays très stérile et désert. De Bovillon, je me suis porté à Sedan. 


\section{Relation de voyage}

\section{Sedan}

Ville de France située au milieu des collines, qui est très petite mais le nombre des fabriques est si grand qu'en comptant la ville et les faubourgs, ces fabriques fournissent le pain à plus de huit mille personnes grands et petits. Les draps de ces fabriques fines prennent le nom du patron comme Mr Paignon (Pagnon), Mr Rousseau (Rosso). Les draps de ces deux fabriques sont ceux qui ont acquis la réputation d'être les premiers pour la qualité et la finesse, chacune de ces deux maisons a seulement cinquante métiers battants. Les principaux patrons ont leur demeure à Paris et viennent une fois par an à la fabrique pour en faire l'inventaire. Pour le reste, elle est dirigée par des commis qui n'ont aucun intéressement dans celle-ci, si bien qu'ils font du bon ou du médiocre parce que, quand ils achètent dix balles de laine, il faut qu'elles soient réduites en draps fins. Mais étant donné leur crédit, ils vendent très souvent le nom et non la qualité. II y a de très nombreuses maisons ici qui ont plus de métiers battants et qui font des draps semblables à Paignon et Rousseau. Parmi celles-ci, il y a la maison Lovis Labauche et fils qui fait des draps de toutes sortes comme le font tous les autres fabricants, en observant pourtant la règle de la fabrique. Mais sa fabrique est divisée en deux catégories : la première, et la plus importante, est de draps communs; elle est dirigée par ses fils et les têtes des draps sont signées "Labauche et fils " ; l'autre catégorie est celle du père qui, à l'arrivée des laines, fait choisir les plus fines pour former une qualité de draps super fins qui porte sur la tête de la pièce "Louis Labauche », et ceci avec un privilège égal à celui de Paignon et Rousseau. Leur bonté réelle commence à leur faire prendre du crédit et, de fait, ce sont des draps parfaits. II peut les faire meilleurs que les deux autres parce qu'il sait quoi faire des laines inférieures qu'il remet à ses fils qui les emploient dans les draps ordinaires. Entre père et fils, tous unis sous le seul gouvernement du père, ils ont deux cent trente métiers battants toute l'année. La règle de la fabrique de Sedan est que chacun obtient le privilège du nom et est obligé de marquer de combien de centaines de fils la pièce est composée pour pouvoir en donner, au vu de sa qualité, la juste fixation du prix. lls ne font dans cette fabrique que des draps de fortes couleurs, la plus grande quantité en noir avec les lisières plus fortes que dans tous les autres pays, à l'exception de la Hollande. Ils se servent, dans un pays comme dans l'autre, des poils de vache pour l'unir à l'autre laine et en former leur lisière, distinction réservée, en France, à toutes les fabriques de cette ville qui égalent, en ce qui concerne les seuls draps noirs, ceux qui se fabriquent en Hollande. Dans la fabrication, les règles sont les mêmes que dans tous les autres pays à l'exception des presses qu'ils font avec très peu de chaleur afin que le drap reste moelleux et pas trop cartonné, cela pour les draps noirs auxquels une grande chaleur dans la presse pourrait être dommageable. La couleur noire est aussi un privilège qui leur a été concédé au début de la fondation de la fabrique, et que le conseil royal a également concédé au Sieur Van Robais uniquement pour les draps supra fins. Les qualités de draps qu'ils font dans ces fabriques sont indiquées par la lettre D au folio 36, toutes avec leur prix, largeurs, longueurs et qualité proportionnés aux prix signalés à côté. L'usage de ce pays est de vendre avec un délai d'un an, et ils donnent 21 d'aunage pour 20, avec le bénéfice des pouces pour faciliter les acheteurs.

\section{Reims}

De Sedan, je suis passé à Reims, ville capitale de la Champagne, très grande et bien peuplée tant dans la ville que dans les campagnes qui sont autant de petites collines. Le revenu de cette province est constitué en majorité par le vin. La façade de la cathédrale est une chose merveilleuse et c'est dans cette église que les rois de France sont dans l'obligation de venir se faire consacrer. On les oint avec l'huile de l'ampoule sacrée qui est conservée par les réguliers près du grand sépulcre de Saint Rémi, tout en plaques d'argent et [entouré] de statues de pierre de considération ornées de pierres précieuses. On ne fait là-bas que deux commerces, celui du vin et celui de la fabrique de draps : celle-ci est divisée en deux ordres, l'un d'étoffes pannées [pannate] et l'autre d'étoffes sèches. Les pannées se fabriquent dans la ville, ce sont les demi-draps ou droguets, crosie, marbres impériaux, Moffin, Silésie, et flanelles. Les sèches se fabriquent dans les campagnes, ce sont les étoffes nommées Burattes, Tamises, Ełamines, Buralets, voiles et étamines rayées comme on le verra clairement décrit sur le papier.

Les étoffes pannate, tant ouvragées que mélangées et unies, se travaillent comme nous l'avons vu ci-dessus de tous les autres genres semblables et elles se foulent comme les draps. Les sèches sont également travaillées comme celles de même nature, mais elles sont toutes foulées au bâton. Cette opération se fait dans un caisson de même largeur que l'étoffe avec de la terre grasse bien fine, du savon, de l'eau et quatre bâtons qui battent continuellement l'étoffe. Un tel mouvement la fait rentrer tant en largeur qu'en longueur proportionnellement à la finesse et à la légèreté de l'étoffe, car, étant donnée la légèreté de ces étoffes, elles ne pourraient pas résister dans les piles des foulons. En ce qui concerne les pannate, on observe la même proportion de fils dans la chaîne et dans la trame que dans les 
draps. Dans les étoffes fines et sèches, les fils sont égaux tant dans la trame que dans la chaîne, comme on le verra grâce à la description échantillon par échantillon de chaque étoffe qui se fabrique dans cette ville et ses environs.

Celles indiquées par la lettre A, ayant pour nom Royales, sont à deux chaînes, l'une de laine et l'autre de soie, la trame toute en laine ; le dessin de soie est réglé par le lacet disposé à côté du métier. Étant donnée la variété des couleurs, elles sont travaillées avec des laines teintes en fil et foulées au bâton légèrement. En tissant la chaîne de soie, on la laisse aller ferme, elle reste molle parce qu'en se foulant la soie ne peut rentrer autant que la laine. Elles sont pressées à chaud avec les cartons de la même façon que l'on presse les draps. Les laines dont on fait ces étoffes ainsi que les autres pannate sont les laines les plus fines du royaume d'Espagne et, bien qu'ils les appellent Royales, le vrai nom de ces étoffes est Maroc : ils changent le nom pour les distinguer, étant donné le dessin qu'ils ont travaillé avec la soie.

Celles indiquées par la lettre B, ont pour nom Droguets incanaliti. Elles sont travaillées comme le sont les baracans d'Angleterre mélangés avec les restes des laines d'Espagne employées dans les Royales, comme le sont également celles indiquées par la lettre C qui sont toutes unies. Ils se servent pour les mélangés de laines teintes tandis que les unis sont teints en pièces pour économiser la dépense. lls sont tous pressés humides comme on presse les draps ordinaires.

Celles indiquées par les lettres D, E, F, G, sont appelées crosie : ils en font de deux qualités, qui sont appelées Première et Seconde Ségovie. Les 1 ères Ségovie sont travaillées avec les laines les plus fines d'Espagne et les secondes sont de laines de même nature, mais ce sont les rejets des laines ayant servi à faire les 1er Ségovie. De ces crosie sont dérivées les étoffes qui se font à Biella nommées Ambrosette, du nom du premier qui a commencé à faire ces étoffes, la maison Ambrosetti qui existe toujours à Sordevolo dans la province de Biella, et de laquelle sont dérivées toutes les autres manufactures d'un genre semblable. Les Ambrosetti susdits se sont mis à faire de telles saies à imitation des crosie Ségovie à l'instigation de feu Sr Virlie, marchand de cette ville dont ils ont reçu la règle, et qui les faisait alors travailler pour son compte. Aujourd'hui encore, cette maison [Ambrosetti] travaille ces saies de façon plus parfaite que toutes les autres. Les saies nommées $20 \%$ sont celles qui sont à imitation des 1 ères Ségovie, et celles à $18 \%$ ont été faites pour les $2^{\text {nd }}$ Ségovie. Si on avait continué à les travailler selon le devoir, elles seraient bien meilleures que les crosie de Reims. Pour ce qui est de l'usage, celles fabriquées par les Ambrosetti le sont encore actuellement parce qu'elles sont beaucoup plus fortes : il est certain qu'il entre autant de matière première dans deux ras fabriquées à Biella qu'il n'en rentre dans trois fabriquées à Reims.

Celle indiquée $\mathrm{H}$ est de la même laine, avec les mêmes dégradations que les crosie, mais elle est seulement travaillée en toile sans être croisée.

Celles indiquées par la lettre I sont des crosie ordinaires pour la formation desquelles ils mettent tous les restes des laines d'Espagne mélangés avec les laines du pays. À l'imitation de celles-ci, la province de Biella fait les saies $16 \%$ et $14 \%$ qui sont bien meilleures que les crosie de Reims ordinaires mais, étant donné le plus grand poids de laine, elles sont bien plus chères.

Celles indiquées par les lettres $L$ et $M$, tant mélangées qu'unies, ont pour nom impériales; elles sont à la mode des saies de Londres et elles sont d'un tiers de laine d'Espagne ordinaire et le reste de laine du pays choisie. Du rebut des laines susdites, mélangées en dégradation, ils font les étoffes indiquées par les lettre N, O, P, appelées doffin. Elles sont faites à l'imitation des Marocs qui sont travaillées en toile sans être croisées mais simplement foulées et pressées avec les cartons, en les humidifiant un peu avec de l'eau de colle avant de les mettre sous presse pour leur donner du corps.

Celles indiquées par la lettre Q ont pour nom demi-draps ou droguets de Silésie. Les ouvragés sont travaillés au lacet comme on l'a dit auparavant pour toutes les étoffes ouvragées, de même que les rayés et les unis, légèrement tondus et foulés comme les draps, comme on l'a vu à Elbeuf.

L'échantillon indiqué R est appelé Maroc chiné. La variété de la couleur vient de la chaîne comme dans le Silésie chiné indiqué par la lettre S. Pour former un pareil genre d'étoffe, ils préparent la chaîne dans une couleur claire, ensuite ils lient le dessin ou chiné de la largeur qu'ils veulent lui donner avec une petite ficelle afin que la seconde couleur que l'on doit donner ne pénètre pas et ils obscurcissent le reste. Ensuite, ils montent la chaîne sur le métier et la tissent avec la trame de la même couleur sombre : ainsi sont faits ces chinés. Ils sont apprêtés et foulés comme tous les autres genres de draperie. 


\section{Relation de voyage}

Celles indiquées T sont des étamines ordinaires qui se font pour profiter des rebuts des étaims fins et moyens employés dans les étamines fines que l'on verra ci-après. Elles sont au nombre des étoffes sèches, foulées avec le bâton comme on l'a dit auparavant.

Celle indiquée par la lettre $\vee$ est un demi drap blanc ensuite teint en écarlate. Cette fabrique teint tous les demis draps en laine et non en pièce.

Celles indiquées $Y$ et $X$ sont des flanelles croisées à la mode d'Angleterre, mais l'une unie et l'autre cardée. Elles sont travaillées de la même façon que celles d'Angleterre, de laines d'Espagne ordinaires et par conséquent plus chères. Toute la consommation de celles-ci se fait en France, étant donnée l'interdiction des étrangères. Bien peu passent à l'étranger car, outre qu'elles sont plus chères, elles sont beaucoup plus étroites.

Celle indiquée par la lettre $Z$ est une étamine nommée Buratte. Ils font de très nombreuses qualités de celles-ci, réglées selon la plus ou moins grande finesse des fils d'étaim employés. Les prix en sont indiqués sur le papier.

Celle indiquées AA et BB sont des voiles, le premier est un voile clair et le second un voile fort, celui-ci est fait également à la mode des étamines avec les filés les plus fins qu'ils arrivent à avoir. Ces étoffes sont également foulées au bâton, chacune selon sa force, et boullies pour être dégraissées et ensuite teintes.

Celle indiquée CC est une étamine Burata qui est de la qualité la plus fine que l'on fasse sous le nom d'étamine. Celles indiquées D sont les autres étamines : certains ne foulent celles-ci qu'au bâton, mais beaucoup se risquent à les fouler comme les draps, mais légèrement. Celles indiquées EE sont également des étamines foulées seulement au bâton. Pour les rayures, elles sont travaillées comme les camelots rayés de Norwich et de Lille.

Ces marchandises se vendent toutes avec un an de délai et avec l'escompte de 6\%, avec des lettres de change sur Lyon ou Paris sans autre bénéfice. En ce qui concerne les articles faits à Reims, ils s'achètent très bien chez les fabricants, mais pour les étoffes sèches, un étranger doit absolument payer une provision pour se les faire acheter, car les gens de la campagne viennent toutes les semaines vendre brutes toutes les étamines, voiles, burats qui se font dans la campagne et ils trouvent toujours des acheteurs pour leur qualité et leur prix, laissant à cet acheteur le soin de les faire teindre et apprêter.

Dans la présente relation, on a parlé des fabriques de France en général, mais on voit que ce sont seulement celles de Normandie, Picardie, Flandres françaises et Champagne. Il y a encore beaucoup d'autres fabriques dans les autres provinces, surtout en matière d'étoffes travaillées avec des laines ordinaires, comme Carcassonne pour les draps, Romans pour les pirlate, Nîmes pour les saietteries, molletons et autres choses semblables.

Les trois principales nations ont leurs mesures différentes pour les étoffes, si bien que pour une plus grande commodité, on en fait une réduction afin que chacun puisse sans peine compter la largeur des étoffes et la longueur des pièces.

La France mesure en aune, une aune de France fait deux ras du Piémont :

$n^{\circ} 1$ au. fait p. 2

L'Angleterre mesure en verges. Une verge d'Angleterre fait un ras et cinq noni du Piémont :

$1 \mathrm{~V}$. fait 1 5/9 en supposant que le ras soit divisé en 9 et pour cela, selon le calcul ordinaire, 9 verges d'Angleterre font 7 aunes de France et l'aune de France, deux ras du Piémont. Sur ce calcul, il y a 1 1/2 p.\% de bénéfice.

La Hollande mesure en aune. Une aune de Hollande fait un ras et un sixième du Piémont :

1 au fait $11 / 6$

Tout comme il y a variété dans les mesures, il y a variété dans les monnaies et, en en ayant récolté dans chaque pays, on l'a indiqué ici avec la fixation (des prix) et un repère pour le change, en réduisant à notre monnaie camérale. Suivent les valeurs de France, réglées au change de 50 chaque petit écu qui est indiqué au $n^{\circ} 4$ qui vaut trois francs : ce change règle toutes les autres valeurs qui sont décrites ci-dessous et que l'on voit sur la carte.

$210 \diamond$ Documents pour l'histoire des techniques $n^{\circ} 18$ - décembre 2009 


\section{Monnaies courantes de France}

1 Louis d'or au poids

2 Moitié du Louis

3 Ecu neuf d'argent

4 Demi écu

5 Pièce (pessa) d'argent

6 Moitié de la susdite $n^{\circ} 5$

7 Quart de la susdite $n^{\circ} 5$

8 Pièce (pessa) de métal

9 Idem

10 Idem

11 Idem

12 Idem de cuivre nommée liar

13 Idem

\section{Poids (deniers grains) Effectif de France}

6.8

3.4

21.

10.12

4.7

2.4

$1.11 / 12$

2.

1.

"

$"$

5.4

2.12

\begin{tabular}{|c|c|}
\hline 24._._ & 20 \\
\hline 12._. & 10 \\
\hline 6.-.- & 5 \\
\hline 3._-- & 2.10 \\
\hline 1.4. & 1 \\
\hline _.12. & _.10. \\
\hline _.6. & _. 5. \\
\hline _.2._ & .1.8 \\
\hline-1.6 & .1 .3 \\
\hline _. 1. & _._. 10 \\
\hline _. . 9 & _... $71 / 2$ \\
\hline -...6 & -... 5 \\
\hline -...3 & _._.21/2 \\
\hline
\end{tabular}

47.8

39.10 .
Valeur en Piémont (lire, sous deniers)

Aucune autre monnaie n'a cours dans toute la France que celles indiquées ci-dessus. Pour la commodité des étrangers, il y a des changes publics qui prennent toutes sortes de valeurs, mais comme ils font toujours perdre le droit seigneurial, il n'est pas avantageux de se servir de cette commodité mais bien plus de se munir de leurs valeurs effectives avant d'entrer en France.

En Angleterre, les comptes et livres des négociants sont tenus en livres sterling, sous deniers et ceux-ci eux-mêmes divisés avec le système que 20 sous, font la livre et 12 deniers font le sous qu'ils appellent schilling. Comme la livre sterling n'existe pas, ils la règlent de façon imaginaire comme on peut le voir plus clairement ci-dessous en fonction des valeurs effectives réduites en monnaie du Piémont, au change de $20 \mathrm{~L}$. P pour chaque livre sterling.

\begin{tabular}{|c|c|c|c|}
\hline Monnaies effectives d'Angleterre & Poids (deniers grains) & Monnaie sterling & Piémont \\
\hline 1 La guinée en poids & 6.1 & 1.1 & 21._-_ \\
\hline 2 Demie guinée & 3.1 & _. 10.6 & 10.10. \\
\hline 3 Quart de Guinée & 1.12 & .5 .3 & 5.5 \\
\hline 4 Couronne & 22.5 & .5. & 5._-- \\
\hline 5 Demie couronne & 11.2 & .2 .6 & 2.10 \\
\hline 6 Schilling & 4.13 & ${ }_{-}^{-} .1 l_{-}$ & 1._-- \\
\hline 7 Demi Schilling & 1.8 &.- .6 & _.10. \\
\hline 8 Tiers de Schilling & 1.9 & -_..4 & _.6. \\
\hline 9 Quart de Schilling & 1.3 &.- .3 & ${ }_{-} .5$. \\
\hline 10 Sixième de Schilling &. .17 &.- .2 & _.3. \\
\hline 11 Douzième de Schilling &. .10 &..- .1 & _-_ [?] \\
\hline 12 Pièce de cuivre & 7.10 & $-. \cdot .1 / 2$ & _- $[?]$ \\
\hline \multirow[t]{2}{*}{13 Idem } & 4.4 & $-. \cdot .1 / 4$ & $-\cdot[?]$ \\
\hline & & 2.6.7. $3 / 4$ & 46.12. [?] \\
\hline
\end{tabular}

Personne n'est obligé de prendre les valeurs étrangères, mais elles se négocient comme toutes les marchandises, étant toujours réglées selon la proportion du change et par les spéculations de chaque négociant en particulier.

Dans les Flandres autrichiennes, États de la reine de Hongrie, les livres sont tenus et les paiements sont faits en florins hollandais qui sont imaginaires comme on le verra par les valeurs suivantes réglées sur ce pied et réduites en monnaie du Piémont au change de 36 p.\% pour chaque florin. 


\begin{tabular}{|c|c|c|c|}
\hline Monnaies effectives des Flandres autrichiennes & Poids (deniers grains) & Florins & Valeur du P \\
\hline 1 Double souveraine & 8.15 & 17.17 & 32.3.7 \\
\hline 2 Souveraine & $4.71 / 2$ & 8.18 .6 & 16.1.3.1/2 \\
\hline 3 Ducaton & 26. & 11.6. & 6.8 .8 \\
\hline 4 Demi ducaton & 13. & $1.15 .41 / 2$ & 3.4.4. \\
\hline 5 Couronne & 23. & 3.3. & 5.13 .5 \\
\hline 6 Demie couronne & 11.12 & 1.11 .6 & $2.16 .8 .1 / 2$ \\
\hline 7 Quart de ducaton & 6.12 & _.18._-- & 1.12 .14 \\
\hline 8 Huitième de ducaton & 3.5 & .5 .9 & _. 10.3 \\
\hline 9 Pièce appelée escalin & 7.15 & .7. & $\_.12 .7$ \\
\hline 10 Idem & $3.171 / 2$ & _. . $_{-}$ & .9. \\
\hline 11 Idem & 2.2 & _.3._ & .5 .4 \\
\hline 12 Idem de métal & 2.14 &.- .10 & $.1 .57 / 9$ \\
\hline 13 Idem & 1.15 &.- .5 & _._.8 8/9 \\
\hline 14 Idem de cuivre & {$[?] .16$} & -.2 & -..35/9 \\
\hline 15 Idem & 2.11 & $\therefore .1$ & _._. 17/9 \\
\hline & & $38.17 .11 / 2$ & 69.19 .2 \\
\hline
\end{tabular}

Toutes les valeurs indiquées ci-dessus sont à leur prix de change. En ce qui concerne le coût du change, la valeur de [?] au lieu de l'autre [?], chaque pays règle la valeur comme il le veut en marchandises, mais comme l'on convient du prix de la valeur avant celle de la marchandise, ils reprennent la facilité apparente qu'ils font sur les valeurs sur le prix de la marchandise. La réduction ci-dessus est faite pour le paiement d'argent contre argent. Les valeurs étrangères ont aussi un cours abusif mais chacun le prend comme il lui plait. Les remises que l'ont fait dans ce pays sont toujours en florins de Hollande, comme le sont celles que l'ont fait à Aix-la-Chapelle où toutes sortes de monnaies ont cours, y ayant très peu de monnaies effectives dans cette province que l'on décrit ci-dessous réglées sur le prix hollandais avec une réduction en monnaie de Piémont au change de $36 \%$.

\begin{tabular}{|c|c|c|c|c|}
\hline Monnaies effectives d'Aix-la-Chapelle & Poids (deniers grains) & Cours d'Aix & Cours en Florins & Piémont \\
\hline 1 Demi Copsticht & 2.17 & ..6._ & ..3._ & _.5.4 \\
\hline 2 Double Petermen & 1.23 & _.8. & ..4.- & _.7.2 \\
\hline 3 Cinq Petermen & 1.16 & ..5._ & .2 .6 & _.4.6 \\
\hline 4 Deux Petermen &. .16 & .2. & _.1._ & ..1.9 \\
\hline 5 Pièce de métal de 3 Petermen & 1.4 & ..3. & .1.6 & .2 .7 \\
\hline 6 Idem de cuivre appelée liard & 4.3 & _.1.4 [?] &.- .6 & _..10 \\
\hline 7 Liard & 2.2 & _.4. &.- .2 &.- .3 \\
\hline \multirow[t]{2}{*}{$8 \mathrm{ldem}$} & 1.18 & $-\cdot . \cdot 11 / 2$ &.- .1 &.- .1 \\
\hline & & $15.51 / 2$ & .12 .9 & 1.2 .7 [?] \\
\hline
\end{tabular}

Les fabriques des alentours ne constituant pas une place de change, elles prennent les remises en florins qu'elles aiment mieux que la monnaie de France, mais elles envoient négocier les remises de l'une comme de l'autre à Amsterdam où elles font leurs approvisionnements de laines.

Dans tous les États de Hollande, seules les valeurs suivantes ont cours et comme sur le papier l'on n'a pas mis le ducat, que l'on appelle chez nous " ongaro » et «ducat des États généraux 》 sur le tarif, du poids de 2 deniers et 17 grains à £ 9.6.8 qui a cours en Hollande pour 5 florins et 5 sous, ce qui, avec le change à 36 comme se règlent toutes les autres valeurs, donne $9 \# 9$ en monnaie du Piémont. Suivent maintenant les autres valeurs qui ont cours là bas :

212 Documents pour l'histoire des techniques nº 18 - décembre 2009 


\section{Monnaies de Hollande}

1 Pièce d'or nommée Quadue. [?]] de poids

2 Moitié d'un quadrue

3 Idem d'argent nommée Risdaler

4 Idem dite Ducaton

5 Idem Daler

6 Idem

7 Idem Golde qui vaut un florin

8 Idem dite Sheling

9 Idem dite estaff

10 Idem

11 Idem

12 Idem de cuivre appelées dutte*

\section{Poids (deniers grains) Florins}

7.18

3.19

14.14

22.

14.6

12.

8.6

3.18

3.13

$-.14$

1.5

2.13

2.8
14._-

7._.-

2.12 .

3._._

1.10 .

1.8 .

1._-

..5.

$-.5 .6$

$-1$

-.2.

$-\cdot .2$

31.4.10
Monnaie de Piémont

25.4.

12.12 .

4.13.7

5.8.

2.14.

1.16 .

1.16.

$-10.9$

$-.9 .10$

$-1.9$

-.3.6

-..3 $1 / 2$

56.4.4

* desquelles 8 font un sous de même valeur mais différents dans les pièces [?]

Dans les États généraux, on ne peut obliger personne à prendre autre chose que les valeurs susdites, mais chaque négociant est libre de prendre la valeur étrangère qui lui plait le plus pour la conserver ou la renvoyer à l'étranger comme il veut.

Dans les juridictions du Prince de Liège, toutes sortes de valeurs courent au prix que chacun veut, la conversion de la valeur étant un contrat à part. Les quelques valeurs qui sont battues par le prince susdit sont cependant tarifées et décrites ci-dessous et à ma connaissance [?]

Monnaies effectives de Liège
1 Pièce d'argent de deux scalini
2 Idem faisant un scalino
3 Idem une plachetta
4 Idem de cuivre
5 Idem
6 Idem

\section{Poids (deniers grains) Valeurs de Liège}

$\begin{array}{lc}6.13 & 1 .{ }_{-} \\ 3.6 & -.10 . \\ 1.17 & .5 ._{-} \\ 10.1 & -.1{ }_{-} \\ 6.4 & -. \cdot 6 \\ 2.18 & -. .3\end{array}$

1.16 .9
Cours hollandais Monnaie de Piémont

\begin{tabular}{|c|c|}
\hline _. 14. & 1.5 .2 \\
\hline _.7. & ..12.7 \\
\hline-.3 .6 & .6 .5 \\
\hline _._.8 2/5 & _.1.3 \\
\hline _._.4 1/5 & _._7 1/2 [?] \\
\hline _._.2 1/10 & _._.3 1/2 [?] \\
\hline $1.5 .87 / 10$ & 2.6.2 1/2 [?] \\
\hline
\end{tabular}

On a pris le cours hollandais tel qu'il est à Maastricht pour pouvoir en faire la réduction, car dans ce pays il n'y a pas de cours de change et tous les paiements qui se font par l'étranger sont en monnaie de France ou de Hollande, comme de même les remises se font sur les deux places susdites et c'est ce que j'ai l'honneur de référer.

À votre Excellence. 


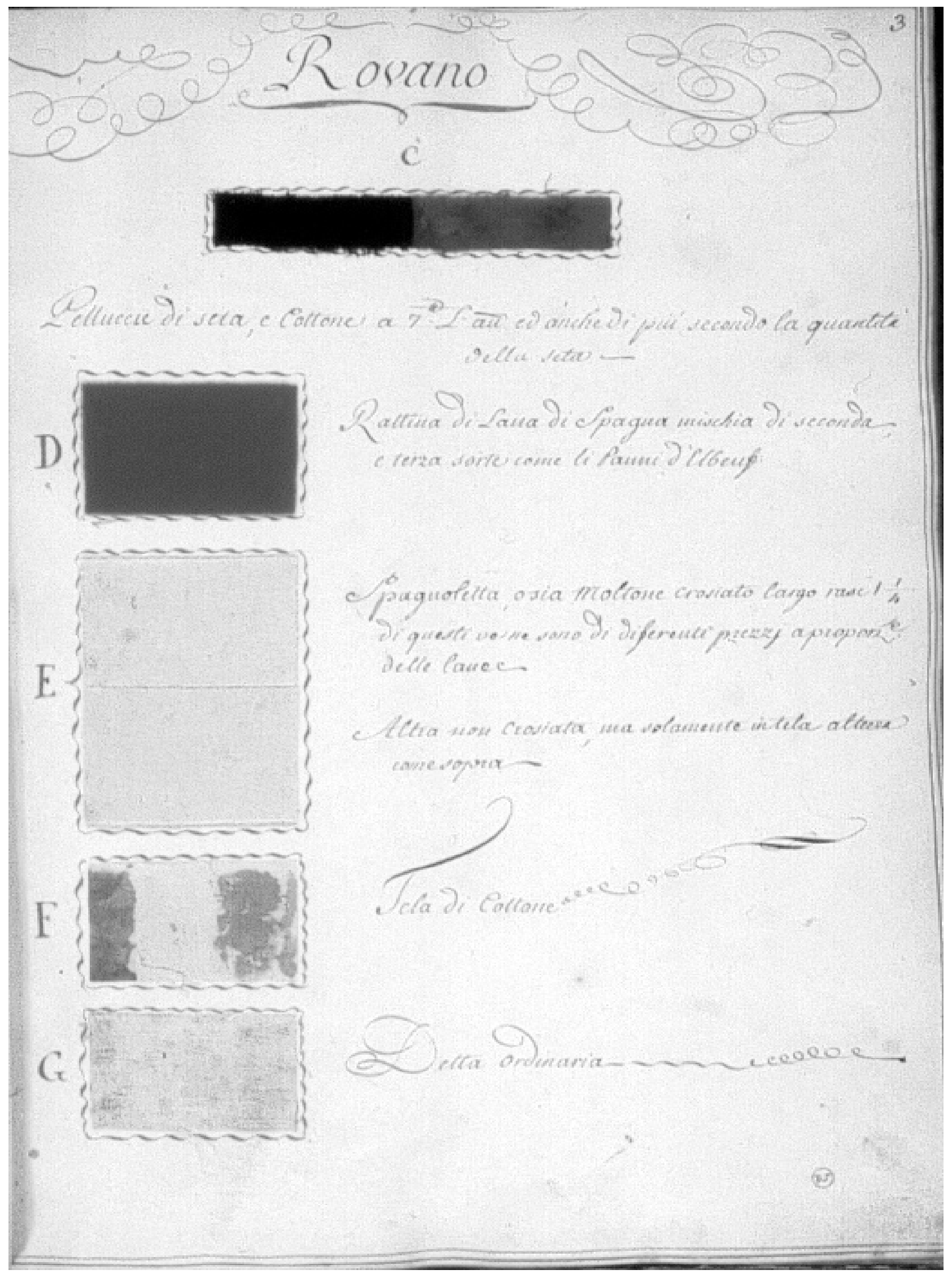

Bibliothèque Forney, Manuscrit Moccafy - Rovano, p. 3 


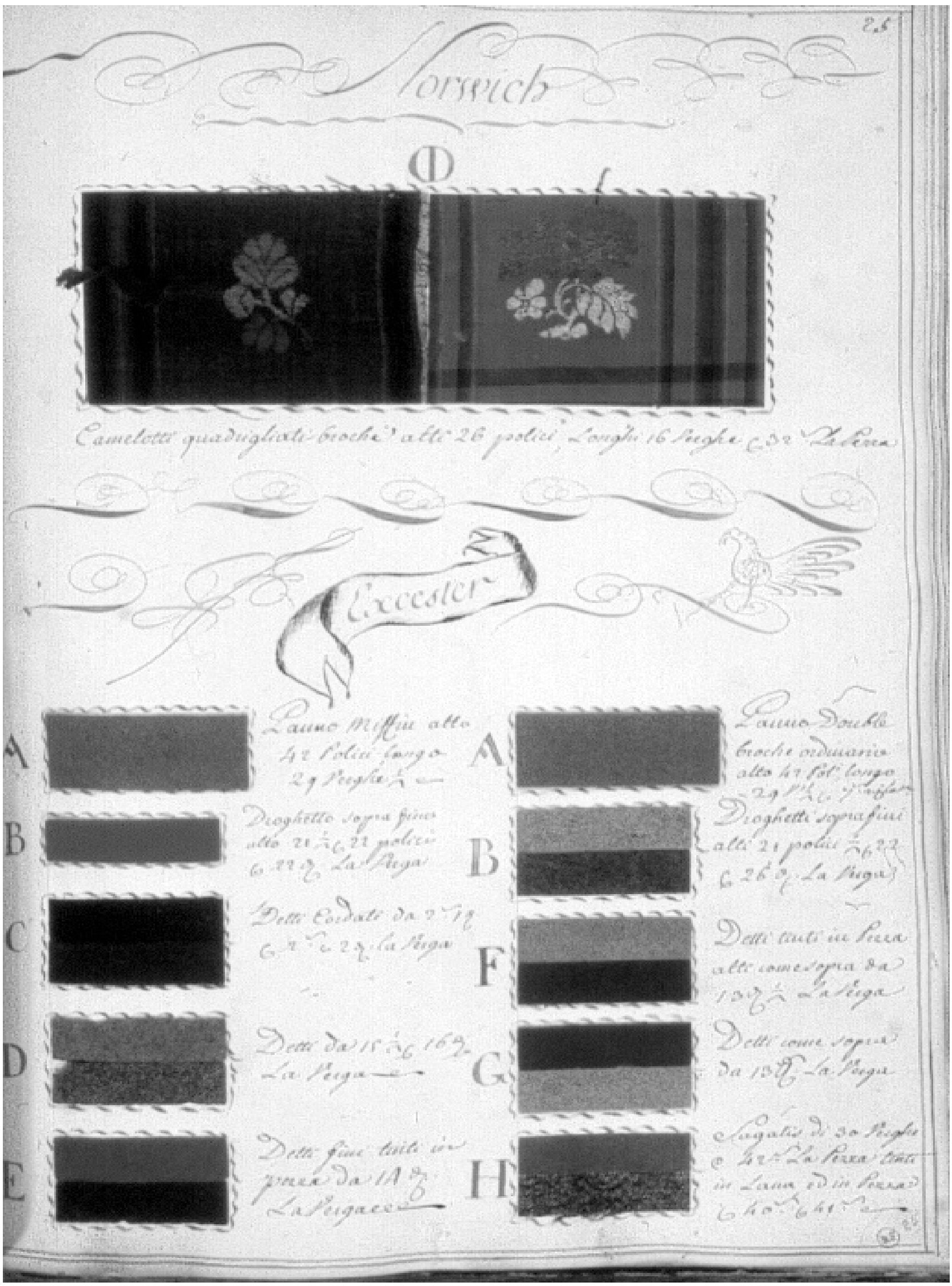

Bibliothèque Forney, Manuscrit Moccafy - Norwich, p. 25. 


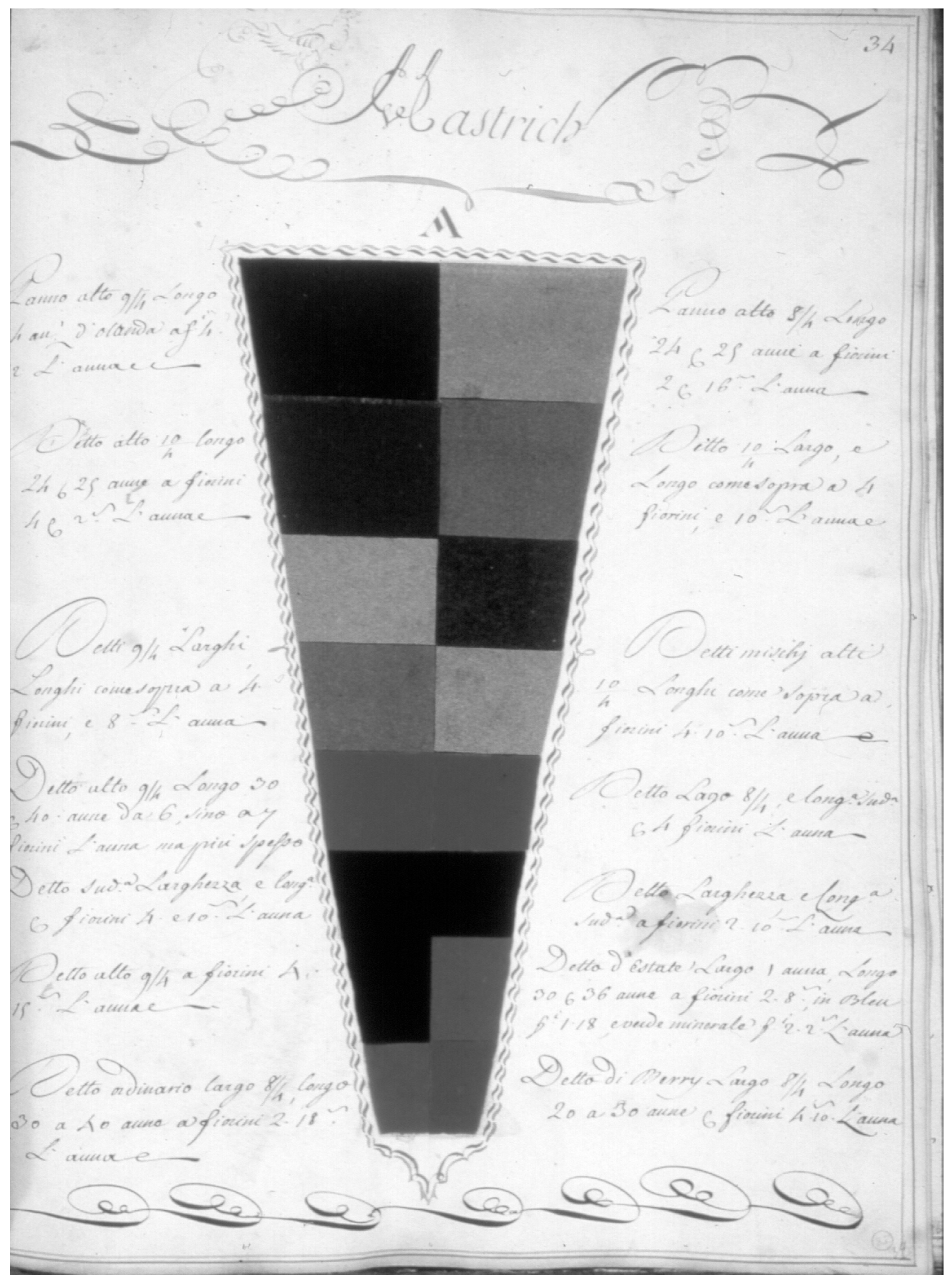

Bibliothèque Forney, Manuscrit Moccafy - Maastricht, p. 34 


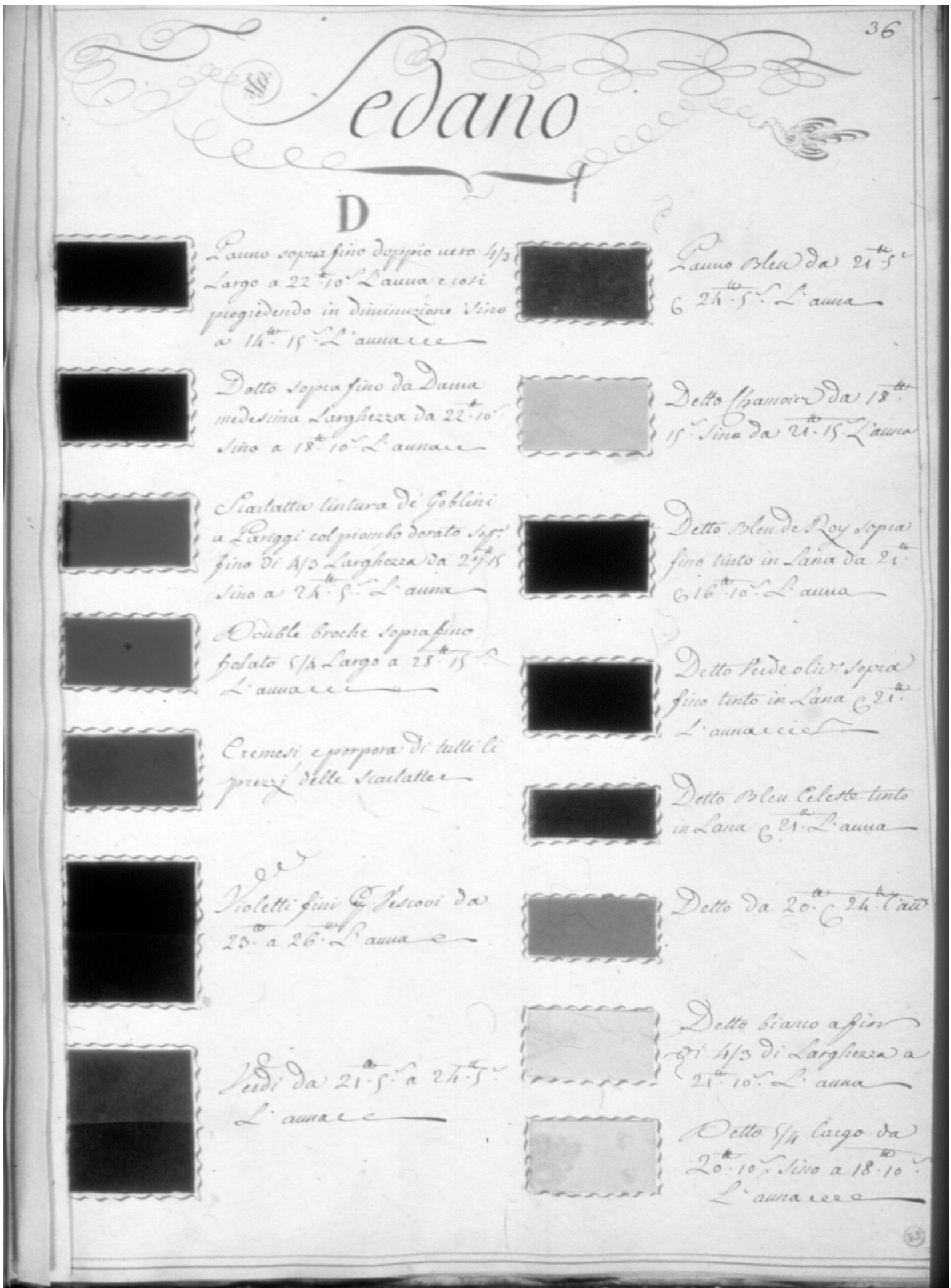

Bibliothèque Forney, Manuscrit Moccafy - Sedan, p. 36 

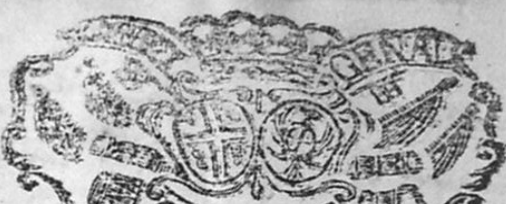

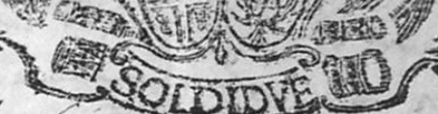

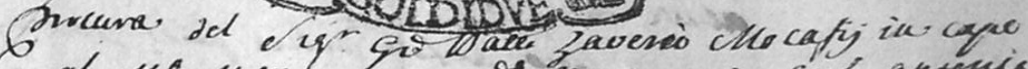

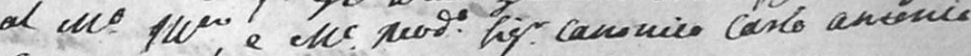

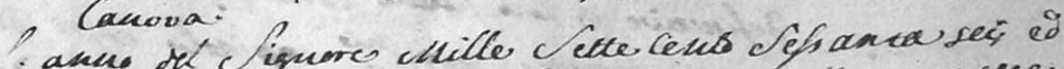
alli nove set mese siluglio all aresette; e myja

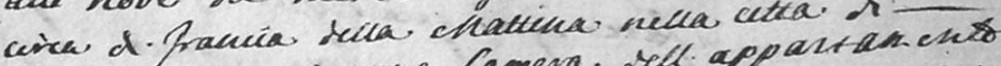

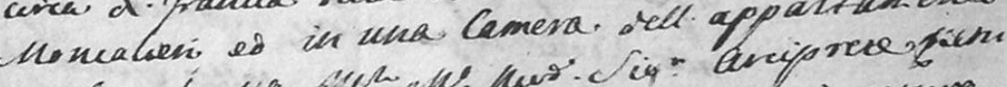

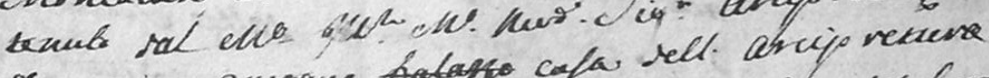

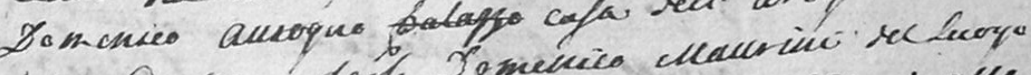

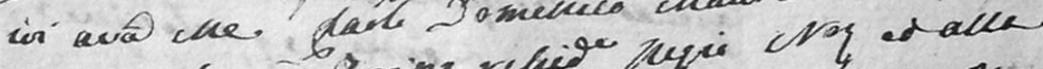

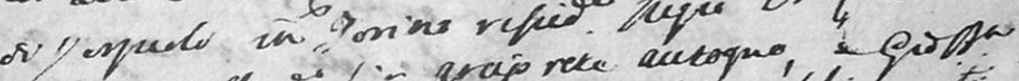

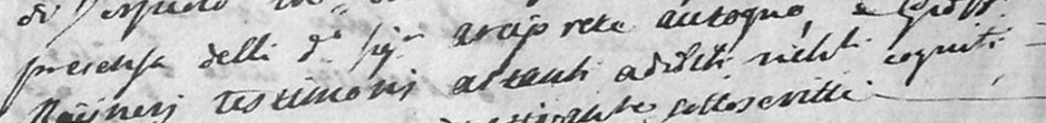

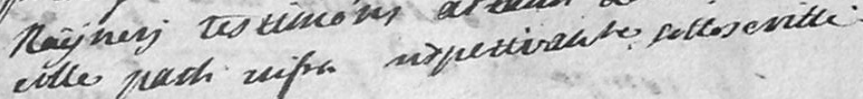

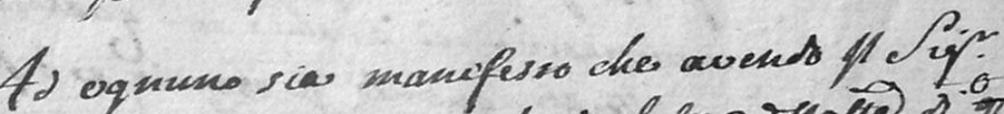

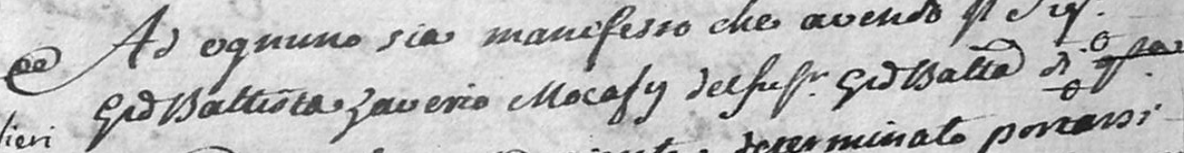

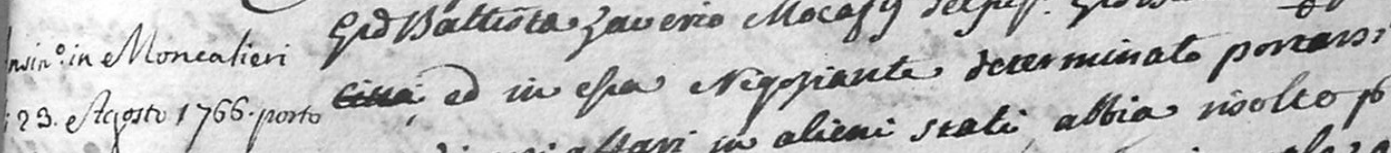

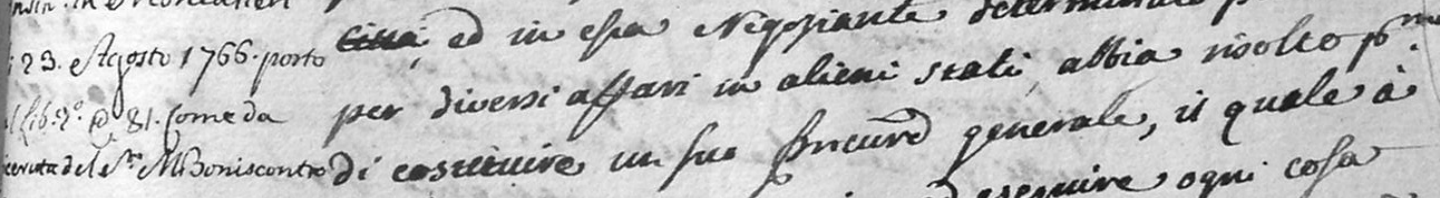
Wh Diluo nome pafor agine sespaine oqu cofos

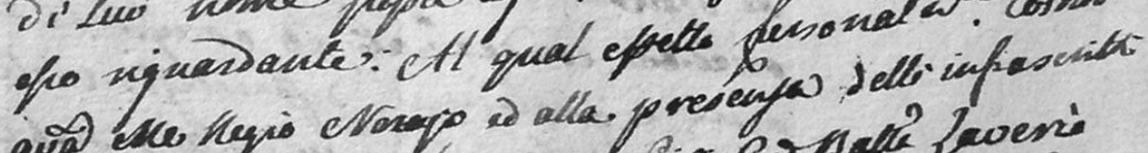

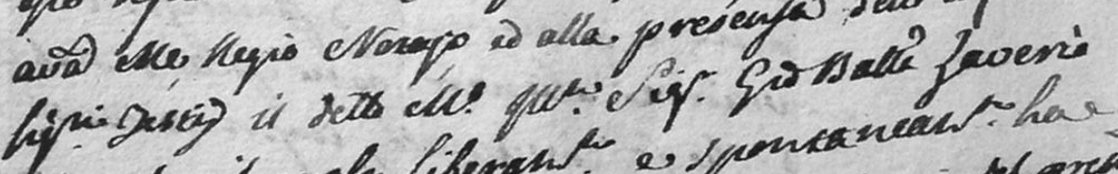

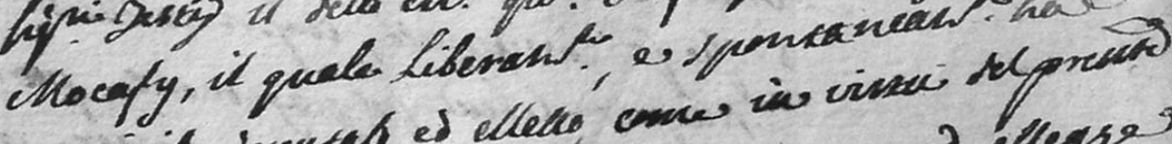

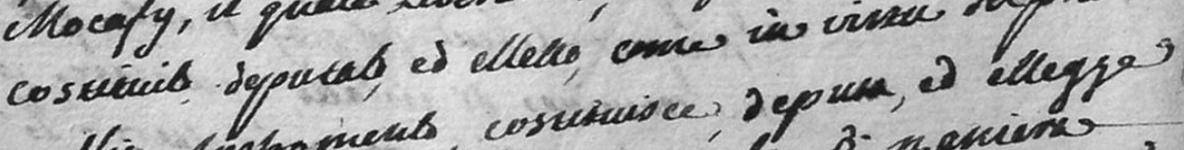

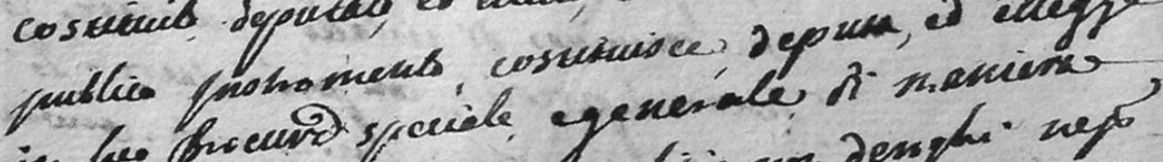

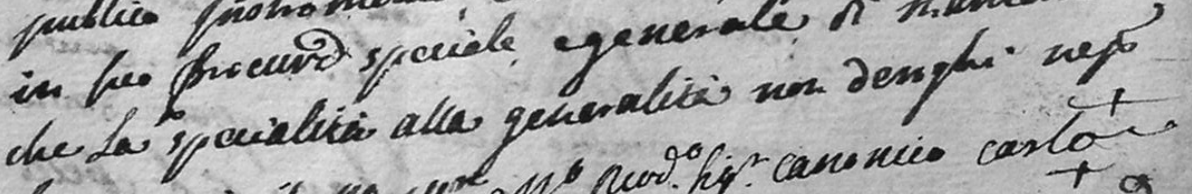

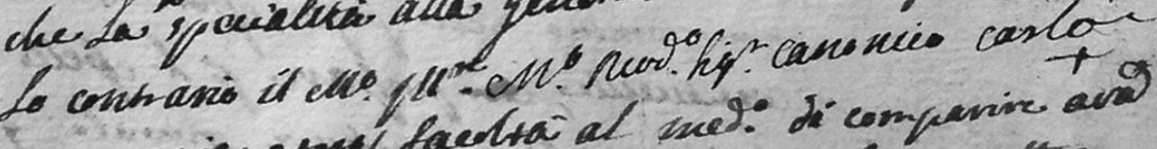

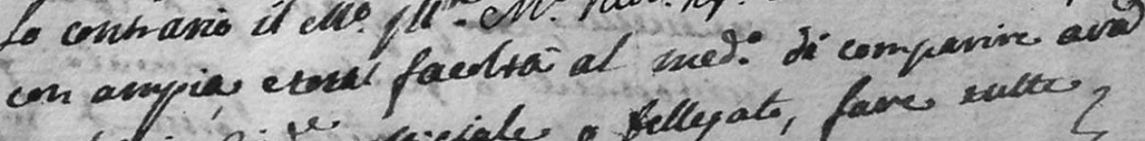
qualien ia quied, ofriciale, a Dillegate,

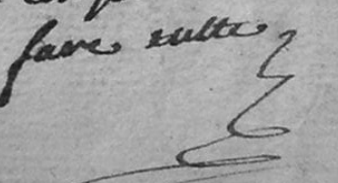

Archivio di Stato di Torino, Insinuazione di Moncalieri, 1766, libro 2, c.81 et c.82. Procuration de Moccafy avant son départ 


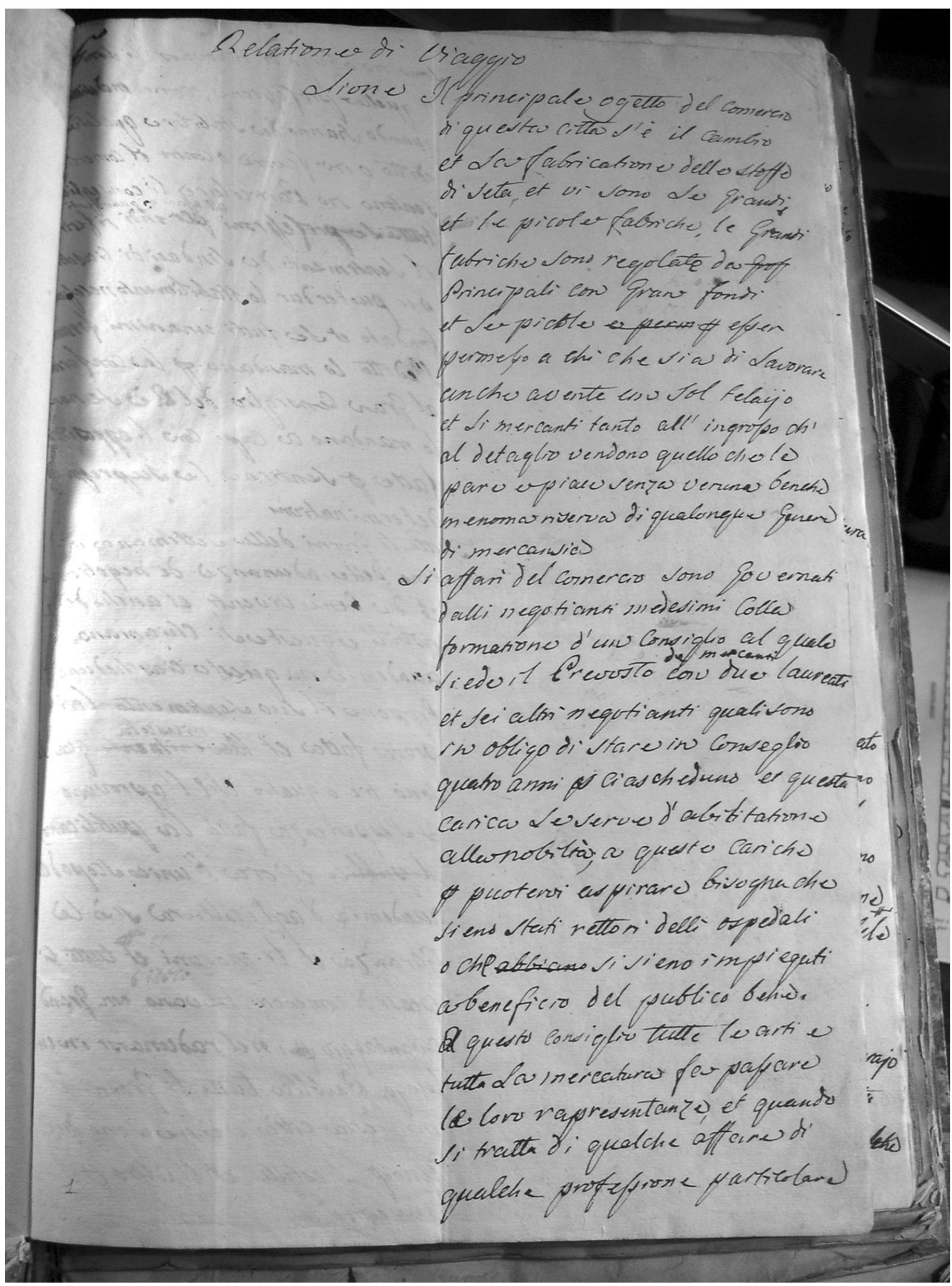

Biblioteca Reale di Torino, Storia Patria, 907 - Première page de la relation de voyage de Moccafy 


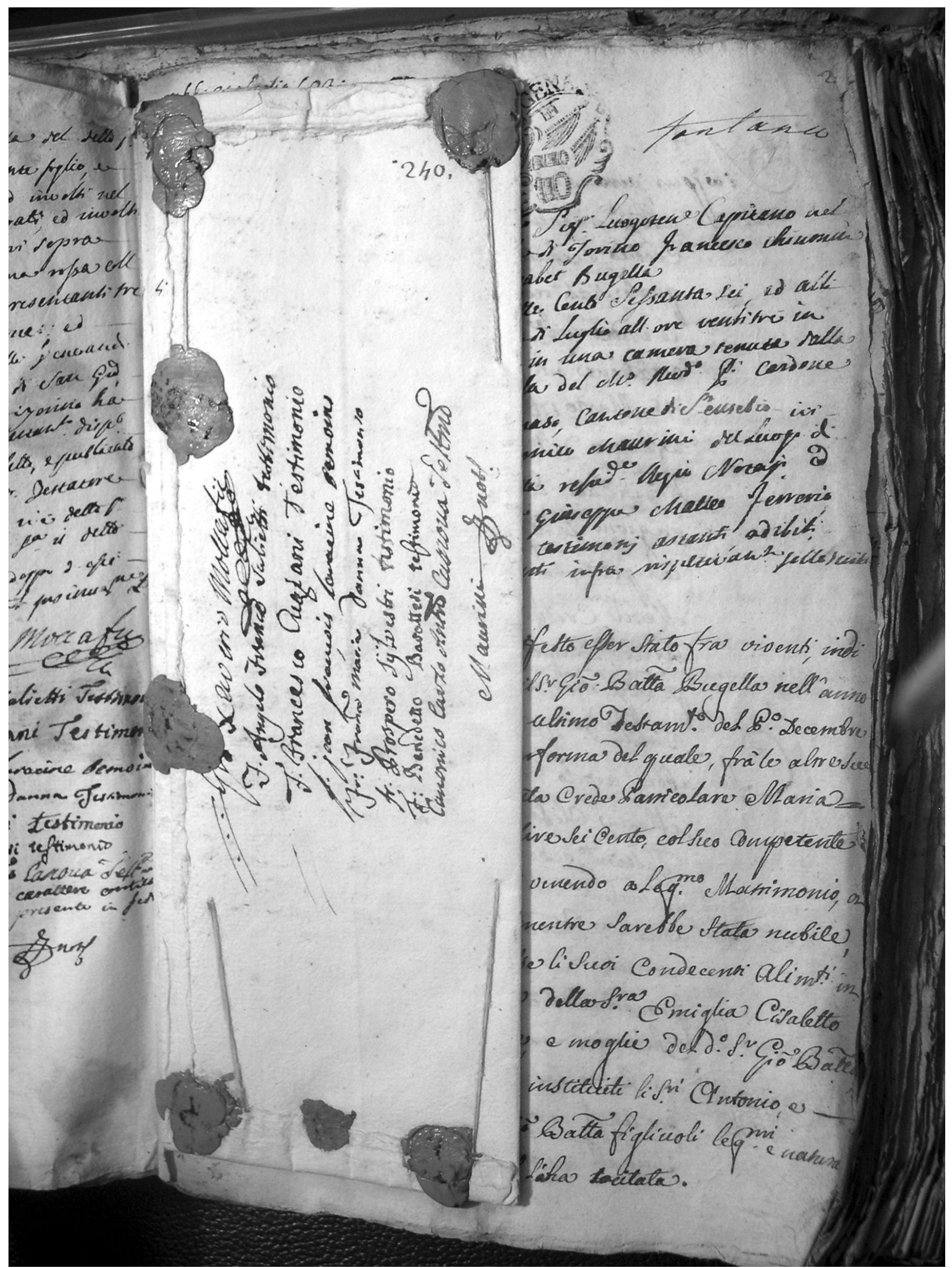

Archivio di stato di Torino, AST, Notai di Torino, primo versamento, Maurini 1764-66, registro 4245 - Testament de Gian Xaverio Moccafy 